No to Rawlsian Public Reason and Yes to the Enlarged Mentality: An Affirmative Role for Moral and Religious Arguments in Canadian Public Discourse in light of Charter Values

by

Andrew R. Morrison

A thesis submitted in conformity with the requirements

for the degree of Master of Laws (LL.M.)

Graduate Department of the Faculty of Law

University of Toronto

(c) Copyright by Andrew R. Morrison (2011) 


\title{
No to Rawlsian Public Reason and Yes to the Enlarged Mentality: An Affirmative Role for Moral and Religious Arguments in Canadian Public Discourse in light of Charter Values Master of Laws, 2011 Andrew R. Morrison Faculty of Law University of Toronto
}

\begin{abstract}
This paper examines two different theories in relation to the optimal modes of public deliberation about constitutional values and the public good in the context of democratic pluralism: Rawlsian Public Reason and Nedelsky's Enlarged Mentality.

I challenge Rawlsian public reason's claim to epistemic abstinence, autonomy and its claim to reflect a political conception of justice by examining certain contradictory aspects of its theoretical rendition. I argue that significant aspects of the picture of democracy that Rawlsian public reason reflects are unempirical. I argue that Rawlsian public reason's concept of bracketing moral and religious argumentation from public deliberation is unjustifiable, unattainable and derogates from Canadian constitutional values.

I proffer that Nedelsky's enlarged mentality is preferable as it is more realistic and consonant with Canadian constitutional values. I argue that Nedelsky's enlarged mentality is facilitative of genuine and meaningful dialogic exchange in spite of difference whilst managing the risk of democratic instability.
\end{abstract}




\section{Acknowledgments}

I would like to thank my wife, Cherone Phillips-Morrison, for her patience and thoughtfulness. I would like to thank Anver Emon for his guidance and supervision. I would also like to thank Jennifer Nedelsky for her inspired pedagogy. I thank my colleagues, Donald McLeod and Royland Moriah, and other friends for their well wishes and inspiration. I thank my parents for egging me on to greater heights and for ever encouraging me to pursue my dreams. Thanks to all who assisted me on my journey. 


\section{TABLE OF CONTENTS}

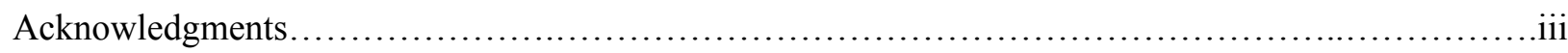

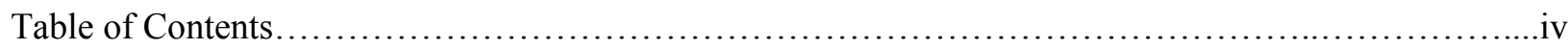

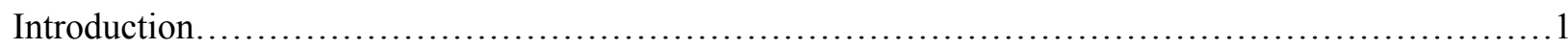

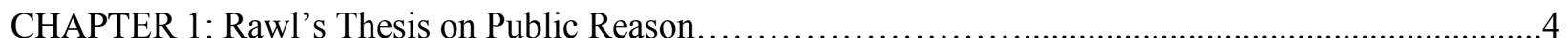

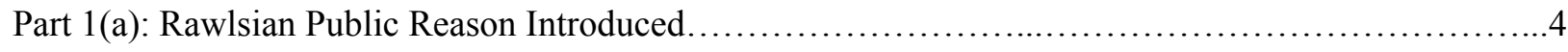

Part 1(b): Public Reason's Autonomy and Epistemic Abstinence..................................................6

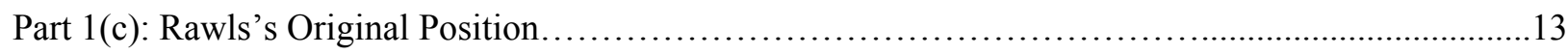

Part 1(d): The Questions To Which Public Reason Applies..........................................................21

Part 1(e): The Proposal to Bracket Comprehensive Moral and Religious Doctrine........................30

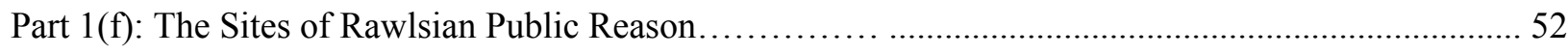

Part 1(g): Rawlsian Public Reason's treatment of Religious Comprehensive Doctrines..................65

CHAPTER 2: A Better Way: Jennifer Nedelsky's Thesis on the "Enlarged Mentality"..................76

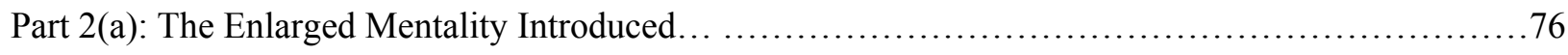

Part 2(b): Accommodation Rather than Preclusion.......................................... 76

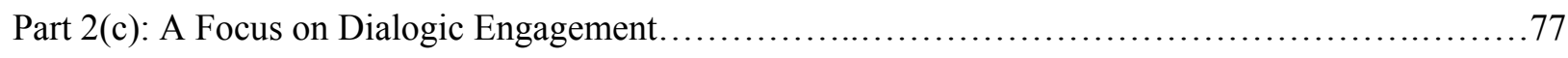

Part 2(d): Managing the Difficulties Associated With Religious Arguments.........................79

Part 2(e): Democratic Pluralism Embraced Not Transcended or Transformed........................82 
Part 2(f): The Sites of the Enlarged Mentality and The Questions To Which It Applies

CHAPTER 3: Canadian Constitutional Values and Their Implications For The Inclusion of Moral and

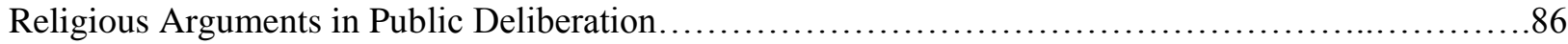

CHAPTER 4: Brief Study of the Ontario Sharia Debate in Light of Rawl's Public Reason and Nedelsky's

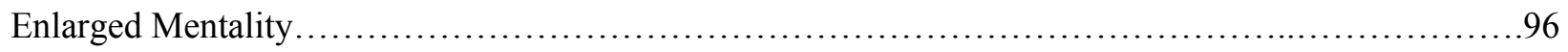

Part 4(a): Profile of the Ontario Sharia Debate.............................................. 96

Part 4(b): The Ontario Sharia Debate and Rawlsian Public Reason................................103

Part 4(c): The Ontario Sharia Debate and Nedelsky's Enlarged Mentality......................... 105

CHAPTER 5: Final Act-Balancing Act................................................. 107

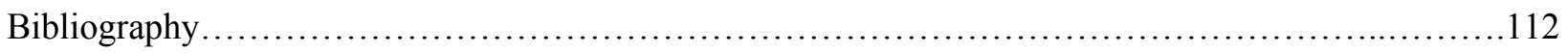




\section{INTRODUCTION}

Invariably wherever there is a liberal democratic state there is the reality of democratic pluralism; indeed the influential legal philosopher, John Rawls, declares:

... a basic feature of democracy is the fact of reasonable pluralism-the fact that a plurality of conflicting reasonable doctrines, religious, philosophical, and moral, is the normal result of its culture of free institutions. ${ }^{1}$

In reality just as where there is smoke there is fire, where there is democratic pluralism one invariably finds that there is polemical debate on the type of arguments and justifications and by extension positive laws appropriate for the public sphere in light of the differing and in many cases conflicting world views, interests and values held by the various groups within the democratic polity. I propose to examine two theoretical models in relation to the norms that ought to govern public deliberation in the context of democratic pluralism, John Rawls' thesis on public reason and Jennifer Nedelsky's thesis on the Enlarged Mentality.

John Rawls's thesis on Public Reason is one of the most influential in relation to the type of arguments appropriate for public deliberation in the context of democratic pluralism. Rawls' thesis on Public Reason is so influential in terms of its contribution to liberal democratic thought that it is irresistible to say the least or arguably unwise, to undertake any discussion in relation to the type of arguments to be allowed in public discourse without some treatment of Rawls' thesis. Notably Rawls in his thesis on Public Reason propounds that comprehensive doctrine including religious arguments ought to be bracketed from public deliberation as "...Public reason requires us to justify our proposals in terms of proper political values". ${ }^{2}$ This proposal by Rawls has engendered substantial controversy especially among religious adherents many of whom subscribe to liberal ideals and particularly the constitutional democratic paradigm. Many of these adherents argue that the proposal to exclude religious arguments from the public sphere is

\footnotetext{
${ }^{1}$ John Rawls, "The Idea of Public Reason Revisited" (1997) 64:3 U. Chicago L. Rev p. 765 at 765-766.

2 John Rawls, "The Idea of Public Reason Revisited" (1997) 64:3 U. Chicago L. Rev p. 765 at 778.
} 
untenable in light of other liberal principles and that the proposal is generally unreasonable and unworkable.

This paper is situated in the vein of criticism of Rawlsian public reason particularly its proposal to bracket religious arguments from public deliberation. My criticism of Rawlsian public reason is pointed specifically toward the Canadian experience and particularly Canadian Charter values. I will argue for the position that converse to the 'demands' of Rawlsian public reason, Canadian Charter values demand an affirmative role for religious arguments in public deliberation. I will argue that the Canadian Charter from its very starting point-its preamble, signals the converse of what Rawls' public reason calls for and unmistakably recognizes a role for religious reasoning in public deliberation in Canada. I will adopt Will Kymlicka observation that “...underlying much liberal opposition to the demands of ethnic and national minorities is a very practical concern for the stability of liberal states, ${ }^{, 1}$ and assert that this is applicable in relation to liberal opposition to public argumentation and reasoning based on comprehensive doctrines. Applying Kymlicka's thesis to the case of public deliberation, I will argue that the fear that allowing comprehensive doctrines to freely enter public deliberation threatens democratic stability is overstated. I will argue that the way to manage the risk of the unraveling of instability, on account of the reality of conflicting conceptions of the good, is not the pursuit of Rawlsian public reason. I will argue that the pursuit of public reason as an ideal far from mitigating the perceived threat to the stability of liberal states, may serve to instigate it by virtue of the marginalizing and muzzling effect such a pursuit is likely to have on some citizens. I will seek to demonstrate the constraining effect and disenfranchisement that a policy of excluding religious arguments from public discourse may have in the Canadian polity by briefly discussing the resolution of the Ontario Sharia debate.

In my conclusion I will argue for an approach which utilizes the 'enlarged mentality' as advocated by the scholar, Jennifer Nedelsky. I will argue that the enlarged mentality as propounded by Jennifer Nedelsky is preferable to Rawls' public reason in that it is compatible with and promotes Canadian Charter values

${ }^{1}$ Will Kymlicka, "Multicultural Citizenship: A Liberal Theory of Minority Rights” (Oxford: Clarendon Press, 1995) at 192. 
and has much promise in terms of satisfying the need for a normative framework of mutual respect and public spirited deliberativeness which is at the heart of the liberal democratic paradigm. I will argue that the employment of the 'enlarged mentality in the case of the Ontario Sharia debate converse to the actual result reached, would have likely ensured the securing of the two aforementioned benefits: compatibility and promotion of Charter values and ensuring that the deliberation proceeded based on a normative framework of mutual respect and public spirited deliberativeness. 


\section{Chapter 1: Rawls' Thesis on Public Reason}

\section{Part 1(a): Rawlsian Public Reason Introduced}

John Rawls' thesis re public reason begins with an acknowledgment of the fact that reasonable pluralism is a basic feature of democracy. ${ }^{1} \mathrm{He}$ asserts that as a result of the plurality of conflicting reasonable comprehensive doctrines, citizens of a democratic polity are unable to reach agreement or reconcile viewpoints informed by their comprehensive doctrines. ${ }^{2}$ He suggests that in light of their irreconcilable comprehensive doctrines, citizens "...Need to consider what kinds of reasons they may reasonably give one another when fundamental political questions are at stake".

Indeed the notion of conflicting, irreconcilable comprehensive doctrines within the context of democratic plurality is unobjectionable. This invariably leads the 'reasonable' citizen or to use an apter phrase'citizen aspiring to be reasonable' to seek out a middle ground to mediate between the 'clashing cymbals' of conflicting comprehensive doctrines. It may be said that ever since the embracing of liberal democratic values in Western Europe such concepts as 'tolerance' and "respect" have been deployed to this end. It is therefore to Rawls' credit that his thesis on public reason starts out by acknowledging the indubitable reality of irreconcilable comprehensive doctrines in the context of liberal democratic pluralism and evidences the recognition of the imperativeness of coming to terms with this reality and its concomitant challenges. Rawls' introductory acknowledgment comports with and appeals to our sense of the desirability of the attainment of some measure of mediation in light of the reality of irreconcilable comprehensive doctrines. However Rawls' proverbial 'man for the job' is no mere mediatory conception, it is the idea of public reason.

According to Rawls 'public reason' is a political conception of justice. ${ }^{4}$ He suggests that as such it ought to be distinguished from such ideas as 'tolerance' and 'respect' expressed from within a religious or non-

\footnotetext{
${ }^{1}$ John Rawls, "The Idea of Public Reason Revisited" (1997) 64:3 Chicago L.Rev 765.

2 ibid, p. 766.

${ }^{3}$ Ibid, 766.

"John Rawls, “The Idea of Public Reason Revisited” (1997) 64:3 Chicago L.Rev 765 at 766.
} 
religious doctrine. ${ }^{1}$ He conceives of 'public reason' as “...An idea of the politically reasonable addressed to citizens as citizens"2. Rawls' public reason transcends the bounds of a mere mediatory conception in that it aspires to do more than "Intervene in a dispute in order to bring about an agreement or reconciliation" ". He unmistakably asserts that his thesis of public reason does not aspire merely to quiet divisiveness, encourage social stability and maintain civil peace. ${ }^{4}$ According to Rawls it is not sufficient that the irreconcilable comprehensive doctrines accept a democratic regime merely as a modus vivendi. ${ }^{5}$ In Rawls' schema where a democratic regime is accepted merely as a modus vivendi stability is not secured for the right reasons. ${ }^{6}$ He asserts that democratic stability ought to be "... Secured by a firm allegiance to a democratic society's political (moral) ideals and values" ${ }^{\text {"7 }}$ It is therefore inferable that Rawls' thesis far from contemplating mere reconciliation among comprehensive doctrines in the liberal democratic fray envisages something much more akin to a transformation of liberal democracy. Joseph Raz in his critique of Rawls' thesis of public reason surmises that the aim is transcendence in relation to the disagreement among the many incompatible moralities in liberal democracies. ${ }^{8}$ I suspect that 'transcendence' is an understatement and that this is inferable when one delves into the implications of Rawlsian public reason particularly in relation to religious comprehensive doctrines. Further upon close examination of Rawls' elucidation of his thesis it is inferable that his thesis envisages more than 'transcendence'. A close reading of Rawls' thesis on public reason evidences that it contemplates as it were 'active combat within the fray' with the end in sight of transformation. For the purpose of challenging Rawls' argument for the 'autonomy' of his thesis and as Joseph Raz styles it, its-epistemic

\footnotetext{
${ }^{1}$ Ibid, at page 783 .

${ }^{2}$ Ibid, at page 766 .

${ }^{3}$ This is the meaning of "mediate" provided by Oxford University Press' online resource: oxforddictionaries.com. See Oxford University Press, online: Oxford Dictionaries 〈http://oxforddictionaries.com/definition/mediate>

${ }^{4}$ John Rawls, Political Liberalism (New York: Columbia University Press, 2005) at pages 459.

${ }^{5}$ Ibid, at page xxxvii.

${ }^{6}$ Ibid, at page 459.

${ }^{7}$ Ibid.

${ }^{8}$ Joseph Raz, "Facing Diversity: The Case of Epistemic Abstinence" (1990) 19:1 Philosophy \& Public Affairs page 3-46 (JSTOR), at page 8 .
} 
abstinence $^{1}$, I will acknowledge that the idea of 'transcendence' is kinder to him where he makes the argument for 'epistemic abstinence' and 'autonomy'. I will defer elucidating why I surmise 'transformation' is apter to describe Rawlsian public reason's project. I will return to it later when I discuss public reason's proposal to bracket moral and religious comprehensive doctrines and its particular treatment of religious comprehensive doctrines and some of its likely ramifications as it relates to public deliberation in the context of democratic pluralism. For now I will work with the kinder notion of 'transcendence' being as it is more in keeping with Rawls' argument for the objectivity of his thesis. I now propose to investigate this claim to autonomy and epistemic abstinence.

\section{Part 1(b): Public Reason's Autonomy and Epistemic Abstinence}

Rawls posits that his thesis does not criticize nor reject any particular theory of the truth of moral judgments. ${ }^{2}$ According to him the enterprise of his overarching theory, political liberalism (of which the conception of public reason forms a part and reflects its enterprise), is founded upon a political constructivist approach which provides political liberalism with an appropriate conception of objectivity. ${ }^{3}$ He asserts that this approach, political constructivism, modeled by the original position (this conception will be discussed later), conceives of a procedure where rational agents as representatives of citizens and subject to reasonable conditions, select the public principles of justice to regulate the basic structure of society. ${ }^{4}$ According to Rawls his political constructivist approach has four features:

1. The content of the principles of political justice may be represented as a procedure of construction wherein rational agents as representatives of citizens and subject to reasonable conditions select the principles to regulate society's basic structure ${ }^{5}$;

\footnotetext{
${ }^{1}$ Ibid, at page 9.

2 John Rawls, Political Liberalism (New York: Columbia University Press, 2005) at xix-xx.

${ }^{3}$ John Rawls, Political Liberalism (New York: Columbia University Press, 2005) at 90.

${ }^{4}$ Ibid at page 93 .

${ }^{5}$ Ibid.
} 
2. The procedure of construction is based essentially on practical reason and not on theoretical reason. ${ }^{1}$ Practical reason is concerned with the production of objects according to a conception of those objects while theoretical reason is concerned with the knowledge of given objects ${ }^{2}$;

3. The procedure of construction employs a complex conception of persons and society. ${ }^{3}$ It conceives of the person has possessing two moral powers-the capacity for a sense of justice and a conception of the good. ${ }^{4}$ It conceives of the person belonging to a political society understood as a fair system of social co-operation from one generation to the next ${ }^{5}$; and

4. The approach specifies an idea of the reasonable and this applies to the conceptions, judgments, persons and interests within the society. ${ }^{6}$ It specifies criteria to judge reasonableness without using or denying the concept of truth. ${ }^{7}$ The idea of the reasonable is provided by the two aspects of persons being reasonable: their willingness to propose and abide by fair terms of social cooperation among equals and their willingness to accept the consequences of the burden of judgment. $^{8}$

\section{Joseph Raz's Critique}

The scholar, Joseph Raz, provides cogent commentary in relation to Rawls employment of political constructivism to arrive at his 'political conception of justice' as he styles it'. ${ }^{9}$ Raz's commentary is particularly helpful as it pointedly addresses all four features of Rawls' political constructivist approach. According to Raz's critique the abovementioned four features of Rawls' political constructivist approach

\footnotetext{
${ }^{1}$ John Rawls, Political Liberalism (New York: Columbia University Press, 2005) at 93.

${ }^{2}$ Ibid.

${ }^{3}$ Ibid.

${ }^{4}$ Ibid.

${ }^{5}$ Ibid.

${ }^{6}$ John Rawls, Political Liberalism (New York: Columbia University Press, 2005) at 94.

${ }^{7}$ Ibid.

${ }^{8}$ Ibid.

${ }^{9}$ See Joseph Raz, "Facing Diversity: The Case of Epistemic Abstinence" (1990) 19:1 Philosophy \& Public Affairs page 3-46 (JSTOR)
} 
evidences Rawls' four (4) measures of modesty. ${ }^{1}$ As it relates to Rawls' first feature of his constructivist approach Raz notes that this first feature is characterized by the limited applicability of the principles of justice to the basic structure of society. ${ }^{2}$ Rawls asserts that the "basic structure of society" means: ...A society's main political, social, and economic institutions, and how they fit together into one unified system of social co-operation from one generation to the next. ${ }^{3}$

Not only is Rawls conception limited to the basic structure of society it is limited to the basic structure of a 'modern constitutional democracy'. ${ }^{4}$ Joseph Raz submits that this particular limitation is designed by Rawls to make his thesis political and not metaphysical, as well as to render it realistically relevant to contemporary circumstances and remove any trace of utopianism. ${ }^{5}$ Raz submits that one of the attractive features of Rawls' avoidance of analysis of the features of modern constitutional democracies which makes his thesis applicable to them is by so doing it firmly roots the political conception of justice in the here and now. ${ }^{6}$ Raz states:

Only because we live in societies of this kind is the construction of a theory of justice along Rawls's lines, a theory which has the aims he set it, a proper task for political philosophy. In parallel, these conditions of contemporary democracies determine not only the content but the very function and role of a doctrine of justice. ${ }^{7}$

I disagree with Raz as to his assessment of the attractiveness of Rawls' treatment of the 'basic structure' of a modern constitutional democracy. I submit that Raz's assessment is misplaced in light of his assertion quoted above and the way in which Rawls chooses to limit his conception of the 'basic structure' of 'modern constitutional democracies'. Rawls assumes that the 'basic structure' is that of a 'closed society'-one regarded as self-contained and as having no relations with other societies and one

\footnotetext{
${ }^{1}$ Ibid, at page 8 .

${ }^{2}$ See Joseph Raz, "Facing Diversity: The Case of Epistemic Abstinence" (1990) 19:1 Philosophy \& Public Affairs page 3-46 (JSTOR), at 5-6.

${ }^{3}$ John Rawls, Political Liberalism (New York: Columbia University Press, 2005) at 11.

${ }^{4}$ See Joseph Raz, "Facing Diversity: The Case of Epistemic Abstinence" (1990) 19:1 Philosophy \& Public Affairs page 3-46 (JSTOR) at page 6.

${ }^{5}$ Ibid.

${ }^{6}$ Ibid.

${ }^{7}$ Ibid.
} 
where its members enter it only by birth and leave only by death. ${ }^{1}$ Rawls acknowledges that this conception of a closed society is a considerable abstraction, justified only because it enables us to focus on certain main questions free from distracting details. ${ }^{2}$ One wonders what these distracting details are. Rawls does not elucidate. Are these distracting details the 'airs of reality' that would require Rawls' conception to come to terms with the reality of life in a plural liberal democracy? Rawls' conception of a closed society is far removed from any society known to us in modernity or even the recent past. How may such a conception justifiably meet the description of being 'rooted in the here and now' or paralleling the conditions of contemporary democracy? I fail to see how this is possible. Rawls' conception of the basic structure of society to which his principles of political justice apply is as contingent on a hypothetical presupposition as any proposition could possibly be. This feature of Rawls' conception inevitably manifests as rather utopian and at least calls into question the plausibility of a claim to a 'political' and not a 'metaphysical' thesis. Therefore it can scarcely be said that his thesis, featuring as it does such a conception of the 'basic structure', renders it realistically relevant to contemporary circumstances and removes any trace of utopianism.

Returning to Raz's critique of Rawls, Raz states that Rawls second feature of his political constructivism manifests shallow foundations. ${ }^{3}$ Raz submits that the shallow foundations of Rawls' thesis arise on account of its other two features-its autonomy and its epistemic abstinence. ${ }^{4} \mathrm{He}$ asserts that Rawls' shallow foundations may be explained by the fact that it takes as its starting point not general moral truths but the givens of our common culture, which Rawls' thesis takes as facts irrespective of their truth or validity. ${ }^{5}$ Raz states that the limited applicability of Rawls' thesis and its shallow foundations are independent but complementary features and that these two features are informed by its third feature

\footnotetext{
${ }^{1}$ John Rawls, Political Liberalism (New York: Columbia University Press, 2005) at 12.

${ }^{2}$ John Rawls, Political Liberalism (New York: Columbia University Press, 2005) at 12.

${ }^{3}$ See Joseph Raz, "Facing Diversity: The Case of Epistemic Abstinence" (1990) 19:1 Philosophy \& Public Affairs page 3-46 (JSTOR) at page 6

${ }^{4}$ Ibid, at page 8 .

${ }^{5}$ Ibid.
} 
which he characterizes as 'the doctrine of the social role of justice'. ${ }^{1}$ Raz submits that in light of its bid to transcend the disagreement among the many incompatible moralities present in the context of liberal democratic pluralism, Rawls' thesis adopts the fourth measure of modesty: epistemic abstinence. ${ }^{2}$ According to Raz, epistemic abstinence is desired by Rawls' thesis, as were it to claim truth as its raison d'être or its reason for acceptance, such a claim would negate the overarching enterprise of transcending the disagreement among irreconcilable comprehensive doctrines. ${ }^{3}$

What of this claim to epistemic abstinence? Raz cogently argues that the natural concomitant of Rawls' claim to epistemic abstinence is the practical aim of his public reason. ${ }^{4}$ He notes that Rawls does not advocate an unprincipled search for consensus at all costs. ${ }^{5}$ As aforementioned, Rawls unmistakably declares that a mere modus vivendi will not do, his thesis contemplates firm allegiance to a democratic society's political (moral) ideals and values. ${ }^{6}$ Raz notes that Rawls thesis contemplates the development of an overlapping consensus. ${ }^{7}$ Rawls defines such a consensus as consisting of:

...All the reasonable opposing religious, philosophical, and moral doctrines likely to persist over generations and to gain a sizable body of adherents in a more or less just constitutional regime, a regime in which the criterion of justice is that political conception itself. ${ }^{8}$

Raz argues that the fact that Rawlsian public reason reflects the consensus of our societies presents a problem for Rawls' thesis as by its reliance on the fact of consensus within the very societies it acts as principles of justice for, it is self-referential and citizens of such societies will live up to their own standards. ${ }^{9}$ Raz submits that the idea that consensus is the only goal in nearly just societies is an external

\footnotetext{
${ }^{1}$ Ibid, at page 9.

2 Joseph Raz, "Facing Diversity: The Case of Epistemic Abstinence" (1990) 19:1 Philosophy \& Public Affairs page 3-46 (JSTOR) at page 9.

${ }^{3}$ Ibid.

${ }^{4}$ Ibid, at page 10 .

${ }^{5}$ Ibid, at page 12 .

${ }^{6}$ Cited previously at page 7 of this paper, see citation at footnote 8 of page 7 .

${ }^{7}$ Joseph Raz, "Facing Diversity: The Case of Epistemic Abstinence" (1990) 19:1 Philosophy \& Public Affairs page 3-46 (JSTOR) at page 12.

${ }^{8}$ John Rawls, Political Liberalism (New York: Columbia University Press, 2005) at 15.

9 Joseph Raz, "Facing Diversity: The Case of Epistemic Abstinence" (1990) 19:1 Philosophy \& Public Affairs page 3-46 (JSTOR) at page 12
} 
condition on Rawls' methodological conception and that this limits its applicability. ${ }^{1} \mathrm{He}$ argues that based on Rawls' rendition of the overlapping consensus it clearly is a consensus not among members of the society but it is primarily a consensus among the different conceptions of the good in society. ${ }^{2}$ Raz argues that while Rawls' thesis declares its abstinence from establishing any evaluative truths it unmistakably accepts some such truths as the presuppositions which make its enterprise of developing a political conception of justice intelligible. ${ }^{3}$ Raz asserts that the Rawlsian thesis of public reason recognizes that social unity and stability based on a consensus are goals of such importance that it makes them the foundations of a theory of justice for our societies. ${ }^{4}$ Raz concludes by repudiating Rawls claim to epistemic abstinence. He argues that Rawls theory of justice can deserve that name simply because it deals with such matters as true theories of justice deal with. ${ }^{5}$ He posits that there are many theories of justice and to recommend one as a just theory of justice inevitably means recommending it as a true, or reasonable, or valid theory. ${ }^{6} \mathrm{He}$ asserts that if as Rawls argues-what makes his political conception of justice the theory of justice for societies like ours is that it is built on an overlapping consensus and therefore secures stability and unity, then it follows that consensus-based stability and unity are the values that underpin such a theory of justice. ${ }^{7}$ Raz's criticism of Rawls is cogent particularly in light of the fact that the preponderance Rawls attributes to consensus based stability is far from unobjectionable. I will return to this point when I deal with public reason's proposal to bracket comprehensive moral and religious comprehensive doctrines from public deliberation. Raz's criticism may be linked with that of Sandel who suggests that even if one were to concede the importance of the interest in consensus-based stability there is no guarantee that this interest is of such import that it will outweigh any competing

\footnotetext{
${ }^{1}$ Joseph Raz, "Facing Diversity: The Case of Epistemic Abstinence" (1990) 19:1 Philosophy \& Public Affairs page 3-46 (JSTOR), at page 13 .

${ }^{2}$ Ibid.

${ }^{3}$ Ibid.

${ }^{4}$ Ibid.

${ }^{5} \mathrm{Ibid}$, at page 15 .

${ }^{6}$ Ibid.

${ }^{7}$ Ibid.
} 
interest that could arise from within a comprehensive moral or religious doctrine. ${ }^{1}$ Notwithstanding this Rawls thesis proceeds on the presupposition that the preponderance of the value of consensus based stability is a foregone conclusion and this fact shows up the claim to epistemic abstinence as objectionable to say the least.

Raz asserts that Rawls conceives of epistemic abstinence, the shallow foundations of his theory and its autonomy as mutually supported..$^{2}$ According to Raz an autonomous political theory is a theory which argues for the truth of propositions about specifically political virtues, it is not concerned with nonpolitical moral truths. ${ }^{3}$ Raz explains that there are two ways in which a political theory can be autonomous: it can be weakly autonomous and strongly autonomous. ${ }^{4}$ Raz states that a political theory may be weakly autonomous where it is part of a pluralistic conception of the good that is to say a conception that recognizes the existence of irreducibly many intrinsic goods, virtues and values. ${ }^{5} \mathrm{He}$ suggests that a strongly autonomous political theory is one whose validity or truth does not depend on nonpolitical considerations. ${ }^{6}$ Raz points out that Rawls conceives of his thesis as making no claim to truth or validity, and that it is therefore independent of any moral foundations. ${ }^{7}$ It is therefore clear that Rawls conceives of his thesis as being strongly autonomous and that weak autonomy does not cut it for him as he unmistakably asserts that his thesis is not a part of a comprehensive conception of the good. ${ }^{8}$ Raz argues that Rawls' thesis suggests that the people who are subject to public reason accept the principles of justice from the point of view of their own comprehensive conception of the good. ${ }^{9}$ Raz suggests that for these people their political philosophy does not have any shallow foundations, they regard it as the

\footnotetext{
${ }^{1}$ See Michael J. Sandel, Liberalism and the Limits of Justice 2d ed. (Cambridge, Cambridgeshire: Cambridge University Press, 1998), at 196.

${ }^{2}$ Joseph Raz, "Facing Diversity: The Case of Epistemic Abstinence" (1990) 19:1 Philosophy \& Public Affairs page 3-46 (JSTOR) at page 20.

${ }^{3}$ Ibid.

${ }^{4}$ Ibid, at 22.

${ }^{5}$ Ibid.

${ }^{6}$ Ibid.

${ }^{7}$ Joseph Raz, "Facing Diversity: The Case of Epistemic Abstinence" (1990) 19:1 Philosophy \& Public Affairs page 3-46 (JSTOR) at page 22.

${ }^{8}$ Ibid, see also John Rawls, Political Liberalism (New York: Columbia University Press, 2005) at 174-176.

${ }^{9}$ Ibid(Joseph Raz), at 21.
} 
application of their comprehensive morality to the special problem of politics. ${ }^{1}$ Consequently Raz argues that contrary to Rawls suggestion, his theory cannot be strongly autonomous. Raz further asserts that a strongly autonomous political theory does not yield practical conclusions as it prevents us from considering its political values in the comprehensive context of a complete moral theory. ${ }^{2}$ Based on Raz's analysis Rawls' thesis cannot be anything more than weakly autonomous ${ }^{3}$. This is problematic for Rawls' thesis on public reason as it proceeds based on the assumption that the principles of justice which inform it are not formulated in terms of any comprehensive doctrines but in terms of certain fundamental ideas viewed as latent in the public political culture. ${ }^{4}$

Based on Raz's cogent analysis in relation to Rawls' claim for the epistemic abstinence and autonomy of his schema it is inferable that the theoretical grounding of his 'political' conception of justice which organizes around 'political values' rather than 'moral values' and metaphysical premises is at least questionable. It is hard to imagine the development of the political values that Rawls' thesis of public reason requires to inform public deliberation without such values being generated by some comprehensive doctrine or values derived therefrom. Therefore separate and apart from the myriad of problems foreseeable in relation to public reason's implementation which will be discussed in the ensuing pages, the thesis is problematic even at the rarified level of theory. The theoretical claims it makes turn out to be conceptually problematic and objectionable and particularly its proposal to isolate 'political values' separate and apart from moral and metaphysical premises manifest as unsubstantiated.

\section{Part 1(c): Rawls' Original Position}

The idea of the "original position'5 is fundamental to Rawls overarching theory, Political Liberalism, and underpins his thesis on public reason. Rawls proposes the original position as a hypothesis to enable the identification of the political guidelines and principles to which the citizen must appeal pursuant to the

\footnotetext{
${ }^{1}$ Joseph Raz, "Facing Diversity: The Case of Epistemic Abstinence" (1990) 19:1 Philosophy \& Public Affairs page 3-46 (JSTOR) at page 21 .

${ }^{2}$ Ibid.

${ }^{3}$ Ibid, at page 24 .

${ }^{4}$ John Rawls, Political Liberalism (New York: Columbia University Press, 2005) at page 175.

5 John Rawls, Political Liberalism (New York: Columbia University Press, 2005). Rawls discusses this concept at 22-28.
} 
ideal of public reason. ${ }^{1}$ In seeking to determine the fair terms of cooperation between free and equal citizens his thesis recasts the doctrine of the social contract. ${ }^{2}$ He posits that the hypothetical contract to which the citizens in a constitutional democracy agree must be entered into under the appropriate conditions. ${ }^{3}$ The conditions Rawls set out as prerequisites for his hypothetical social contract are that free and equal citizens must be situated fairly, some citizens must not be allowed greater bargaining advantages than others, and that threats of force and coercion, deception and fraud must be excluded. ${ }^{4}$ Rawls offers the hypothesis of the original position to fulfill the need for a 'point of view' from which the fair agreement required by his contractarian hypothesis can be reached. ${ }^{5}$ This point of view is characterized by the 'veil of ignorance' which ensures that the citizen is not privy to the abovementioned contingencies of the social word and that therefore a fair agreement is ensured. ${ }^{6}$ At this point the "mental gymnastics' required by Rawls' thesis on public reason looms into view. His thesis on public reason which may have already begun to appear as rarified not only rests on a hypothetical social contract but the hypothetical social contract on which it rests in turn rests on an hypothesis-that of the original position which is characterized by the 'veil of ignorance'. As the scholar, Michael Sandel aptly terms it-"It imagines an event that never really happened, involving the sorts of beings who never really existed". ${ }^{7}$ Another scholar-Ronald Dworkin asserts, "A hypothetical contract is not simply a pale form of an actual contract; it is no contract at all". ${ }^{8}$ Indeed the fact that the political guidelines and principles constituting the ideal of public reason are generated in a hypothetical contract in and of itself makes Rawls' thesis at least of diminished appeal. One doubts its ability to actually do what it sets out to do-isolate principles of justice to enable the 'real world' resolution of fundamental constitutional questions without regressing to

\footnotetext{
${ }^{1}$ Ibid, at page 450 .

${ }^{2}$ John Rawls, Political Liberalism (New York: Columbia University Press, 2005), at 22-23.

${ }^{3}$ Ibid, at 23 .

${ }^{4}$ Ibid.

${ }^{5}$ Ibid.

${ }^{6}$ Ibid.

${ }^{7}$ Michael J. Sandel, Liberalism and the Limits of Justice 2d ed. (Cambridge, Cambridgeshire: Cambridge University Press, 1998), at 105.

${ }^{8}$ Ronald Dworkin, Taking Rights Seriously (London: Duckworth Press, 1977) at 17-18. Also quoted in Sandel(cited above) at 105.
} 
the intractable 'real world' problems instigated by the reality of irreconcilable comprehensive doctrines. Notwithstanding that the hypothesis of the 'original position' may strike one as airy fairy, we endeavor to avoid philistinism, theory too separate and apart from the practical has its own merits. So we seek to examine more closely Rawls' hypothesis to determine whether and how it hangs together.

Rawls acknowledges that there is some difficulty with his hypothesis of the original position; he states this difficulty to be that as a device of representation its abstractness invites misunderstanding. ${ }^{1}$ He asserts that the idea of the original position is introduced because there seems no better way to elaborate a political conception of justice for the basic structure of society. ${ }^{2}$ As aforementioned this 'basic structure of society' is also hypothesized to be a closed society-that is one which is self-contained and which has no relations with other societies. We are presented with yet another layer of hypothetical supposition. The fact that there seems to be no better way than this may very well indicate the utopianism inherent in Rawls' thesis on public reason. This 'way' is one founded upon multiple layers of hypothetical suppositions, and it is reasonable to conclude that this 'way' is far removed from the realm of the attainable. It is therefore fair to ask whether Rawls' sought after 'political conception' of justice is attainable at all.

Rawls acknowledges that the description he provided of the representative citizen in the original position may seem to presuppose a particular metaphysical conception of the person. ${ }^{3}$ He specified the description which his thesis contemplates as that of the essential nature of persons being independent of and prior to her contingent attributes, including their final ends and attachments, their conception of the good and their character as a whole. ${ }^{4} \mathrm{He}$ submits that the conclusion that his thesis presupposes a particular conception of the person is illusory and is caused by not seeing the original position as a device of representation. ${ }^{5}$ According to Rawls the hypothetical notion of the 'veil of ignorance' which is integral to the original

\footnotetext{
${ }^{1}$ John Rawls, Political Liberalism (New York: Columbia University Press, 2005), at 27.

2 Ibid, at 26.

${ }^{3}$ John Rawls, Political Liberalism (New York: Columbia University Press, 2005), at 27.

${ }^{4}$ Ibid.

${ }^{5}$ John Rawls, Political Liberalism (New York: Columbia University Press, 2005), at 27
} 
position has no specific metaphysical implications concerning the nature of the self-it does not suggest that the self is ontologically prior to the facts about persons that the parties are excluded from knowing. ${ }^{1}$ Rawls submits that simulating being in the original position no more commits us to a particular metaphysical doctrine about the nature of the self than our acting in a play such as Macbeth commits us to thinking that we are really a king or queen engaged in a desperate struggle for political power. ${ }^{2}$ According to him what it is important for us to take from the exercise is the attempt to show:

...how the idea of society as a fair system of social cooperation can be unfolded so as to find principles specifying the basic rights and liberties and the forms of equality most appropriate to those cooperating, once they are regarded as citizens, as free and equal persons. ${ }^{3}$

It is clear that Rawls takes great pains to distance himself from the accusation that his 'original position' has metaphysical implications concerning the nature of the self. The scholar, Michael J. Sandel illuminatingly indicates reasons for Rawls efforts to distance himself from such. Sandel states that Rawls locates his theory of justice in the contractarian tradition going back to John Locke and Immanuel Kant. ${ }^{4}$ According to Sandel actual contracts must presuppose an antecedent principle to justify their results and therefore the question arises as to how such a principle might be derived. ${ }^{5} \mathrm{He}$ asserts that as it is with actual contracts, so it is with ideas of social contracts in the theses of Locke, Kant and Rawls. ${ }^{6} \mathrm{He}$ submits that where Locke backs up the original contract with the law of God and Nature, Kant backs it up with a principle of right given not by nature but by pure reason. ${ }^{7}$ Sandel asserts that of the two approaches, Kant's approach comes closest to what Rawls envisages in that it avoids deriving the right from the good and so preserves deontological assumptions such as the priority of the self over its ends. ${ }^{8}$

\footnotetext{
${ }^{1}$ Ibid.

${ }^{2}$ Ibid.

${ }^{3}$ Ibid.

${ }^{4}$ Michael J. Sandel, Liberalism and the Limits of Justice 2d ed. (Cambridge, Cambridgeshire: Cambridge University Press, 1998), at 105.

${ }^{5}$ Michael J. Sandel, Liberalism and the Limits of Justice 2d ed. (Cambridge, Cambridgeshire: Cambridge University Press, 1998), at 115 .

${ }^{6} \mathrm{Ibid}$, at $115-118$.

${ }^{7}$ Ibid, at page 119 .

${ }^{8}$ Ibid.
} 
Sandel argues that Rawls is resistant to Kant's particular solution as it depends on metaphysical assumptions he finds objectionable. ${ }^{1}$ He states that Kant's formulation is unclear as to whether the principles of right is the product of the original social contract or its premise, and significantly relies on 'pure reason' which legislates a priori. ${ }^{2}$ According to Sandel, Rawls develops the 'original position' as a procedural interpretation of Kant's conception and casts the principles of right as the outcome of a certain process of rational choice and although hypothetical it enables his thesis to lay some claim to human experience. ${ }^{3}$ Rawls himself declares that the original position enables his thesis to avoid the metaphysical grounding of Kant's schema and establish a claim on human experience in a way that might not otherwise be apparent. ${ }^{4}$ It is no wonder that Rawls' thesis avoids the suggestion that it has metaphysical implications concerning the nature of the self. One thing is clear, despite Rawls protestation to the contrary, his denial and assertion that it is 'not so' does not make it 'not so'. His suggestion that imagining ourselves in the original position no more commits us to a metaphysical conception of the person than acting as a king in a play faces a significant challenge. Yes, his two examples are analogous just as any two hypothetical scenarios are analogous to the extent that they demand an exercise of the imagination. Yet the two scenarios demand us to stretch our imaginations to a significantly different degree, so much so that it may be said that what the 'original position' requires of us is of a different ilk altogether from playing the role of king in Macbeth. The role of the king in Macbeth demands us to do no more than to imagine ourselves in a desperate struggle for political power, a reality which is very close to home in the realm of human experience. We can readily think back to times when we really, really wanted something so much so that we felt we could exert our last sinew and nerve for it. Yes, the role of the king in Macbeth in a desperate struggle for political power is a role we can readily take on as it is firmly situated in the realm of human experience. After all early on in our human development we

\footnotetext{
${ }^{1}$ Michael J. Sandel, Liberalism and the Limits of Justice 2d ed. (Cambridge, Cambridgeshire: Cambridge University Press, 1998), at 119.

${ }^{2}$ Ibid, at 120.

${ }^{3}$ Michael J. Sandel, Liberalism and the Limits of Justice 2d ed. (Cambridge, Cambridgeshire: Cambridge University Press, 1998), at page 120 .

${ }^{4}$ John Rawls, A Theory of Justice (Cambridge, Mass: Belknap Press, 2005), at page 264. Also cited in Michael Sandel(ut supra) at page 119 .
} 
recognize that we inevitably contend with impulses for vice or virtue however defined. Roles in plays require us to convey emotions not dissimilar to any we have experienced or are capable of experiencing. The role and imaginative capacity Rawls' original position demands of us are creatures of a significantly different breed. Is it really possible to imagine oneself devoid of social position, race, ethnicity, sex and gender, and our various natural endowments such as strength and intelligence-all the things that make us who we are and think like how we think? Rawls demands no less of us in the original position. ${ }^{1}$ It is hard to escape either of two conclusions. The first, that Rawls is hard pressed to come up with a suitable hypothesis to ground and justify his contractarian conception so he reaches for this 'far-fetched' conception of the original position like a man clutching at straws. The second, that Rawls in fact subscribes to the metaphysical conception of the self as prior to its end and that his hypothesis of the original position is infused with this presupposition. Neither conclusion is helpful to the marketability of Rawls' original position; his rendition of the original position suggests that the second alternative is true. It is hard to escape the conclusion-the original position as unraveled by Rawls depends on a certain conception of the self as prior to its ends or to use Sandel's elegant phrase 'the possibility of an unencumbered self' ${ }^{2}$ Certainly the conception of the self demanded by the original position is not unobjectionable and unproblematic as say a conception of King Macbeth desperately struggling to hold on to power. The original position does not merely require us to 'get into character' and embark on a journey of imagination it requires us to as it were 'get out of character' by checking our selves at the door first. We instinctively respond to the director who instructs us to deploy our imaginative capacities toward the project of envisioning ourselves in the original position bereft of our individuating circumstances; we ask quizzically_-“How do we do that?” We have never done that before, nor can we imagine ever doing that. We can scarcely expect the director to provide directions much less demonstrate; he too is human

\footnotetext{
${ }^{1}$ See John Rawls, Political Liberalism (New York: Columbia University Press, 2005) at 24-25.

${ }^{2}$ Michael J. Sandel, Liberalism and the Limits of Justice 2d ed. (Cambridge, Cambridgeshire: Cambridge University Press, 1998 ) at 121, 179 and 188. Sandel to the view that Rawls' conception of the person is that of a free and independent self, unencumbered by prior moral ties.
} 
after all. Contrary to Rawls' assertion that his hypothesis "may invite misunderstanding" it may be apter to say that his hypothesis stretches, challenges and defies our usual understanding.

Contrary to Rawls' protestations to the contrary his hypothesis of the original position depends on a certain metaphysical conception of the person and is therefore objectionable in light of his contrary claim. Rawls' bid to find an Archimedean point in the original position and therefore a vista from which the principles of justice informing public reason may be derived free from implication in the world of comprehensive doctrines and free from otherworldliness faces a significant challenge. ${ }^{1}$ It has after all to start with the human person-grounded as it is in worldly circumstances, encumbered by history and experience and therefore never strictly prior to its ends. ${ }^{2}$ In order to circumvent this human person Rawls inevitably requires us, human persons, to don the hat of hypothesis and to conceive of a particular vision of the self as unencumbered by the usual wide variety of factors and circumstances. Not only does this hypothesis stand out as a stranger to our sensibilities, indeed it requires us to estrange them; his theoretical machine relies heavily on the device of metaphysical doctrine-that of the self as prior to its ends.

\section{$\underline{\text { Sandel's criticism of Rawls' original position }}$}

That is not the end of the matter. There are even more significant implications flowing from the fact that Rawls' thesis on public reason relies on the 'original position' for its underpinning. In my estimation Rawls aforementioned arguments for the metaphysical abstinence of his original position does not evade the force and cogency of Sandel's significant criticism. I shall present Sandel's criticism now. It is inferable that the starting premise of Rawls' contractarian synthesis and thus the raison d'être of his construct, the 'original position', is the notion of the essential plurality of human subjects and the need to resolve conflicting claims. ${ }^{3}$ The Rawlsian schema contemplates that in the original position the parties as

\footnotetext{
${ }^{1}$ Ibid at page 115. Sandel refers to the problem in connection with the Archimedean point-one of distinguishing a standard of appraisal from the thing being assessed

${ }^{2}$ Ibid at page 180 .

${ }^{3}$ Michael J. Sandel, Liberalism and the Limits of Justice 2d ed. (Cambridge, Cambridgeshire: Cambridge University Press, 1998) at 124.
} 
rational representatives specify the fair terms of cooperation by agreeing to principles of justice. ${ }^{1}$ Sandel states that according to Rawls' thesis the parties in the original position come to an agreement on the principles of justice that will bind them. Sandel distinguishes two different senses of 'agreement'. ${ }^{2} \mathrm{He}$ states that the first sense involves agreement with a person or persons with respect to a proposition-a kind of 'choosing together' and the second sense involves agreement to a proposition. ${ }^{3}$ Sandel asserts that the first sense of an agreement is that of an agreement in the voluntarist sense while the second sense is that of agreement in the cognitive sense. ${ }^{4} \mathrm{He}$ submits that in Rawls' thesis the assumptions of choice and plurality stand together as central features of the conception. ${ }^{5}$ Sandel argues that since in the original position the parties are behind the veil of ignorance and are therefore similarly situated so much so that they are guaranteed to reason the same way, there is no basis for discussion and deliberation in the usual sense. ${ }^{6}$ He asserts that this is because 'discussion' and 'deliberation' presupposes some difference in interests, preferences, concerns or perspectives of the discussants or deliberators. ${ }^{7}$ According to him, in the original position where the discussants are similarly situated as to be shorn of difference in their perceptions and interests, it is hard to conceptualize the 'deliberation' proceeding in any fashion other than silence, and it issuing in anything but a single conception which is unanimously agreed to. ${ }^{8}$ Sandel suggests that as a result the agreement secured in the original position can only be in the cognitive sense. ${ }^{9}$ $\mathrm{He}$ asserts that this is because by the original position requiring all individuating circumstances of the deliberators to be excluded, it makes them not merely similarly situated but identically situated. ${ }^{10} \mathrm{He}$ argues that Rawls himself acknowledges that no two subjects could ever be regarded as identically

\footnotetext{
${ }^{1}$ See John Rawls, Political Liberalism (New York: Columbia University Press, 2005) at 28.

${ }^{2}$ Michael J. Sandel, Liberalism and the Limits of Justice 2d ed. (Cambridge, Cambridgeshire: Cambridge University Press, 1998) at page 130.

${ }^{3}$ Ibid at 130 .

${ }^{4}$ Michael J. Sandel, Liberalism and the Limits of Justice 2d ed. (Cambridge, Cambridgeshire: Cambridge University Press, 1998) at 130.

${ }^{5}$ Michael J. Sandel, Liberalism and the Limits of Justice 2d ed. (Cambridge, Cambridgeshire: Cambridge University Press, $1998)$ at 130.

${ }^{6}$ Ibid, at $128-129$.

${ }^{7}$ Ibid.

${ }^{8}$ Ibid.

${ }^{9}$ Ibid, at 130-131.

${ }^{10}$ Ibid, at 132.
} 
situated and still count as distinguishable persons and that therefore Rawls contractarian conception can only be explained in the cognitive sense. ${ }^{1}$ Sandel submits that this is a significant problem for Rawls as his contractarian conception requires an agreement in the voluntarist sense as the plurality of the subject is central to it. ${ }^{2}$ He asserts that the fact that Rawls' original position depends on the interposition of the 'veil of ignorance' means that the required plurality dissolves and consequently the conception of a contract in anything but a cognitive sense dissipates. ${ }^{3}$

The force and cogency of Sandel's criticism of Rawls' conception of the original position is hard to escape. Sandel's arguments present the conception of the original position in full profile as ethereal and therefore difficult to bank on in terms of its role as the coign of vantage from which the principles of justice underpinning public reason are to be derived. That being so it is hard to escape the conclusion that the edifice of Rawlsian public reason is erected on at least shaky foundations.

\section{Part 1(d): The Questions To Which Public Reason Applies}

One may ask when or to what questions does Rawlsian public reason apply? Rawls suggests that the limits imposed by public reason do not apply to all political questions but it applies only to those involving "constitutional essentials" and questions of basic justice. ${ }^{4}$ How do we distinguish 'constitutional essentials' and questions of basic justice from other constitutional questions and questions involving justice? Rawls suggests that constitutional essentials are of two kinds:

a) Fundamental principles that specify the general structure of government and the political process such as the powers of the three arms of government ${ }^{5}$; and

b) Equal basic rights and liberties of citizenship such as the right to vote, liberty of conscience, freedom of thought and association, as well as the protection of the rule of law. ${ }^{1}$

\footnotetext{
${ }^{1}$ Michael J. Sandel, Liberalism and the Limits of Justice 2d ed. (Cambridge, Cambridgeshire: Cambridge University Press, 1998) at 132.

${ }^{2}$ Michael J. Sandel, Liberalism and the Limits of Justice 2d ed. (Cambridge, Cambridgeshire: Cambridge University Press, $1998)$ at $129-132$.

${ }^{3}$ Ibid, at 131-132.

${ }^{4}$ See John Rawls, Political Liberalism (New York: Columbia University Press, 2005) at page 214.

${ }^{5}$ Ibid, at 227.
} 
Rawls submits that many if not most political questions do not concern those fundamental matters such as many laws regulating property but that sometimes these do involve fundamental matters. ${ }^{2}$ According to Rawls a full account of public reason would address these other constitutional and 'justice' questions but that his aim is to consider first the strongest case where the political questions concern the most fundamental matters. ${ }^{3}$ He argues that it is highly desirable to settle political questions via the use of public reason but if we should not honour the limits of public reason as it relates to fundamental matters, it would seem that we need not honour it anywhere. ${ }^{4}$

Kent Greenawalt's analysis concerning the difficulty of agreement in relation to application of $\underline{\text { constitutional essentials }}$

Kent Greenawalt asserts that the basic idea behind Rawls' distinction among political issues is that, “...The fundamentals of political life should be more or less agreed upon and set outside ordinary political wrangling". 5 He submits that that if Rawls is correct that agreement can be achieved on the basic essentials and fundamental matters are taken off the agenda, then undeniably stability and coherence will be enhanced. ${ }^{6}$ Greenawalt examines the status quo as it relates to the constitutional essentials of freedom of religion and separation of church and state. ${ }^{7} \mathrm{He}$ asserts that as it relates to a minimal version of agreement on the two related constitutional essentials, there is evidence of significant agreement as it relates to what would be regarded as the most direct violations of religious liberty and separation of church and state. ${ }^{8}$ Greenawalt submits that a fuller version of these constitutional essentials might include such notions as "no prayer in public schools" and "no substantial direct aid of religious schools". ${ }^{9} \mathrm{He}$ states that agreement about such matters is very difficult to attain as evidenced by the status quo in the

\footnotetext{
${ }^{1}$ John Rawls, Political Liberalism (New York: Columbia University Press, 2005) at page 227.

2 John Rawls, Political Liberalism (New York: Columbia University Press, 2005) at page 214.

${ }^{3}$ Ibid, at page 215 .

${ }^{4}$ Ibid.

${ }^{5}$ Kent Greenawalt, Private Consciences and Public Reasons (New York: Oxford University Press, 1995) at page 106.

${ }^{6}$ Ibid, at 114 .

${ }^{7}$ Kent Greenawalt, Private Consciences and Public Reasons (New York: Oxford University Press, 1995) at page 114.

${ }^{8}$ Ibid.

${ }^{9}$ Ibid.
} 
United States, where such notions are highly polemical. ${ }^{1}$ Greenawalt proceeds from the examples he cites to argue that the distinction between the minimal version of agreement and the fuller version of agreement manifests as soon as we move away from the abstract expression of a constitutional essential, or what constitutes a blatant violation. ${ }^{2} \mathrm{He}$ argues that when we move to the application of a constitutional essential to concrete examples or detailed circumstances, there is seldom wide agreement, and as such the 'agreement' that obtains is nothing other than minimal. ${ }^{3}$ Greenawalt argues that this is likely to be the tendency as it relates to constitutional essentials in liberal democracies-significant disagreement about a range of disputed applications notwithstanding agreement on the abstract conception of the constitutional essential. ${ }^{4}$ Greenawalt's point is cogent and is applicable to the Canadian status quo. In Canada one would scarcely deny that there is general agreement on such constitutional essentials as the right to life, freedom of conscience/religion and equality as it relates to their abstract expression and blatant violation. However when it comes to their application to concrete cases there is much disagreement. To cite an example it is undeniable that the application of the right to life to the issue of abortion is polemical. Further in certain cases the very applicability of a constitutional essential is polemical. Take for instance the 'Ontario Sharia Debate' which unfolded in 2003 and which we will briefly discuss later. Some of the strident and influential voices against the proposal vented the view that that polemic did not implicate the constitutional essential of freedom of conscience and religion. ${ }^{5}$ Therefore following from Greenawalt's points it cannot be said that there is any meaningful consensus as it relates to 'constitutional essentials' in polities like Canada. The notion of consensus is clearly objectionable when it comes to the application of these 'constitutional essentials' as invariably when it comes to the matter of their application to concrete cases polemics manifest. It therefore becomes clear that Rawlsian public reason has its work cut out for it particularly as it relates to the application/concrete manifestation of constitutional essentials for this is by

\footnotetext{
${ }^{1}$ Kent Greenawalt, Private Consciences and Public Reasons (New York: Oxford University Press, 1995) at page 114

${ }^{2}$ Ibid.

${ }^{3}$ Kent Greenawalt, Private Consciences and Public Reasons (New York: Oxford University Press, 1995) at page 114-115.

${ }^{4}$ Ibid.

${ }^{5}$ Margaret Attwood et al, “Open Letter to Ontario Premier Dalton McGuinty: Don't Ghettoize Women's Rights” Globe and Mail Newspaper(10 September 2005) A23 available at online: <http://www.butterfliesandwheels.org/2005/open-letter-dontghettoize-womens-rights/>
} 
and large the locus of public polemics in constitutional democracies like Canada. The polemics relating to the application of constitutional essentials invariably turn on the interpretation of constitutional essentials so Rawlsian public reason has to not only enable meaningful and consensual interpretation of these constitutional essentials but do so according to its particular principles and modus operandi. Greenawalt provides an illuminating analysis of the likely problems Rawlsian public reason faces as it relates to the task of interpreting constitutional essentials. Before discussing Greenawalt's analysis I will discuss Rawls' treatment of the polemical issue of abortion and provide my criticism.

\section{$\underline{\text { Rawls treatment of the abortion polemic }}$}

In his exposition on the mechanics of public reason in relation to polemical issues Rawls uses the polemical issue of abortion as illustration. ${ }^{1}$ Rawls asks that in addressing the issue of abortion we suppose that the society in question is well-ordered and that we are dealing with the normal case of mature adult women. ${ }^{2} \mathrm{He}$ further asks of us that in considering the question of abortion we focus on three important political values: the due respect for human life, the ordered reproduction of political society over time, including the family in some form and the equality of women as equal citizens. ${ }^{3}$ Notably Rawls acknowledges that there are other important political values besides these three. ${ }^{4} \mathrm{He}$ submits that any reasonable balance of these three values will give a woman a duly qualified right to decide whether or not to end her pregnancy during the first trimester. ${ }^{5}$ He submits that the reason is that at this early stage of pregnancy the political value of the equality of women is overriding, and the right to have an abortion is required to give it substance and force. ${ }^{6}$ Rawls assertion is far from objectionable; one may reasonably ask why is it that the 'political value' of the equality of women is overriding at this particular stage? Does public reason lead to this conclusion? Certainly the notion that the equality of the women is overriding at this particular stage must rely on a presupposition about the status of the fetus at this stage of a woman's

\footnotetext{
${ }^{1}$ See John Rawls, Political Liberalism (New York: Columbia University Press, 2005) at 240-247.

${ }^{2}$ John Rawls, Political Liberalism (New York: Columbia University Press, 2005) at 243(note 32).

${ }^{3}$ Ibid.

${ }^{4}$ Ibid.

${ }^{5}$ Ibid.

${ }^{6}$ Ibid.
} 
pregnancy. The conclusion Rawls reaches must at least presuppose that the fetus at this stage of a woman's pregnancy is at least not of equal worth/value meriting equality as is the case for the woman. Does this view of the fetus follow from practical reason? It is not surprising that Rawls takes pains in subsequent publications to state that his previously discussed assertions is not his 'argument' for the right to abortion but his 'opinion' and that his 'opinion' is not an 'argument'. ${ }^{1}$ It is no wonder he states thus, the brief analysis Rawls bring to bear on the issue of abortion in the first trimester is strikingly scanty, so much so that the term 'analysis' may not be apt. We have no reason to disbelieve him when he says his statements regarding abortion is not an argument but the mere fact that he says so does not make it so. Whatever one makes of Rawls' denial of argumentation, it is undeniably that his assertion regarding the right to an abortion is a brief 'reasoned opinion'. Rawls proffers this 'reasoned opinion' to illustrate a reasonable balance of political values and by that mere fact it is undeniably that he understands the "reasoned opinion" he gives to be in keeping with the demands of his thesis on public reason. ${ }^{2}$ Therefore whether it be 'argument' or 'reasoned opinion' his formulation leaves open for questioning why it is that 'political value' of the equality of women is overriding during the stage of the first trimester of a pregnancy. The question looms larger when one recalls that Rawls himself admits that there are other important political values besides the three that he considers in order to arrive at his reasonable balance of constitutional values. ${ }^{3}$ One wonders why notwithstanding his acknowledgment that there are other important political values he chose to consider only three and in particular the three he chose. One wonders what would have been the result had Rawls factored the other undeniably important political values into the mix. There is no reason to suppose that his conclusion would have been the same. Unless he considers that the equality of women is bound to be the preponderant consideration irrespective of the other important political values and therefore a right to abortion during the first trimester is a foregone conclusion. Now if this is the case then it would follow that for Rawls the equality of women is a value

\footnotetext{
${ }^{1}$ See John Rawls, Political Liberalism (New York: Columbia University Press, 2005) at page liii-liv (footnote 31).

${ }^{2}$ Ibid, at page 243-244(footnote 32).

${ }^{3}$ Ibid.
} 
which holds pre-eminence or priority in relation to all other important values including the possible claim for the equality of the fetus. No, this could not be it as the belief in the pre-eminence of equality no matter what competing value or no matter what other competing claim for equality would have to be founded on a decision in respect of the 'truth claim' of the position that human life begins at conception. This would implicate Rawls in skepticism towards a particular comprehensive doctrine and he would be caught in contravention of his own prescription. We ought to expect otherwise from Rawls for he is the expositor of public reason, so we ought to prefer the conclusion that this is not his belief. Yet the question hauntingly lingers: Why is it that the 'political value' of the equality of women is overriding at this particular stage? Could it be that the very formulation and conclusion of Rawls' brief 'reasoned opinion' with respect to the abortion issue betrays the fact that public deliberation concerning constitutional essentials is inevitably value-laden and dependent on moral presuppositions? I submit that this is a conclusion made plausible by Rawls' 'reasoned opinion' regarding abortion and that the force of this conclusion is buttressed in light of Greenawalt's criticism which I shall now discuss.

Kent Greenawalt's critique concerning the difficulty faced by Rawlsian public reason as it relates to Interpreting Constitutional Essentials

Greenawalt uses the polemical issue of abortion to respond to Rawls' express treatment of the issue of abortion and to powerfully illustrate the inevitable difficulty that Rawlsian public reason faces as it pertains to interpreting constitutional essentials without reliance on comprehensive doctrine. Greenawalt proffers the hypothetical example of 'Joan'. ${ }^{1}$ According to Greenawalt Joan espouses the comprehensive view that a fetus deserves as much moral consideration as a newborn baby. ${ }^{2}$ Greenawalt's "Joan" opines that political values cannot tell us how much a fetus should be valued as political values are either radically incomplete on this question or suggest that a fetus is likely to be of less value than a newborn baby. ${ }^{3}$ Greenawalt states that on Joan's understanding, either a woman should not have a legal right to

\footnotetext{
${ }_{1}^{1}$ See Kent Greenawalt, Private Consciences and Public Reasons (New York: Oxford University Press, 1995) at page 116-117.

${ }^{2}$ Ibid.

${ }^{3}$ Kent Greenawalt, Private Consciences and Public Reasons (New York: Oxford University Press, 1995) at page 116.
} 
abortion or the appropriateness of such a right is highly debatable, and a broad right to abortion should not be considered required by constitutional essentials. ${ }^{1}$ Greenawalt argues that the example of Joan illustrates how comprehensive views can influence a person's sense of how fundamental values apply in particular circumstances. ${ }^{2}$ He posits that in Joan's view, the fundamental value of protecting "innocent human beings" against "willful killing" colours how equality for women ought to be regarded or is a value that competes with full equality. ${ }^{3}$ Greenawalt argues that the example of Joan shows how often a person's comprehensive view can lead her to a different understanding of the full content of a constitutional essential than she would reach if she stuck to 'political' values alone. ${ }^{4}$

Following from Greenawalt's illustration it is difficult to see how one may avoid relying on some comprehensive moral view or other in coming to a determination of whether this or that fundamental value applies in a given case or how this or that fundamental value applies in particular circumstances. As aforementioned Rawls argues that his thesis on public reason applies to the constitutional essentials and questions of basic justice because if we should not honour the limits of public reason as it relates to fundamental matters, it would seem that we need not honour it anywhere. Upon examining the polemical issue of abortion in light of the discussion provided by both Rawls and Greenawalt it is inferable that as it relates to the polemical issue of abortion public reason divorced of any presupposition of value offers no help in relation to a resolution as to the determination of the application of constitutional essentials. Determining whether and how constitutional essentials apply to concrete cases inevitably depends on some presupposition of value. Therefore Rawls' proposal that citizens exercise epistemic restraint in relation to interpreting constitutional essentials based on the standard of the 'political' is highly objectionable. Even limited to cases of constitutional essentials public reason does not seem to do anything in and of itself. The balancing exercise described by Rawls seems to require a presupposition of value to act as engine so the machine of 'Rawlsian public reason' can sputter into action. It is hard to link

\footnotetext{
${ }^{1}$ Kent Greenawalt, Private Consciences and Public Reasons (New York: Oxford University Press, 1995) at page 116.

${ }^{2}$ Ibid, at page 117.

${ }^{3}$ Ibid.

${ }^{4}$ Ibid.
} 
this presupposition of value to anything but a comprehensive doctrine; certainly there is no independently derivable, freestanding political 'super value', political meta-rule or political algorithm that enables us to determine a reasonable balance of political values. Therefore the operative question for us may not be: Need we honour public reason? It much more likely is: Can we honour public reason? I think not, taking into consideration the Rawlsian illustration of public reason vis a vis the vexing issue of abortion in the first trimester and how presuppositions of value seem to have inevitably 'crept out of the woodwork'. I will elaborate further on this point when I come to discuss public reason's proposal to bracket moral and religious comprehensive doctrines from public discourse.

The difficulty of determining the lines of distinction between constitutional essentials and 'ordinary' political issues

As it relates to comprehensive moral and religious doctrines, Rawls asserts that citizens and legislators may properly vote their comprehensive views when constitutional essentials and basic justice are not at stake. ${ }^{1}$ Thus Rawlsian public reason contemplates that citizens and legislators will adhere to epistemic restraints in relation to reason giving and voting when it comes to constitutional essentials and matters of basic justice but that there are no such restraints in relation to ordinary political questions. At one level one may say that the restrictions Rawlsian public reason calls for cannot be so onerous after all because after all they do not apply to ordinary political questions. This would be a facile supposition. Certainly a lot of the hotly contested public polemics of the day in any constitutional democracy are political questions that are generally considered to be constitutional essentials and matters of basic justice. These questions aside, given enough thought it becomes clear that a lot turns upon the distinction between what political questions are constitutional essentials/matters of basic justice and those political questions that are of the specie of 'ordinary political questions'. Certainly based on the Rawlsian schema whether you or I can vote our comprehensive doctrines turns upon this distinction. It is undeniable there is no bright line distinction between so called 'constitutional essentials' and 'ordinary political questions'. It is also

${ }^{1}$ John Rawls, Political Liberalism (New York: Columbia University Press, 2005) at 235. 
undeniable that constitutional essentials will have ramifications as it relates to 'ordinary political questions' and that ordinary political questions will in turn have implications for constitutional essentials. One therefore may question the usefulness of such a distinction in public reason's application to the two classes of political questions. As Greenawalt asserts having essentially created these two distinct categories of political questions it would be odd for public reason to say that one can freely use comprehensive doctrine when constitutional essentials are not directly involved but that one cannot use comprehensive doctrines when constitutional essentials are directly at stake. ${ }^{1}$ Greenawalt states that it would also be odd for public reason to say that comprehensive doctrines can be used for ordinary political questions except for those that draw from constitutional essentials. ${ }^{2}$ The fact that these difficulties follow from the distinction between the two categories highlights the fact that the application of Rawlsian public reason is problematic. Far from 'transcending' the hotly contested fray in which irreconcilable comprehensive doctrines jostle together it is foreseeable that the pursuit of public reason in public deliberation may likely in and of itself instigate conflict. This mere suggestion brings out an unmistakable irony in relation to Rawlsian public reason. In that the very raison d'etre of Rawlsian public reason is to overcome the difficulties engendered by the inevitability of intractable differences on account of irreconcilable doctrines yet aspects of Rawlsian public reason itself will likely generate serious difficulties that in turn require resolution. This is because of the likely conflicting views in relation to whether this or that issue is aptly deemed to involve 'constitutional essentials' or merely 'ordinary politics' and therefore whether or not public reason applies or not. Thus it may quite likely present a situation similar to what obtains in federal states like Canada where it is sometimes difficult to determine which head of power (federal/provincial) a statute falls under. The determination as to whether a particular political question falls into either category may be so difficult yet weighty (in light of the implications for public reason's application) that a metarule may have to be developed and employed to address such problems. Such a metarule would be akin to that of the 'pith and substance' doctrine in

\footnotetext{
${ }^{1}$ See Kent Greenawalt, Private Consciences and Public Reasons (New York: Oxford University Press, 1995) at page 119. ${ }^{2}$ Ibid.
} 
Canadian constitutional law, used to determine under which head of power (federal/constitutional) a piece of legislation falls. ${ }^{1}$

\section{Part 1(e): The Proposal to Bracket Comprehensive Moral and Religious Comprehensive Doctrine}

\section{from Public Deliberation}

Rawls thesis on public reason "...Proposes that in public reason comprehensive doctrines of truth or right be replaced by an idea of the politically reasonable addressed to citizens as citizens. "2 It is noteworthy that Rawls uses the word 'replaced'. It is inferable that rather than a mere reconciliation of competing comprehensive doctrines public reason contemplates that the 'politically reasonable' will 'take the place of ${ }^{33}$ or "provide a substitute for ${ }^{, 4}$ comprehensive doctrines of truth or right. One may ask whether Rawls' proposal that comprehensive doctrines be 'replaced' is to be taken in its denotative sense. Rawls' rendition of public reason plainly justifies this, in another place he posits:

...In discussing constitutional essentials and matters of basic justice we are not to appeal to comprehensive religious and philosophical doctrines-to what we as individuals or members of associations see as the whole truth-nor to elaborate economic theories of general equilibrium, say, if these are in dispute. ${ }^{5}$

This quotation leaves no room for doubt as to the fact that Rawlsian public reason conceives of comprehensive doctrines being replaced in the context of discussions of constitutional essentials and matters of basic justice. Later in his restatement of his conception of public reason Rawls reiterates his proposal for the replacement of comprehensive doctrines with an idea of the politically reasonable and elucidates that: "This step is necessary to establish a basis of political reasoning that all can share as free and equal citizens". 6

\footnotetext{
${ }^{1}$ See discussion of pith and substance in: "Special Article: Pith and Substance" online: University of Ottowa Constitutional Law Canada http: <www.uottawa.ca/constitutional-law/pith.html>

${ }^{2}$ John Rawls, Political Liberalism (New York: Columbia University Press, 2005), at 441.

${ }^{3}$ This is the first meaning for 'replace' provided by Oxford Dictionaries online. See Oxford University Press, online: Oxford Dictionaries < http://oxforddictionaries.com/definition/replace>

${ }^{4}$ This is the second meaning for 'replace' provided, ut supra.

${ }^{5}$ Ibid, at page 224-225.

${ }^{6}$ John Rawls, Political Liberalism (New York: Columbia University Press, 2005) at 481.
} 
So then according to Rawlsian public reason we are epistemically barred from invoking our comprehensive doctrines in discussing matters of constitutional essentials and basic justice. To what do we then appeal in our arguments for this or that public policy or legislation? What values are to inform our deliberation concerning the public good? Rawls response is political values everyone can reasonably be expected to endorse and which can provide a public basis of justification. ${ }^{1}$ So we ask: What are these political values that everyone can reasonably be expected to endorse? What is this public basis of justification? I will briefly examine Rawls' response to these questions.

The political values that everyone can reasonably be expected to endorse

Despite the fact that the concept of "political values" is used over 70 times throughout the text, Political Liberalism, which contains Rawl's restatement of his theory on public reason, no definition or definitive explanation of the notion of "political values" is provided. ${ }^{2}$ Is it that the concept of "political values' is self-evident? It cannot be. Rawls must be taken to agree to this otherwise there would be no need for his theoretical enterprise. This is because he starts out by acknowledging that a plurality of reasonable but incompatible comprehensive doctrines is the reality in liberal plural democratic polities. The 'problem' that Rawls' theory tackles is rooted in the reality of various comprehensive doctrines engendering incompatible visions as it relates to the matter of politics-they each offer up values targeted to the political order(its institutions and the regulation thereof), and they each offer conflicting and irreconcilable responses to the vexing political questions of the day. Thus the values offered by each comprehensive doctrine have a justifiable claim to the appellation "political values". So we take it that the meaning of "political values" cannot be self evident and that Rawls must be taken to use this concept in a certain sense and with a certain significance to his theoretical schema. He does provide us with examples of "political values". Recall with me that in his brief "reasoned opinion" regarding the abortion polemic he refers to "the due respect for human life", "the ordered reproduction of political life over time" and "the

\footnotetext{
${ }^{1}$ See John Rawls, Political Liberalism (New York: Columbia University Press, 2005) at page 229, 241, and 479.

2 Thanks to the online resource "Google Books"(books.google.ca) I was able to look at an online copy of Rawls' Political Liberalism and enter the search term "political values" and painstakingly survey whether a definition or clear statement of the meaning of the notion is provided. None was found and to the best of my knowledge and belief none is to be found.
} 
equality of women as equal citizens" as political values. This leaves us to inquire whether "political values" are values like unto those enumerated in his example. Determining the meaning of 'political values" via thinking of 'values like unto those enumerated in Rawls' example' is pointless because determining what values are 'values like unto those enumerated in Rawls' example' is a quest in itself that inevitably depends on moral presuppositions of value. We are stymied. We may then ask: Are Rawls' political values "constitutional values"? Constitutional values, as discussed before, are but the fundamental principles or abstractions of value for a particular polity. They invariably cry out for their substance, meaning and concrete application to be filled in by the varying comprehensive doctrines/moral conceptions within a polity. The scholar, Bradley Miller, tells us, "What one judges to be the principles of a free and democratic society will be largely influenced by what one judges to be sound moral and political philosophy". ${ }^{1}$ Another scholar, Ran Hirschl, citing no less an eminent philosopher and jurist than Ronald Dworkin, submits that although one may conscientiously seek to decide matters based on objective principles by relying on constitutional values it is difficult to see how this could be done without bringing personal values to bear on the process. ${ }^{2}$ Certainly declaring this or that as 'constitutional value' invariably leads us on another quest to 'fill in the blanks' in terms of the meaning to be given to this value in concrete cases. So for Rawls to have meant 'constitutional values' when he spoke of 'political values' would be tantamount to answering a riddle with another riddle, he cannot be taken to have meant 'constitutional values', at least as ordinarily understood. We are back to square one.

Is it that "political values" is a concept fraught with indeterminacy? It cannot be because we do know that each of the comprehensive doctrines in society provide offerings based on its version of the 'political' so to that extent "political values' may conceivably be determined based on the weltanschauung of the various comprehensive doctrines. So we then ask: is it that the concept of "political values" is a concept

\footnotetext{
${ }^{1}$ See Bradley Miller, Appeals to Constitutional Principles in Adjudication (Chapter Five of D. Phil. Thesis, University of Oxford, 2003) [unpublished] at 234 [footnotes omitted]. The quotation is also cited in Derek. B. Mix-Ross, Exploring the Charter's Horizons: Universities, Free Speech, and the Role of Constitutional Rights in Private Legal Relations (LLM Thesis, University of Toronto, 2009) [unpublished] at 40.

${ }^{2}$ Ran Hirschl, Constitutional Theocracy (Cambridge, Mass: Harvard University Press, 2010) at 85-86. Hirschl cites Ronald Dworkin's Taking Rights Seriously for this proposition.
} 
fraught with epistemological/ethical dependence? I submit that it must be so. It is inconceivable to think of "political values" but from an ethical perspective. Therefore at this point the conclusion stares us in the face- a concept such as "political value(s)" is akin to a hollow gourd open to the filling provided by one's ethical conceptualization of the 'political' and what is appropriate for the 'political'. Yet we know that Rawls must mean "political values" in a different sense from this ordinary sense. We know that by "political values" he means values discrete and isolable from say "Kantian political values", "Marxist political values" or "Christian political values". This we know because he prescribes that "political values" replace comprehensive doctrines in public deliberation about constitutional essentials and matters of basic justice. So we may say that he means "Political political values". Still we are stymied-we still do not have a handle on what these political values are. We do know that the "political values" Rawls has in mind must flow from a "political conception of justice" as this he tells us is the aim of his entire enterprise. ${ }^{1}$ So in order to get a handle on what he has in mind when he says "political values" we need to know what he means when he says "political conception of justice" so we examine his exposition of his "political conception of justice". Rawls asserts that a political conception of justice is a moral conception and he explains that in saying it is a 'moral conception' he means that its content is given by certain ideals, principles and standards and that these norms articulate certain values which are political values. ${ }^{2}$ We are again stymied; Rawls tells us that the content of his political conception which is a moral conception is given by certain ideals, principles and standards. What are these 'certain ideals, principles and standards? From whence do they come? Are they not the presuppositional underpinning for this political or moral conception of justice? How can this presuppositional underpinning for his political conception of justice arise outside of some ethical conception? How can an ethical conception be formed outside of some comprehensive doctrine of the good? Yet Rawls declares that this political conception of justice is freestanding. ${ }^{3}$ As to the link between this political conception and comprehensive doctrines

\footnotetext{
${ }^{1}$ See John Rawls, Political Liberalism (New York: Columbia University Press, 2005) at page xviii, 38, and 214.

${ }^{2}$ See John Rawls, Political Liberalism (New York: Columbia University Press, 2005) at page 11 and footnote 11 of page 11.

${ }^{3}$ See John Rawls, Political Liberalism (New York: Columbia University Press, 2005) at page 12.
} 
Rawls intimates that the 'political conception of justice' “...Fits into and can be supported by various reasonable comprehensive doctrines that endure in the society regulated by it". ${ }^{1}$ This is a dubious proposition. If it is that the various comprehensive doctrines merely 'can' support the political conception of justice what supports it? Certainly it cannot be 'freestanding' if it is 'given by certain ideals, principles and standards'. Or is it that these particular ideals, principles and standards 'give' but do not 'support'? Isn't this mere semantics? It is difficult to see how Rawls' political conception of justice can be 'freestanding' though given by 'certain ideals, principles and standards'. The source of these 'ideals, principles and standards' though not articulated by Rawls are not unknowable. They arise from some comprehensive doctrine/ethical construct that offers them up as the desirable ideals and principles to inform Rawls' desired 'political conception' of justice. In effect Rawls proposes to replace comprehensive doctrinal arguments with so called 'political values' that are inevitably and inherently comprehensive doctrine laden. Therefore his proposal is arbitrary to say the least. One may justifiably style it "epistemic hypocrisy". His proposal amounts to replacing comprehensive doctrines with another construct inextricably bound up with and undergirded by some comprehensive doctrine or doctrines and is akin to the proverbial "robbing Peter to pay Paul". Certainly the justification for such a proposal must be external to it for as I have argued (citing several eminent scholars) at several places in this paper it does not follow that Rawls' political conception of justice is autonomous, and epistemically abstinent.

What is the public basis of justification to be provided?

Rawls asserts:

Since we seek an agreed basis of public justification in matters of justice, and since no political agreement on those disputed questions can reasonably be expected, we turn instead to the fundamental ideas we seem to share through the public political culture. ${ }^{2}$

This elicits the question: what are these fundamental values we seem to share through the public political culture? Rawls asserts that these fundamental values are "...fundamental intuitive ideas implicit in the

\footnotetext{
${ }^{1}$ Ibid.

${ }^{2}$ See John Rawls, Political Liberalism (New York: Columbia University Press, 2005) at page 150.
} 
public political culture and abstracting from comprehensive religious, philosophical, and moral doctrines". ${ }^{1}$ He mentions three fundamental intuitive ideas: that of society as a fair system of cooperation over time, the idea of citizens as free and equal and that of a well-ordered society effectively regulated by a political conception of justice. ${ }^{2}$ He asserts that these ideas are central to the democratic ideal. $^{3}$ One may ask the question: is the presence of these fundamental intuitive ideas in the public political culture of constitutional democracies like Canada unobjectionable? Rawls seem to think this is an empirical fact. The scholar, Shaun Young suggests that Rawls grounds the viability of his thesis on public reason on the presumed presence and support for these fundamental intuitive ideas. ${ }^{4}$ According to Young if Rawls' presumption can be shown to be exaggerated or unfounded, then the basis for a purely political conception of justice and thus the very fundament of Rawl's entire thesis is compromised. ${ }^{5}$ Young submits:

....the proposed incongruency between Rawls's claim concerning the presence of and support for the fundamental intuitive ideas, and the empirical reality of existing modern constitutional democracies, significantly undermines (to say the least) the theoretical viability of his theory. ${ }^{6}$

Young's submission is cogent. The truth or facticity of these fundamental intuitive ideas in liberal constitutional democracies remains unverified. There is no reason to believe that the existence of these intuitive fundamental ideas is factual or must be factual. Nonetheless Rawlsian public reason pivots on the facticity of these ideas. The fact that this is so evidences that his thesis is somewhat founded on a 'leap of faith'. Indeed faith in one famous formulation is the 'substance of things hoped for, the evidence of things not seen ${ }^{, 7}$ and Rawls' fundamental intuitive ideas are for now ideas hoped for, the proof of which remains to be seen. This is one more reason why Rawlsian public reason is not dissimilar to

\footnotetext{
${ }^{1}$ Ibid, at 192.

${ }^{2}$ Ibid, at 14. Also referred to in Samuel Freeman, Rawls (London: Routledge, 2007) at page 332.

${ }^{3}$ John Rawls, Political Liberalism (New York: Columbia University Press, 2005) at page 167.

${ }^{4}$ See Shaun P. Young, "Political Stability And The Need For Moral Affirmation" online: (2005) 4 Minerva Internet Journal of Philosophy 7 <http://www.ul.ie/ philos/vol4/rawls.html>

${ }^{5}$ Ibid.

${ }^{6}$ Ibid.

${ }^{7}$ This is the formulation in the Christian Bible. Hebrews 11:1.
} 
comprehensive moral/religious beliefs. Ultimately both Rawlsian public reason and comprehensive doctrinal conceptions rely on 'faith' in some shape or form.

The sustainability of bracketing comprehensive moral/religious doctrines from public discourse

Michael Sandel asserts that, “... it is not always reasonable to bracket, or set aside for political purposes, claims arising from within comprehensive moral and religious doctrines". ${ }^{1}$ Sandel suggests that with respect to many of the polemical moral issues of our times the reasonableness of bracketing moral and religious controversies for the sake of political agreement depend on which of the competing moral or religious doctrines is true. ${ }^{2}$ Sandel tellingly uses the contemporary polemical issue of abortion and the historical debate between Abraham Lincoln and Stephen Douglas regarding the abolition of slavery to make his point. ${ }^{3}$ A point which has much force and which starkly indicates the significant limitations of Rawlsian public reason. Concerning the issue of abortion Sandel argues that the case for abortion cannot be neutral in relation to moral and religious controversy. ${ }^{4}$ He asserts that this is because if the Catholic Church doctrine that human life in the moral sense begins at conception is true, than bracketing the moral theological question of when human life begins is far less reasonable than it would be on a rival moral or religious doctrine. ${ }^{5}$ Any way you take it a decision concerning the polemical issue of abortion either will effectually decide that the Catholic doctrine is untrue or irrelevant (it is difficult to see why this would be so) or that the value of protecting fetal life is less than that of the secular values of women's equality and toleration. ${ }^{6}$ Sandel submits that if the Catholic doctrine is true then abortion is morally tantamount to murder and the liberal's case for the priority of 'political' values must become an instance of just-war theory, the Rawlsian liberal proponent would have to show why political values should prevail even at the

\footnotetext{
${ }^{1}$ Michael J. Sandel, Liberalism and the Limits of Justice 2d ed. (Cambridge, Cambridgeshire: Cambridge University Press, 1998) at 196.

${ }^{2}$ Ibid.

${ }^{3}$ Ibid, at page 197.

${ }^{4}$ Ibid, at 198.

${ }^{5}$ Ibid.

${ }^{6}$ Michael J. Sandel, Liberalism and the Limits of Justice 2d ed. (Cambridge, Cambridgeshire: Cambridge University Press, 1998) at page 198.
} 
cost of some million civilian deaths(in the USA) each year. ${ }^{1}$ The force of Sandel's point is inescapable, Rawlsian public reason's claim to replace comprehensive doctrines with freestanding political values and to avoidance of scepticism in respect of comprehensive moral or religious doctrines is shown to be untenable in light of its treatment of the abortion question. ${ }^{2}$

Sandel's second example is that of the historical debate between Abraham Lincoln and Stephen Douglas concerning the then polemical issue of slavery. ${ }^{3}$ He tells us that Stephen Douglas' argument was for a national policy of neutrality in relation to the morality of slavery for the sake of political agreement and concomitantly the protection of the union of the United States of America. ${ }^{4}$ The similarity between Stephen Douglas' form of argumentation and the Rawlsian proposal to bracket controversial moral questions for the sake of political agreement is undeniable. Sandel states that Abraham Lincoln on the other hand argued that the national policy should express rather than avoid a substantive moral agreement about slavery. ${ }^{5}$ According to Sandel Abraham Lincoln framed the key issue implicated in the debate as the 'morality of slavery' and argued that the proposal that it was reasonable to bracket the question of the morality of slavery inevitably rested on some assumption regarding the morality of slavery. ${ }^{6}$ Certainly Douglas' proposed resolution at least had to turn on an estimation that the value of the equality or human dignity of the slave was less than that of the value of national consensus, stability and the protection of the union. Lincoln tellingly rhetorized, "Is it not a false statesmanship that undertakes to build up a system of policy upon the basis of caring nothing about the very thing that everybody does care the most about? ", Lincoln's incisive rhetoric provokes through the corridors of time, I cannot see Rawlsian public reason replying to it. After all Rawlsian public reason prescribes that the citizens of a polity voluntarily restrain

\footnotetext{
${ }^{1}$ Ibid.

${ }^{2}$ On Rawls' claim to avoid scepticism in relation to comprehensive doctrines see Political Liberalism (New York: Columbia University Press, 2005) at pages 62, 150 and 151.

${ }^{3}$ Michael J. Sandel, Liberalism and the Limits of Justice 2d ed. (Cambridge, Cambridgeshire: Cambridge University Press, 1998) at page 199-202.

${ }^{4}$ Ibid at page 199 .

${ }^{5}$ Ibid.

${ }^{6}$ Ibid.

${ }^{7}$ This passage is quoted in Michael J. Sandel, Liberalism and the Limits of Justice 2d ed. (Cambridge, Cambridgeshire: Cambridge University Press, 1998) at 200-201 and was taken from Abraham Lincoln, Stephen Douglas and Paul M. Angle, Created Equal? The Complete Lincoln-Douglas Debates of 1858 at 388-389.
} 
themselves from reasoning and arguing about the things they care about for the reasons they care about them because such reasons are not 'political' as defined by its 'political conception of justice'. If it is said in response that the moral indefensibility of slavery is a settled issue of the ilk of a 'fundamental political value' in liberal constitutional democracy and it therefore is a non-issue, that doesn't answer the question. Hindsight is 20/20 vision, so the adage reminds us. As Sandel suggests, the institution of slavery was arguably supported by the notions of equal citizenship implicit in American political culture of the midnineteenth century. ${ }^{1}$ Therefore Douglas' overtly 'political argument' for abstention from deciding the morality of the issue in the interest of societal stability and protection of the union would appear to satisfy the prescriptions of public reason. ${ }^{2}$ After all Rawlsian public reason seems to take its cue from the notions of citizenship implicit in the political culture. ${ }^{3}$ Further it is likely that Lincoln would have been barred from his invocation of principles of morality as such would violate public reason's requirement that the debate about constitutional essentials proceed on the basis of 'political values'. ${ }^{4}$ Worse, let us try to imagine the debate between Abraham Lincoln and Douglas in light of public reason's prescription to bracket moral and religious argument from public discourse. This thought should make anyone cringe. In the interest of dissociating Rawlsian public reason from even the idea of it serving to support the dreaded institution of slavery the proponent of Rawlsian public reason may wish to challenge this idea. $\mathrm{He} / \mathrm{she}$ may quite likely remind us that public reason is a 'political conception of justice' which “...belongs to a more or less just constitutional democracy, where the criterion of justice is that political conception itself." ${ }^{5}$ A ready response may be provided in light of insights provided by Joseph Raz. Raz notes that public reason is said to reflect the consensus of our societies forged between the various opposing doctrines likely to thrive in these societies over generations. ${ }^{6}$ He states that a society may avow

\footnotetext{
${ }^{1}$ Michael J. Sandel, Liberalism and the Limits of Justice 2d ed. (Cambridge, Cambridgeshire: Cambridge University Press, 1998) at page 202 .

${ }^{2}$ Ibid.

${ }^{3}$ Ibid.

${ }^{4}$ Ibid.

${ }^{5}$ John Rawls, "The Idea of An Overlapping Consensus" (1987) 7 Oxford J. Legal Stud. 1 at page 1. (JSTOR)

${ }^{6}$ Joseph Raz, "Facing Diversity: The Case of Epistemic Abstinence" (1990) 19:1 Philosophy \& Public Affairs page 3-46 (JSTOR), at page 12 .
} 
principles which it does not live up to but that does not prevent such a society from pursuing a consensus as the consensus sought is between the competing comprehensive moral and religious doctrines. ${ }^{1}$ Raz submits that the fact that the practice of the society does not conform to the principles it avows will not be reflected in the consensus that emerges and does nothing to discredit that consensus. ${ }^{2}$ He therefore concludes that “...the condition of 'near justice' imposed by Rawls is vacuous and does little to qualify the unqualified pursuit of consensus at any price." ${ }^{3}$ Raz further asserts that Rawlsian public reason's reliance on the fundamental intuitive ideas of our more or less just societies evidences the complacency inherent in his theory. ${ }^{4}$ Raz asserts that a moral or political theory like Rawls' ought to at least be open to the possibility that the societies to which it applies are fundamentally defective. ${ }^{5}$ I fully agree with Joseph Raz. The fact that Rawls relies on the idea that our societies are 'more or less just', in order to support his claim that the principles of justice are derivable from its fundamental intuitive ideas, evidences another reason why it is seriously objectionable. One wonders what societies Rawls refers to as 'more or less just'. It certainly could not be societies like the US and Canada, where large swathes of its citizenry have borne and still endure the ugliness of injustices like racism, sexism, classism, ethnic prejudices and where democracy deficits persist. One can scarcely deny this. The fact that Canadian society for example, by and large espouses lofty ideals of equality and human dignity for all does not make it just, indeed the fact that the reality so often falls below the ideal may be said to make the existing injustices particularly upsetting. Further one would scarcely deny that the American society of Lincoln's day was far advanced in liberal democratic values compared to other Western countries, and was viewed by some enlightened minds as more or less a just society by the standards of the day. ${ }^{6}$ Yet one would not deny that the heinous

\footnotetext{
${ }^{1}$ Joseph Raz, "Facing Diversity: The Case of Epistemic Abstinence” (1990) 19:1 Philosophy \& Public Affairs page 3-46 (JSTOR), at page 12.

${ }^{2}$ Ibid.

${ }^{3}$ Ibid.

${ }^{4}$ Ibid, at page 19 .

${ }^{5}$ Ibid.

${ }^{6}$ Tocqueville referred to Americans as the 'freest and enlightened men' in his famous book, Democracy in America. See Alexis de Tocqueville, Democracy in America edited by Harvey C. Mansfield and Delba Winthrop (Chicago: University of Chicago Press, 2000) at page 511-512.
} 
system of slavery, a reality starkly antithetical to notions of equality and human dignity, was allowed to thrive. Raz's argument comports with the suggestion that the arguments proffered by Stephen Douglas in the debate with Lincoln, resting exclusively on the value of maintaining consensus, societal stability and the protection of the Union, seems to fit snugly within the mould of Rawlsian public reason. As Raz's argument shows, Rawlsian public reason's claim to be a moral conception reflective of the intuitive fundamental values of our more or less just societies, and thereby not merely geared toward consensus at any price, is highly objectionable to say the least.

It is undeniable that the polemical issues of our time cry out for resolution-they are real world problems and how these problems are resolved inevitably has real world consequences. Real people have real and passionate feelings and opinions regarding these issues and they have no other way to see these issues than how they see them-in the light of their real ethical convictions, opinions and emotions. Sandel delivers the insight that the human self is never strictly prior to its ends and is therefore inevitably an encumbered self, thus real people in reasoning about the public good and the policy implications in keeping with that, cannot but rely on their moral presuppositions. To ask of them that they refrain from doing so is to effectually ask them to refrain from conceiving the issues. How they conceive these issues is inevitably coloured by their world view. As William Galston suggests, even if it is that after political institutions have functioned for some time, their legitimacy may come to be taken for granted, and their constitutive values may come to be seen as freestanding, this idea is usually quickly dispelled in times of internal or external crisis. ${ }^{1}$ Galston tells us that slavery drove President Lincoln to rely on philosophical arguments for human equality and the US Civil War drove him to invoke theological reflections on divine judgment. ${ }^{2}$ Galston argues that the antidemocratic threats of the mid $20^{\text {th }}$ century propelled Western Democracies toward moral universalism which was manifest in the Nuremberg trials at the end of World

\footnotetext{
${ }^{1}$ William A. Galston, Liberal Pluralism: The Implications of Value Pluralism for Political Theory and Practice (Cambridge, UK: Cambridge University Press, 2002) at page 41.

${ }^{2}$ William A. Galston, Liberal Pluralism: The Implications of Value Pluralism for Political Theory and Practice (Cambridge, UK: Cambridge University Press, 2002) at page 41.
} 
War II and the Universal Declaration of Human Rights in $1948 .{ }^{1}$ Galston submits further that even if we take certain constitutional values as agreed, the interpretation of such general questions as the "public good" will inevitably elicit competing moral understandings. ${ }^{2}$ He asserts that

Differences of moral doctrine will come into play when rights conflict, or when rights-based claims collide with the requirements of consequentialism. ${ }^{3}$

Galston's point is certainly evidenced by the abortion polemic as discussed in several places in this paper. In light of these points we may ask: in what world is the Rawlsian proposal to bracket comprehensive moral and religious arguments practicable? It is exceedingly difficult to conceive it being applicable to our world at least as we know it.

Even if we were to grant the idea that Rawlsian public reason is attainable, were it to be achieved, the prospect seems far from desirable. As Sandel convincingly suggests, in a world where the norms of public deliberation reflect Rawlsian public reason it is very likely that in relation to the abortion polemic, those who believe that the fetus is a person from conception, and that abortion is murder could not seek to persuade their fellow citizens of their view in public debate. ${ }^{4}$ Sandel asserts that those who would seek to challenge the Catholic teaching on abortion would be barred from making their points, as the normative proscription against moral doctrine in the political arena would also enjoin their rebuttal of the position. ${ }^{5}$ Also those who oppose homosexuality as immoral could not legitimately voice their views in public debate; neither would those advocates of gay rights who contest the substantive moral judgments behind opposition to gay rights be able to persuade their fellow citizens that homosexuality is morally permissible. ${ }^{6}$ In such a world it would be quite justifiable to suggest that a 'moral freeze' would obtain in relation to public deliberation. Those whose views on the aforementioned issues are informed by moral positions in order to participate in debate about such issues would have to find a way to couch their

\footnotetext{
${ }^{1}$ Ibid.

${ }^{2}$ Ibid.

${ }^{3}$ Ibid.

${ }^{4}$ Michael J. Sandel, Liberalism and the Limits of Justice 2d ed. (Cambridge, Cambridgeshire: Cambridge University Press, 1998) at page 212 .

${ }^{5}$ Ibid.

${ }^{6}$ Ibid.
} 
arguments in 'political values'. As previously argued, the concept of 'political values' is arguably epistemologically/morally dependent, it leaves room for interpretation of the substance of these values and their application in concrete cases. Therefore the enterprise to couch arguments in relation to the interpretation of 'political values' according to the idiom of 'political values' would be foreseeably difficult. It is a different matter entirely in terms of mind boggling potential if one were to suggest the question-who gets to be the arbiter of whether a particular argument regarding the interpretation of a political value is in keeping with the idiom of political values or not? Those citizens who demonstrate aptitude in relation to 'political translation' may likely become prized and sought after to work their 'magic' in relation to voicing the concerns of particular interest groups in the official 'political' mode of reasoning and deliberating that would obtain. Worse yet, it is likely that many voices will effectually be muzzled for want of ability to express themselves in terms of proper 'political values'. Still worse, the fundamentalist 'loudmouths' who are never deterred from ensuring that their views are heard, may come to be the lone religious and/or moral voices 'crying in the wilderness'.

Sandel's criticism in relation to the asymmetry between the right and the good implicit in public reason Sandel begins his criticism by noting Rawls' submission that the 'fact of reasonable pluralism' demands the establishment of principles of justice acceptable to all. ${ }^{1}$ Sandel also notes Rawls' position that the formation of these desired principles of justice is a problem of political justice, not a problem concerning the highest good. ${ }^{2}$ Sandel asserts that Rawls proceeds from the idea of 'the fact of reasonable pluralism' to assume that the principles of justice must uphold the right in priority to the good because otherwise the principles of justice will favour particular conceptions of the good rather than others. ${ }^{3}$ Sandel suggests that based on Rawls' conception, if the priority of the right is not upheld there would be no basis for social co-operation among citizens of a plural constitutional democratic polity due to their incompatible

\footnotetext{
${ }^{1}$ See Michael J. Sandel, Liberalism and the Limits of Justice 2d ed. (Cambridge, Cambridgeshire: Cambridge University Press, 1998) at page 203.

2 Ibid. Sandel cites Rawls' Political Liberalism at page xxv.

${ }^{3}$ See Michael J. Sandel, Liberalism and the Limits of Justice 2d ed. (Cambridge, Cambridgeshire: Cambridge University Press, 1998) at page 203.
} 
but reasonable moral and religious convictions. ${ }^{1}$ Sandel submits that even if 'the fact of reasonable pluralism' is true this 'fact' is not sufficient to establish the priority of the right as one has to further assume that despite our reasonable disagreements about morality and religion, we do not have similar disagreements about justice. ${ }^{2}$ He suggests that this further assumption on which Rawlsian public reason depends is objectionable in light of the fact that the evidence suggests that modern democratic societies are teeming with disagreements about justice. ${ }^{3}$ Sandel cites such examples as the debate concerning affirmative action, income distribution and tax fairness, immigration, free speech versus hate speech, as but a few examples of the disagreements about justice in modern democracies. ${ }^{4}$ I opine that this is a solid point by Sandel. It is hard to conceive of one denying that this is so; disagreements about income distribution and tax fairness fundamentally implicate concerns about what distributive justice demands. Sandel states that the proponents of Rawlsian public reason may venture to assert that disagreements about justice often concern disagreements about the principles of justice while disagreements about morality invariably are more fundamental as they tend to reflect incompatible conceptions of the good life. ${ }^{5}$ Sandel has a ready response, he intimates that the debates about distributive justice which rages on between such approaches as the libertarian approach and the liberal egalitarians (Rawls falls into this category) is one about what the correct principle of distributive justice is and not its application. ${ }^{6}$ Sandel suggests that in relation to such questions as that concerning the correct principle of distributive justice, Rawls seems to think that there is no reasonable pluralism. ${ }^{7}$ He states that Rawls would maintain that the libertarian's objection to aspects of his particular theoretical conceptualization of distributive justice does not constitute a 'fact of reasonable plurality 'as there are good reasons to conclude that his arguments are

\footnotetext{
${ }^{1}$ See Michael J. Sandel, Liberalism and the Limits of Justice 2d ed. (Cambridge, Cambridgeshire: Cambridge University Press, 1998) at page 203.

${ }^{2}$ See Michael J. Sandel, Liberalism and the Limits of Justice 2d ed. (Cambridge, Cambridgeshire: Cambridge University Press, 1998) at page 203.

${ }^{3}$ Ibid, 204.

${ }^{4}$ Ibid.

${ }^{5}$ Ibid.

${ }^{6}$ Ibid, 204-205.

${ }^{7}$ Ibid, 205-206.
} 
more convincing. ${ }^{1}$ Sandel proceeds to argue that just as how Rawls concludes that upon due reflection there are better reasons to prefer his approach to distributive justice rather than the libertarian approach, there is no reason in principle why we cannot conclude that some moral/religious doctrines are more plausible than others. ${ }^{2}$ Sandel rhetorizes:

"If we can reason about controversial principles of distributive justice by seeking a reflective equilibrium, why can we not reason in the same way about conceptions of the good?"3

He quotes Rawls as asserting in relation to arguments about justice that:

“...In philosophy questions at the most fundamental level are not usually settled by conclusive argument. What is obvious to some persons and accepted as a basic idea is unintelligible to others. The way to resolve the matter is to consider after due reflection which view, when fully worked out, offers the most coherent and convincing account. ",4

Sandel therefore concludes his argument by asserting that the undeniable possibility of arguing about the good as well as the right and to come to conclusions in relation to such arguments based on a balance of plausibility undermines Rawlsian public reason's asymmetry between the good and the right. ${ }^{5}$ He asserts that Rawls assumption that our moral and religious disagreements reflect a 'fact of reasonable pluralism' while our disagreements about justice do not is unsupported and therefore arbitrary.

I find Sandel's arguments forcefully persuasive. It is inconceivable that one would deny that in the Western democratic societies that Rawls conceives as nearly just, there are disagreements about comprehensive moralities and about justice as well. There is no justifiable reason to consider the disagreements concerning comprehensive moralities as reflective of 'reasonable pluralism' while those about justice reflective of 'unreasonable pluralism'. As Sandel asserts there is no reason to consider Milton Friedman's objection to redistributive policies as not reflective of 'reasonable pluralism' and Pat

\footnotetext{
${ }^{1}$ Ibid, 208-209

${ }^{2}$ See Michael J. Sandel, Liberalism and the Limits of Justice 2d ed. (Cambridge, Cambridgeshire: Cambridge University Press, 1998) at page 210-211.

${ }^{3}$ Ibid, at 207.

${ }^{4}$ Ibid, at 209-210. Sandel quoting Rawls, Political Liberalism, at page 53.

${ }^{5}$ See Michael J. Sandel, Liberalism and the Limits of Justice 2d ed. (Cambridge, Cambridgeshire: Cambridge University Press, 1998) at page 210 .
} 
Robertson's objection to gay rights as being so reflective. ${ }^{1}$ Based on Sandel's arguments, out of Rawls' own mouth comes significant points suggesting the undoing of the foundation on which his proposal to bracket religious and moral arguments is built. Rawls acknowledges that the way to resolve philosophical questions in light of the fact that what is obvious to some is unintelligible to others, is to consider after due reflection which view offers the most coherent and convincing account.. ${ }^{2}$ So it is with regards to questions implicating comprehensive moral and religious doctrines, what is obvious to some will be unintelligible to others, the resolution of such doctrinal disputes lies in considering what view/views offer the most coherent and convincing account. There is no reason why it should not be so. After all Freedom of Religion in Western countries is not conventionally understood as demanding that such a balancing of plausibility regarding the public good be excluded. Indeed as previously argued decisions about such highly controversial issues as abortion inevitably involve the determination that some moral views are more plausible or more convincing than other moral or religious views. Since this is so why the illusion that such a balancing analysis is not applicable to conflicting comprehensive moral and religious doctrines?

If the asymmetry between the treatment of the disagreements among comprehensive moral and religious doctrines and those among philosophical schools of thought on justice is to be justified such justification cannot come from the mere designation that one type of disagreement is reflective of 'reasonable pluralism' while the other type is not. That designation is manifestly arbitrary and therefore unjustifiable. I suspect that the idea of justification for this asymmetrical treatment of disagreements among comprehensive moral and religious doctrines and conceptualizations of justice resides in a particular conceptualization of moral and religious doctrines, in particular their 'sensitivity to moral scrutiny'. ${ }^{3}$

\footnotetext{
${ }^{1}$ See Michael J. Sandel, Liberalism and the Limits of Justice 2d ed. (Cambridge, Cambridgeshire: Cambridge University Press, 1998 ) at page 210.

${ }^{2}$ See John Rawls, Political Liberalism (New York: Columbia University Press, 2005) at page 53.

${ }^{3}$ Bryan Thomas in his thesis, Public Reason and Canadian Constitutional Law (LLM thesis, University of Toronto, 2008) [unpublished] at pages 150-153 argues that 'religious comprehensive doctrines are morally and epistemologically opaque' and At page 146 he argues that they are sensitive to moral scrutiny and that this justifies asymmetrical treatment. While I oppose his conceptualization of religious comprehensive doctrines I respect his candour. I think that Rawls asymmetrical treatment of conflicting comprehensive moral and religious doctrines vis a vis varying conceptualizations of justice on the basis that they
} 
According to this view the proposal to resolve doctrinal disputes by deciding which view is the most coherent and convincing is much more intolerable to adherents of moral and religious doctrines than adherents of schools of thought on justice. I suspect that associated with this justification is the idea that the 'verdict' that their comprehensive moral/religious doctrinal views are less coherent and convincing than others may instigate such dissension among adherents of such views as to result in societal instability and threaten the democratic establishment. Following from this idea is the concomitant idea that moral/religious doctrinal views have to be mollycoddled in the interest of democratic stability ergo we treat them as special cases. We affix such labels as "reflective of reasonable pluralism" to them and thereby insulate them from the harrowing glare of public deliberation about fundamental public policy concerns. This conceptualization of comprehensive moral and religious doctrines is objectionable. Such an approach to comprehensive moral and religious doctrine are based on presuppositions about such doctrines that are based on generalizations from extreme cases where 'verdicts' as to them being less coherent and convincing than others have resulted in violent and undemocratic expression of dissent. Such an approach smacks of prejudice and stereotype in relation to adherents of comprehensive moral and religious doctrines. I will elucidate further when I come to discussing public reason's treatment of religious comprehensive doctrines.

The fact that Canada's policy regarding abortions and homosexual marriage is permissive may be taken to be reflective for all intents and purposes of a 'public verdict' that the moral and religious views against this permissiveness is less convincing or less coherent than other views. This fact in itself evidences that in reality what Sandel calls for as possible is actually the reality. In other words in democratic societies like the USA and Canada, the 'public verdict' reflects the determination that upon due reflection the moral and religious views supporting the 'public verdict' are more coherent and convincing than others.

reflect 'reasonable pluralism' is arbitrary. Thomas should at least be credited for giving an explicable reason for this asymmetry which I suspect is similar to what Rawls had in mind. I will come to my reasons for this later when I discuss Rawls' treatment of religious comprehensive doctrines. 
In Canada and the United States notwithstanding the fact that the 'public verdict' reflects permissiveness in relation to abortion and homosexuality, and that this runs counter to the deeply espoused doctrinal and religious views of many, the reality is that this 'public verdict' is at least tolerated. One would scarcely suggest that the democratic stability of Canada has been undermined on account of the fact that many hold moral and religious views opposed to the status quo. The majority of those who hold comprehensive moral and religious views opposed to the status quo, if and when they voice their disagreement, do so via nonviolent and disruptive means such as via the pulpit(Rawls would treat this as part of the background culture), leaflets, newspaper articles and placards. Occasionally in democratic countries like Canada, radical zealots venture to commit violent and disruptive acts in the name of opposition to what they regard as 'moral decay' evidenced by the status quo of permissiveness in relation to homosexuality and abortion. ${ }^{1}$ In such cases it cannot be said that they receive the endorsement and support of those opposed to the status quo regarding the permissiveness in relation to homosexuality and abortion. ${ }^{2}$ So too, infrequently in democratic countries like Canada, radical zealots venture to commit violent and disruptive acts in the name of opposition to what they regard as injustice on account of the prevailing conceptualizations of distributive justice, or permissiveness with regards to immigration policy. ${ }^{3}$ Likewise, in such cases it cannot be said that these radical zealots receive the endorsement and support of those opposed to the prevailing conceptualization of distributive justice. Many will agree that in democratic countries like Canada and the United States, the majority of citizens who hold views opposed to the status quo stridently condemn such violence and disruptiveness perpetrated in the name of opposition to the status quo. Why? They do so because they subscribe to democratic values, and they maintain their support notwithstanding the fact that the public verdicts regarding some polemical issues contradict their deeply held views. It may be said that they conceive of Democracy as involving a

\footnotetext{
${ }^{1}$ See for example, Michael A. Fletcher, "Sniper Kills Abortion Doctor Near Buffalo" (25 October 1998) A01, online: The Washington Post <http://www.washingtonpost.com/wp-srv/national/longterm/abortviolence/stories/sniper.htm>

${ }^{2}$ Ibid.

${ }^{3}$ See for example, The Leadership Conference on Civil and Human Rights Report, 'The State of Hate: Escalating Hate Violence Against Immigrants' part of report Confronting the New Faces of Hate: Hate Crimes in America (June, 2009) online: <http://www.civilrights.org/publications/hatecrimes/escalating-violence.html>
} 
continuous dialogue in relation to the public good. They therefore hold unto the possibility that at some time in the future they may persuade their fellow citizen that with regards to polemical questions, their comprehensive moral and doctrinal views in relation to what the public good calls for, is more convincing and plausible than contrary views. In time some of these citizens become persuaded themselves that the views they formerly opposed is more convincing than the views they formerly endorsed stridently, while some of those who subscribed to the prevailing views come to see opposing views as more convincing. In other cases while not becoming persuaded that the opposing views are more convincing, some citizens may come to appreciate aspects of opposing views as persuasive while not being necessarily persuaded by the view on a whole. In other cases citizens whose comprehensive doctrinal views conflict in many respects, may find that certain lines of arguments pursued by opposing doctrinal views, in certain instances may be adopted as persuasive analogues in support of their comprehensive doctrinal views. Take for instance the fact that in many cases Seventh Day Adventist Christians and Shia Muslim's have opposing positions in relation to some public policy issues. This notwithstanding, a Shia Muslim's conceptualization of his religion as ultimately calling for submission and obedience to the will of God may likely strike a nerve with the Seventh Day Adventist Christian in terms of the ultimate reality he contemplates in relation to his relationship with God. Such recognition of common ground in a particular respect would not be possible without some dialogic engagement with the other. I submit that that is the democracy we know and are able to recognize. One where meaningful exchange and even proselytization occur not only in matters of subscription to philosophical schools of thought regarding justice but also in relation to subscription to comprehensive moral and religious doctrines. The fact that some will adopt a posture of close-mindedness with respect to even the possibility of meaningful exchange ought not to forestall the pursuit of dialogue even implicating whether one or the other view is more coherent or convincing. The irrefutable fact that meaningful exchange and even proselytization occurs notwithstanding the fact of conflicting moral and religious comprehensive doctrines may be taken as empirical evidence that open dialogic engagement across the lines of conflicting comprehensive doctrines 
is meaningful and productive. Open dialogic engagement across the lines of conflicting comprehensive doctrines need not eventuate in clashes. The thing is to promote an approach that centres on mutual respect.

An alternative account of the overlapping consensus in light of the experience of democracy

The overlapping consensus that obtains in democracies like Canada may justifiably be said to be centred on the notion that we have a common concern in relation to the public good, and dialogic engagement across the lines of opposing comprehensive doctrines and conceptualizations of justice is meaningful and productive in relation to this common concern. What stokes the fire of this overlapping consensus so described is not the reliance on an inevitably obscure notion of 'political values' and the need to bracket comprehensive moral and religious doctrine (as this clearly does not obtain in reality and likely will never obtain). Instead it may be said with some reference to the experience of democracy that it is the very interest in ensuring that the cinders of dialogue continue to crackle and burn that stokes the democratic consensus. In other words the consensus resides in the interest that all possesses, across the lines of the varying comprehensive doctrines and conceptualizations of justice, in ensuring that the 'democratic marketplace' remains democratic or open for dialogic exchange. This interest in open dialogic exchange lives and thrives because the interest of citizens in having the public policy with respect to polemical issues dictated by their comprehensive doctrine continuously lives and thrives. Varying comprehensive doctrines are de facto allies that win out and lose out in relation to the public verdict subsisting at any point in time in relation to public policy issues. In relation to the variety of public issues varying comprehensive doctrines are winners with respect to certain public issues and losers with respect to others and vice versa.

The fact that the dialogue is always subsisting and ongoing means that though the status quo at any point in time is reflective of a certain 'public verdict' re public policy issues, there is always the prospect of revision and amendment causing formerly winning de facto allies to lose out and vice versa. As a result of this reality there are crosscutting interests in defending the status quo and seeking to amend the status 
quo. The prospect of revision and amendment in turn keeps the dialogue ongoing. This prospect of revision and amendment is in turn reflective of our 'free will' selves as always susceptible to changes of the mind as new learning and new 'revelation' presents. This conceptualization of the 'overlapping consensus' that obtains and drives democracies like Canada is more in keeping with our experience of democracy than Rawlsian public reason is. It captures the essence of the idea of democracy as government of the people by the will of the people, in that it recognizes that the 'genius' of democracy rests on the idea that sustainable government of free and equal beings capable of critical thought can only be 'willed' government. To elucidate, the 'genius' of democracy is the recognition that the coercive power of the government ought to be willingly endorsed by the majority and that the majority's will may change with respect to its determination of what the public good demands. The fact that the majority may change its 'mind' due to increase in learning or greater 'revelation' means that there is the potential that certain prevailing views may become 'minority views', therefore out of self-interest(for we never know whether ours will become a minority view) a certain floor of inalienable rights has to be recognized. Such an overlapping consensus may be described as a 'mere modus vivendi' but it is not necessarily so. The principle of mutual respect and the willingness to dialogue ensure that there are firm principles that underpin the democratic arrangement.

I submit that Rawls' original position with its features of the 'veil of ignorance' is unnecessary and inapposite as a theoretical construct to explain the formation of the democratic consensus because there is no need for ignorance in relation to personal and individuating circumstances for a principled consensus to be formed. The formulation I have sketched out works with the facticity of individuating circumstances and the existence of conflicting comprehensive doctrines. In a real democratic realm where conflicting comprehensive moral and religious doctrines and varying conceptualizations of justice are real social facts, the democratic consensus is plausibly explained by conceiving democracy as a continuous dialogue. Liberal democracy so conceptualized does not require bracketing comprehensive moral and religious doctrines and resort to 'political values'. Rather than subscribing to the utopian idea of transcendence of 
conflict as an ideal, liberal democracy appropriately conceived as a continuous dialogue accepts the reality of conflict as reflective of the human condition and productive in the sense that it is the harbinger of revision and change. Liberal democracy conceived as a continuous dialogic engagement more aptly captures the fact that fluidity, change and movement are the definitive features of liberal democracy rather than solidity, inflexibility and stagnation. The principles of justice though at each snapshot in time reflective of a particular public verdict are constantly being reassessed, reinterpreted in new lights and even amended. Conversely Rawlsian public reason with its reliance on such constructs as the "original position' and its 'veil of ignorance' apart from its reliance on hypothetical presuppositions that have never happened outside of the realm of 'make believe' are less apt to describe the reality of liberal democracy. This is because Rawlsian public reason seems to rely on the idea of a frozen moment in time when the citizen legislators divorced of their individuating circumstances determined the principles of justice that underpin the 'political conception of justice'. After this initial constitutional moment amendments and new interpretations in relation to the constitutional values have to be deliberated on and such deliberation proceeds based on invocation of 'political values' and 'political values' only. The Rawlsian picture of liberal democracy may be justifiably described as inflexible and deficient in terms of capturing democracy as an ongoing event, a phenomenon of movement and change.

Liberal democracy conceived as an ongoing dialogue does however recognize that dialogic engagement cannot be taken for granted. The democratic roundtable must always be prepared for the dialogue and therefore dialogic engagement can only be ensured and maintained if close mindedness is averted and open mindedness is promoted. This open mindedness is the willingness to try to conceive of the perspective of the 'other' or to at least venture to imagine oneself being persuaded otherwise there would be no meaningful dialogue in any sense. Therefore this conceptualization of plural democracy has at heart mutual respect or the will to conceive of the position of the 'other' as the driver of democratic stability. It is this willingness to engage the other in dialogue that will forestall violent upheavals and ensure a commitment to staying at the democratic roundtable, not the isolation of freestanding political values that 
will transcend the disagreement among conflicting comprehensive moral and religious doctrines. In this conceptualization the promotion of dialogic initiatives through the educational system, the media, community associations and other public institutions are integral. Such initiatives as multifaith coalitions, think tanks and roundtable discussions are considered as desirable in facilitating dialogic engagement and the development of shared understanding.

Public reason's proposal to bracket comprehensive doctrines from public deliberation is not feasible. For one this proposal runs against the grain of the significant fact that these comprehensive doctrines are inherently politically oriented and invariably seek to engage the political realm in terms of their own moral universe. I will move on to discuss public reason's treatment of religious comprehensive doctrines.

\section{Part 1(f): The Sites of Rawlsian Public Reason}

I now turn the question: Where does public reason apply or what are the sites of public reason?

Rawls posits that the idea of public reason applies to discussions of fundamental questions in the public

political forum. ${ }^{1}$ He states that this forum may be divided into three parts: the discourse of judges in their decisions; the discourse of government officials, especially chief executives and legislators; and the discourse of candidates for public office. ${ }^{2}$ Rawls posits that the ideal of public reason applies to citizens when they engage in political advocacy in the public forum, for members of political parties and for candidates in political campaigns. ${ }^{3}$ He asserts that the ideal holds for how citizens are to vote in elections when constitutional essentials and matters of basic justice are at stake. ${ }^{4}$ He submits that the ideal of public reason not only governs the public discourse of elections to the extent that the issues involve fundamental political questions but it also governs how citizens are to cast their vote on such questions. ${ }^{5}$

He distinguishes between the 'public political forum' and the 'background culture' ${ }^{6}$ Rawls states: "The idea of public reason does not apply to the background culture with its many forms of non-public reason

\footnotetext{
${ }^{1}$ John Rawls, Political Liberalism, Political Liberalism (New York: Columbia University Press, 2005) at page 442-443.

${ }^{2}$ Ibid, at 443 .

${ }^{3}$ John Rawls, Political Liberalism (New York: Columbia University Press, 2005) at 215.

${ }^{4}$ Ibid.

${ }^{5}$ Ibid.

${ }^{6} \mathrm{Ibid}$, at 768 .
} 
nor to media of any kind". ${ }^{1}$ According to him, the 'background culture' includes the culture of churches, and other kinds of associations such as universities, and scientific societies. ${ }^{2}$

Rawls's treatment of the family as an institution within the democratic polity illustrates the operation of “public reason' within the public political forum as against the background culture. Rawls posits that in order for public reason to be applicable to the family, it must be seen as a matter for political justice. ${ }^{3}$ According to him the primary subject of political justice is the basic structure of society. ${ }^{4}$ Rawls asserts that the family is a part of the basic structure of society. ${ }^{5}$ As such political principles apply directly to it in the sense of imposing constraints on the family as in institution; in that these principles guarantee the basic rights and liberties, and freedom of opportunity of its members. ${ }^{6}$ He suggests that these political principles do not apply directly to the internal life of the family. ${ }^{7}$ Rawls' thesis thus lends itself to the inference that public reason applies to the family as an institution forming a part of the basic structure of the democratic polity but not directly to its internal life-which falls within the 'background culture'. I submit that this proposition is at least problematic, in that it is difficult to perceive the line of demarcation between the family as 'structural' and the family in the sense of its 'internal life'. Furthermore, the 'internal life' of the family is so definitive of the notion of family that it is inconceivable that public reason may apply only directly to the family in the 'structural sense' but only indirectly in the 'internal sense'.

The Public Political Forum vis a vis the "Background Culture"

The distinction between the public political forum and the background culture is significant in that public reason is strictly applicable to discussions in the public political forum but citizens may freely air their comprehensive doctrines within the background culture. In light of this we are led to question whether this distinction is sustainable.

\footnotetext{
${ }^{1}$ John Rawls, "The Idea of Public Reason Revisited" (1997) 64:3 Chicago L.Rev 765 at 768.

${ }^{2}$ Ibid, at footnote 13 of page 768 .

${ }^{3}$ John Rawls, "The Idea of Public Reason Revisited" (1997) 64:3 Chicago L.Rev 765 at 788

${ }^{4}$ Ibid.

${ }^{5}$ Ibid, at 789 .

${ }^{6}$ John Rawls, "The Idea of Public Reason Revisited" (1997) 64:3 Chicago L.Rev 765 at 789.

${ }^{7}$ Ibid.
} 
As previously argued, Rawlsian public reason betrays a particular conceptualization of the self as prior to its ends. This conceptualization of the self seems manifestly objectionable in light our common human experience. As Sandel cogently suggests the self is never fully prior to its ends. In relation to religious comprehensive doctrines in particular Sandel asserts that Rawlsian public reason "...misses the role that religion plays in the lives of those for whom the observance of religious duties is a constitutive end, essential to their good and indispensable to their identity." I agree with Sandel. In relation to adherents of religious comprehensive doctrines the distinction between the public political forum and the background culture is more difficult to maintain. Rawlsian public reason requires religious citizens to undertake “... an artificial division within their own minds without jeopardizing their existence as pious persons". ${ }^{1}$ It fails to recognize that to many religious adherents their deep-felt, religiously inspired beliefs and reasons defy being pigeonholed into such neat categories as 'private', 'religious', 'social' and 'political'. Their religion is not something other than their social and political existence. ${ }^{2}$ In other words their religion is totalizing and it is not an option to switchover their religiously rooted political convictions onto a different cognitive basis. ${ }^{3}$ Public reason's requirement that religious citizens be morally restrained from deciding and reasoning about political issues based on their deeply felt religious motivations seems incompatible with the quintessential liberal democratic principle that citizens ought to enjoy equal freedom to live out their lives as they see fit. ${ }^{4}$ Further if and when religious citizens manage to translate their religious reasons in keeping with the Rawlsian proviso it is arguable that like any other process of translation something is inevitably lost in relation to the original meaning. After the translation it may very well be that the now translated reason may no longer be said to be a 'religious' reason. Thus far from merely losing 'something' of its essence, the translated reason or argument loses its religious inherency.

\footnotetext{
${ }^{1}$ Jürgen Habermas, "Religion in The Public Square", European Journal of Philosophy 14(1), at page 8.

${ }^{2}$ Ibid.

${ }^{3}$ Ibid.

${ }^{4}$ Wolterstorff, The Role of Religion in Political Issues, p.94. According to Kymlicka in "Multicultural Citizenship: A Liberal Theory of Minority Rights", Clarendon Press, Oxford, 1995, at page 80: the freedom m to live one's life as one sees fit is the defining feature of liberalism.
} 
Rawls' thesis on public reason postulates that citizens may freely reason from their comprehensive doctrines within the background culture but that when it comes to public political questions such reasoning ought to meet the proviso of translation into the language of proper political values. In effect the Rawlsian proviso requires of the religious citizen the herculean task of splitting their identity into a public and private part the moment they participate in public discourse. ${ }^{1}$ In another place Rawls asserts that citizens:

...May regard it as simply unthinkable to view themselves apart from certain religious, philosophical and moral convictions, or from certain enduring attachments and loyalties... These convictions and attachments help to organize and give shape to a person's way of life, what one sees oneself as doing and trying to accomplish in one's social world. ${ }^{2}$

It is amazing that notwithstanding this insight Rawls goes on to assert that these convictions and attachments are part of their 'non-public identity'. Indeed for Rawls to so assert is in keeping with his formulation of the background culture in contradistinction to the public political forum where public reason operates. One wonders though by what wondrous, magical or supernatural process the unthinkable becomes thinkable. In other words how is the citizen despite it being 'unthinkable' to view himself apart from his religious convictions, to be expected to suddenly see himself apart from his religious conviction at the moment of public deliberation, and assume a new 'public identity' wherein his private religious convictions are fully translated into political values. Such an enigmatic proposition in itself seems to defy experience and is arguably more readily imaginable when looked at through the lens of theology. Indeed Christian dogma for example cognizes of such inexplicable instant transformations when it speaks about the eschatological transformation of the saved 'in the twinkling of an eye'. ${ }^{3}$ Therefore quite ironically it may very well be that the religious reasoning which Rawls proposes to keep out of the public sphere

\footnotetext{
${ }^{1}$ Jürgen Habermas, "Religion in The Public Square", European Journal of Philosophy 14, at page 10.

${ }^{2}$ John Rawls, "Justice as Fairness: Political not Metaphysical", Philosophy and Public Affairs, Vol. 14, No. 3. (Summer, 1985 p.223, at page 241 .

${ }^{3} 1$ Corinthians 15: 52 of the King James Translation of the Bible states: "In a moment, in the twinkling of an eye, at the last trump: for the trumpet shall sound, and the dead shall be raised incorruptible, and we shall be changed."
} 
comes to his aid. Religious reasoning is the only thing that may lend explanatory force to the inexplicable and instant transformation experienced by Rawl's citizen, enabling him to forego his enduring attachment to his moral and religious convictions and to adopt political reasons at the moment of public deliberation. Ergo this evidences the usefulness of dialogic engagement with other conflicting doctrines, notwithstanding the reality of conflict there may still be some meaningful exchange.

The idea of religion being sequestered in the 'background culture'

The fact that Rawls thesis on public reason requires an active role for reason in public discourse but places no such requirement on reasoning within the private sphere or background culture is also suspect. It raises such questions as to what accounts for this differentiated treatment and why must it be so? Is it that the discourse in the public sphere is more important to society than the discourse in the background culture? In the dynamic flux of life where the private inevitably impinges on the private and the public the private what accounts for the differentiated treatment? Rawls thesis does not account for this differentiation between the public and the private sphere. The scholar Madhavi Sunder provides a very illuminating thesis in relation to the implications of the differentiated application of public reason in the public sphere vis a vis the private sphere. ${ }^{1}$ Sunder argues for a role for the exercise of reason in the so called 'private sphere' including religion and not only in the 'public sphere' as suggested by Rawls. Based on Sunder's thesis, one may conclude that Rawls' conceptualization of public reason belongs to the 'old Enlightenment'. ${ }^{2}$ Her thesis largely focuses on the role of law in underlining and perpetuating the conventional demarcation between the "public sphere" and "private sphere". She argues that "Revisiting law's story reveals not only how law has objectified religion but, more importantly sheds light on how law's transition narrative obstructs new constructions of religion". ${ }^{3}$ Sunder asserts that:

\footnotetext{
${ }^{1}$ Madhavi Sunder, "Piercing the Veil”, Yale Law Journal Volume 112, April 2003, p.1399-1472.

${ }^{2}$ Madhavi Sunder, "Piercing the Veil", Yale Law Journal Volume 112, April 2003, p. 1415-1419.

${ }^{3}$ Ibid, at page 1420 .
} 
In order to justify legal control of the public sphere, the Enlightenment banished religion from its jurisdiction and constructed religion as a separate, sovereign sphere in which the law does not belong. ${ }^{1}$

Sunder argues that law recognizes religion as a sovereign sphere and therefore cedes complete authority to religion and exempts it from the tests of rationality and legitimacy to which it subjects other phenomena conventionally conceived as belonging to the "public sphere". ${ }^{2}$ Sunder asserts that as a result of this exemption law enables the perpetuation of a particular conception of religion and obstructs movements for change within religious communities. ${ }^{3}$ She argues for the operationalization of the 'New Enlightenment' by piercing the veil to the 'private sphere' and opening up religious communities to the searchlight and scrutiny of reason. This 'New Enlightenment" according to Sunder “...does not reject the old one, but rather takes it further, demanding reason and rights within normative as well as secular community". 4

In fairness to Rawls thesis, while it does not go quite as far as Sunder requires in terms of her thrust for the embracing of the "New Enlightenment", his account does conceive of the idea at least notionally that 'public reason' does and should impact significantly on the 'private sphere' including practices within religion. He asserts that the public and private sphere "...fall out from the content and application of the conception of justice and its principles" and that "If the so-called private sphere is alleged to be a space exempt from justice, then there is no such thing". ${ }^{6}$ Rawls argues that principles of political justice do constrain ecclesiastical governance in that by public law not recognizing heresy and apostasy as crimes it prevents churches from practicing effective intolerance and allows members to be free to leave their faith. ${ }^{7}$ Notwithstanding this point, it is recognizable that in Rawls account much still depends on the

\footnotetext{
${ }^{1}$ Madhavi Sunder, "Piercing the Veil", Yale Law Journal Volume 112, April 2003, at page 1420.

${ }^{2}$ Ibid.

${ }^{3}$ Ibid, at page 1421 .

${ }_{5}^{4}$ Ibid, at page 1472.

${ }_{6}^{5}$ John Rawls, Political Liberalism (New York: Columbia University Press, 2005), at page 471.

${ }^{6}$ Ibid.

${ }^{7}$ Ibid, at page $468-471$.
} 
categories-"public sphere' and "background culture" being left intact. This is evident in his suggestion that:

In order for public reason to apply to the family, it must be seen, in part at least, as a matter for political justice. $^{1}$

Regarding Rawls' point that members are free to leave, Sunder's retort is that the freedom to leave is not enough and this evidences a manifest limitation of the "old Enlightenment". ${ }^{2}$ According to Sunder far from accepting the singular option to leave their religion, "Individuals in the modern world increasingly demand change within their religious communities in order to bring their faith in line with democratic norms and practices". ${ }^{3}$ Therefore based on Sunder's scholastic contribution it may be argued that Rawls' formulation of public reason in many ways retards the forward march of the very liberal values which he declaredly sets out to promote. His formulation appears to chalk out an area wherein absolutist religious oligarchs are allowed sovereign jurisdiction on the basis that religion is a private affair and therefore it is not imperative that the 'light' of public reason penetrate its bounds. Further it may be argued that by so doing Rawls' formulation confers legitimacy on the efforts of absolutist religious oligarchs to suppress the 'rebels' who dare to seek change and reformation within their religious communities-after all it is their ‘sovereign' prerogative.

Public Reason as inapplicable to the media

Rawls not only posits that the idea of public reason does not apply to the 'background culture'; he also asserts that it does not apply to media of any kind. ${ }^{4}$ According to him media of all kinds-newspapers, reviews and magazines, television and radio and all different kinds of media belong to the "non-public political culture which mediates between the public political culture and the background culture. ${ }^{5}$ This is a strange proposition in light of our experience of the media and its public role in constitutional

\footnotetext{
${ }^{1}$ John Rawls, Political Liberalism (New York: Columbia University Press, 2005), at page 468.

${ }^{2}$ Madhavi Sunder, "Piercing the Veil", Yale Law Journal Volume 112, April 2003, at page 1403.

${ }^{3}$ Ibid.

${ }^{4}$ See John Rawls, Political Liberalism (New York: Columbia University Press, 2005) at 443-444.

${ }^{5}$ Ibid, also footnote 13 at page 443-444.
} 
democracies like Canada and the United States. Such is the undeniably significant public role of the media in modern democracy that the media has been referred to as the 'fourth estate' and the 'fourth branch of government'. The media is considered to play a significant role in terms of ensuring an informed electorate which is indispensable to democracy. ${ }^{1}$ It is considered as playing a pivotal role in the cultural and democratic life of modern democratic countries. ${ }^{2}$ The media in modern democracy undoubtedly encourages and disseminates a wide variety of views in relation to issues of topical concern. ${ }^{3}$ The significance of the media in relation to the encouragement and dissemination of views in relation to topical issues is of such importance to the 'machinery' of democracy that it has been referred to as the 'constitutional role' of the media. ${ }^{4}$ Not only does the media have a significant role in terms of being a forum for the expression and exchange of views on topical issues, it also has considerable influence on public opinion. ${ }^{5}$ The British Government in its 1995 policy proposals with respect to media regulation in Britain declared: 'The justification for a special regime to regulate media ownership is that the power of the media to influence and form opinion makes it an industry like no other". ${ }^{6}$ An examination of the Canadian experience in relation to the media evidences that the aforementioned description of the role and influence of the media also obtains in Canada. Similarly to the policy outlook expressed in the abovementioned quotation from the British government in 1995, the Canadian status quo reveals that the media is in fact subject to regulation by government on account of the Canadian understanding that it has a unique and significantly important and influential role in relation to public opinion. One does not need to look any further than the Canadian Broadcasting Act to discern the significance of the Canadian media to the Canadian democratic apparatus. The Canadian Broadcasting Act in section 3(captioned "Broadcasting Policy for Canada") declares:

\footnotetext{
${ }^{1}$ See John Clifford, "Political Broadcasts and the Informed Electorate: A Call for Action" (1972-1973) 22 Cath. U. L. Rev. 177 at page 177 .

${ }^{2}$ See Hazel Fleming, "Media Ownership: In the Public Interest? The Broadcasting Act 1996" (1997) 60 Mod. L. Rev 378 at 379.

${ }^{3}$ Ibid.

${ }^{4}$ Ibid.

${ }^{5}$ Ibid.

${ }^{6}$ Ibid, at 379 .
} 
3. (1) It is hereby declared as the broadcasting policy for Canada that

(a) the Canadian broadcasting system shall be effectively owned and controlled by Canadians;

(b) the Canadian broadcasting system, operating primarily in the English and French languages and comprising public, private and community elements, makes use of radio frequencies that are public property and provides, through its programming, a public service essential to the maintenance and enhancement of national identity and cultural sovereignty. ${ }^{l}$

The Act goes on to prescribe that the programming provided by the Canadian broadcasting system shall “...provide a reasonable opportunity for the public to be exposed to the expression of differing views on matters of public concern". ${ }^{2}$ It also prescribes that the programming provided shall be predominantly and distinctively Canadian ${ }^{3}$, contribute to shared national consciousness and identity ${ }^{4}$ and reflect the multicultural and multiracial nature of Canada ${ }^{5}$.

It is inferable from the abovementioned provisions of the Broadcasting Act of Canada that the Canadian polity envisages the media playing an undeniably significant public role. It is declared to be effectively owned and controlled by Canadians, therefore public in nature and constituted as a public service in the public interest. It is inferable that the Canadian polity conceives of the Canadian media as instrumental in forging and maintaining a shared national identity and culture, and facilitating public deliberation. Thus this Canadian conception of the Canadian media stands out as dissonant when compared to Rawls' description of the media as belonging to the 'non-public political culture' which mediates between the public political culture and the 'background culture. The vision of the Canadian media provided by the Canadian Broadcasting Act and the prescriptions that it is effectually 'publicly oriented and publicly constituted' derogates from any notion of the 'non-public' as Rawls describes.

\footnotetext{
${ }^{1}$ See Broadcasting Act, S.C. 1991, c.11, s.3(1)(a) and s. 3(1)(b).

${ }^{2}$ Ibid, s.3 (1)(i)(iv).

${ }^{3}$ Ibid, s.3(1)(m)(i)

${ }^{4}$ Ibid, s.3(1)(m)(iv)

${ }^{5}$ Ibid, s.3(1)(m)(viii)
} 
Rawls conception of the role of the media as merely a part of the 'non-public political culture' also seems askew in light of the fact that he declares his thesis on public reason as envisaging a deliberative democracy. Rawls asserts that the three essentials of deliberative democracy are:

1. an idea of public reason;

2. a framework of constitutional democratic institutions that specifies the setting for deliberative legislative bodies; and

3. the knowledge and desire on the part of citizens generally to follow public reason and to realize its ideal in their political conduct. ${ }^{1}$

Rawls explains that public financing of elections, and the providing of occasions of orderly and serious discussion of issues of public policy are immediate implications of these essentials of deliberative democracy. ${ }^{2}$ He asserts that public deliberation must be recognized as a basic feature of democracy and set free from the 'curse of money' as otherwise politics is dominated by corporate and other organized interests who are able to distort if not preclude public discussion and deliberation. ${ }^{3}$ Rawls further submits that:

Deliberative democracy also recognizes that without a widespread education in the basic aspects of constitutional democratic government for all citizens and without a public informed about pressing problems, crucial political and social decisions simply cannot be made. ${ }^{4}$

If Rawls' aforementioned insights with respect to the implications of the essentials of deliberative democracy were clues in a game show which seeks to elicit the identity of the institution described, it would have been a dead giveaway. One can imagine contestants impatiently motioning, ready and rearing to shout the answer; one can almost hear the shouts: the media! The media! Surely Rawls must have contemplated that the media is the very institution which plays the pivotal role in relation to the implications of the essentials of democratic governance he enumerates so aptly and eloquently. It is

\footnotetext{
${ }^{1}$ See John Rawls, Political Liberalism (New York: Columbia University Press, 2005) at 448.

${ }^{2}$ Ibid, at 448-449.

${ }^{3}$ Ibid, at 449.

${ }^{4}$ Ibid, at page 449 .
} 
undeniable that the media plays a significant role in providing the public occasions necessary for orderly and serious discussion of fundamental questions. In countries like Canada and the United States it is abundantly clear that it is the media that brings prospective candidates vying for election into the living rooms of families and enables a two way dialogue between them. The public gets to field their questions to the candidates via their journalist proxies (sometimes they get to do so directly by calling in, and via town hall meetings) and the candidates get to respond to these questions, promulgate aspects of their manifestoes and demonstrate their grasp of the issues. One just has to direct one's mind to the way such media events as national debates by the party leaders in the United States and Canada receive wide audiences in these countries. Recent studies indicate that such debates are also impactful on electors' candidate choices and in terms of enhancing young citizen's democratic attitudes and strengthening political information efficacy. ${ }^{1}$ The media in countries like Canada perform a significant watchdog role in terms of ensuring that democratic politics is not dominated by organised interests and ensuring that public functionaries perform their duties ethically. ${ }^{2}$ As one famous journalist styles it the media performs the role of "keeping them [politicians] honest". ${ }^{3}$ Of Rawls' aforementioned assertions in relation to the implications of deliberative democracy it may be said that none is more definitive of the media's function in a democracy like Canada than that of keeping the public informed about pressing problems. Surely this may be regarded as the very 'raison d'etre' of the media, at least in theory. It is at least astounding that despite the media's undeniable pivotal role with respect to the 'immediate implications of the essentials of deliberative democracy' as he puts it, he conceives the media as merely a part of the 'non-public political

\footnotetext{
${ }^{1}$ See John G. Greer, "The Effects of Presidential Debates On The Electorate's Preferences for Candidates" (1988) 16:4 American Politics Research 486-501, online: Sage Journals <http://apr.sagepub.com/content/16/4/486.abstract> at Abstract, this study concluded that presidential debates are impactful on the candidate choices of the electorate. See Mitchell S. McKinney, "Political Engagement Through Debates: Young Citizens' Reactions to the 2004 Presidential Debates" (May, 2007) 50:9 American Behavioral Scientist 1169-1182, online: Pine Forge Press <http://www.pineforge.com/ballantine2study/articles/Chapter\%2013/McKinney.pdf> at page 1180 for conclusion in relation to enhancing democratic attitudes and strengthening information efficacy.

${ }^{2}$ See Warren Francke, “ The Evolving Watchdog: The Media's Role in Government Ethics” (January, 1995) 537:1 The Annals of The American Academy of Political and Social Science 109-121, online: Sage Journals < http://ann.sagepub.com/content/537/1/109.abstract> see abstract.

${ }^{3}$ This is a phrase famously linked to CNN journalist, Anderson Cooper. See David Bauder, “Anderson Cooper's 'Keeping Them Honest' Segment Catches On" (13 June, 2011) online: Huffington Post <http://www.huffingtonpost.com/2011/06/13/anderson-coopers-keeping-_n_876176.html>
} 
culture'. I have already argued that Rawls conception of liberal modern democracy seems to be incongruous with one's experience of modern democracy, surely Rawls' conception of public reason as unnecessary or inapposite for the media reflects a skewed picture of the imperatives of deliberative democracy. It is undeniable that the media has a significant role in terms of facilitating public deliberation, promulgating information in terms of various perspectives and views on topical issues, and also framing the issues for discussion. In relation to the public discourse the media may be regarded as a 'megalithic conglomerate of loudspeakers'. One would scarcely deny that the media has profound influence on democratic deliberation so much so that it can influence it for the good or bad. One would think that public reason would necessarily apply to the media as in modern democracy the media is undeniably part of the 'hustings'. The media is such a significant part of the 'hustings' or political platform to modern democratic polities that in many Western countries including Canada and the United States, legislation has been passed to regulate broadcasting during elections and to ensure some measure of fair opportunity of access to the broadcast media. ${ }^{1}$

The normative practices that obtain in the media may have a significantly distorting effect in relation to the type of arguments that are filtered in or out of the public discourse re issues of fundamental importance. Rawls himself expresses the insight that deliberative democracy presupposes 'deliberation' and deliberation presupposes 'information'. ${ }^{2}$ The media may have a 'make or break' effect in relation to the type of information that is promulgated within a polity and whether this 'information' actually amounts to 'information' and not 'disinformation' or 'misinformation'. It is inconceivable how Rawlsian public reason may actually take root and thrive in a particular democracy if the media houses insist on promulgating exactly the type of arguments he prescribes ought to be bracketed from public deliberation about constitutional essentials. What if a particular city councillor were to faithfully adhere to public

\footnotetext{
${ }^{1}$ With respect to the American situation see John Clifford, "Political Broadcasts and the Informed Electorate: A Call for Action" (1972-1973) 22 Cath. U. L. Rev. 177 at 179-182. Regarding Canadian situation see James R. Robertson and Sebastian Spano, The Canadian Electoral System (Ottawa: Library of Parliament, Parliamentary Information and Research Service, Law and Government Division, BP-437E, September 15, 2008) online: Library of Parliament <http://www.parl.gc.ca/Content/LOP/ResearchPublications/bp437-e.pdf> at page 18-22.

${ }^{2}$ See John Rawls, Political Liberalism (New York: Columbia University Press, 2005) at page 448-449
} 
reason's prescriptions when he delivers arguments in Toronto City Council meetings but also write a weekly contribution to a widely circulated newspaper and thereby vent unabashed invocations to fundamentalist religious beliefs. One may say that by virtue of his office the duty of circumspection or civility is expected of the city councillor even in the case where he contributes to a widely circulated newspaper. Is this necessarily so? Let us depart from the case of the mayor. What if the host of Toronto's most watched morning show were to in relation to a recent proposal for Sharia arbitration take an hour of the show to fully vent his views that Sharia is a backward and primitive system that will instigate the stoning of women on the streets of Toronto? What if he were to seek to back up his arguments with selective references to quotes from Islamic adherents? I submit that this in itself may have a significant distortive effect on the effectuation of Rawlsian public reason in relation to the issue at hand. Further if similar sectarian views were to be widely endorsed and promulgated by media players in relation to the myriad of issues implicating constitutional essentials and issues of basic justice, it is undeniably that it would have a significant distortive effect in relation to the ability of public reason to take root in public deliberation. Far from merely having a distortive effect, the promulgation of divisive sectarian views by the media may have a nullifying effect on the ability of public reason to take root in public deliberation. I therefore conclude that Rawls conception of the media as merely part of the "non-public political culture" is incoherent with his thesis on public reason. His conceptualization of the sites of public discourse is shockingly narrow, the fact that it does not take in the media as a part of the public forum is bound to impair the ability of public reason to engender the respectful public deliberation founded on 'political values' that it envisages. Rawls misses a significant reality of modern democracy-the media is a force that has to be reckoned with as in many ways it is the gatekeeper to the arena of public deliberation. Thus Rawls' treatment of the media and its role in deliberative democracy may be said to be another instance of how Rawlsian public reason suffers from the disability of failing to approach a realistic or realizable conception of democracy as we know it. 


\section{Part 1(g): Rawlsian public reason's treatment of religious comprehensive doctrines}

Rawls acknowledges that there are benefits to introducing comprehensive doctrines into public discourse. Rawls asserts:

We may think of the reasonable comprehensive doctrines that support society's reasonable political conceptions as those conceptions' vital social basis, giving them enduring strength and vigor. $^{1}$

Rawls posits that these religious or non-religious comprehensive doctrines may be introduced into political discussions at any time provided that they meet the 'proviso'. ${ }^{2}$ According to Rawls' 'proviso', during the course of political discussions citizens must provide public reasons to support the proposals their comprehensive doctrines are said to support, and this must be done in good faith. ${ }^{3} \mathrm{He}$ asserts that “...Public reason requires us to justify our proposals in terms of proper political values". ${ }^{4}$ Rawls specifically declares that it is necessary to distinguish public reason from secular reason and secular values. ${ }^{5}$ To his credit this declaration may be taken to be in theory consistent with his rendition of public reason as transcending the irreconcilable comprehensive doctrines which are a feature of plural democracy. I submit that Rawlsian public reason in terms of the practical implications of its normative prescriptions is inconsistent with its object of transcending the irreconcilable comprehensive doctrines but rather favours secular comprehensive doctrines. Therefore rather than 'transcendence' the practical implications of its normative prescriptions is more in keeping with transforming public deliberation so that secular comprehensive doctrines and values will reign supreme. In terms of substantiating this point I first wish to note as significant the fact of how Rawls conceptualizes the difference between the problems of justice as known in the ancient world and those of the modern world. ${ }^{6}$ Rawls declares:

\footnotetext{
${ }^{1}$ See John Rawls, Political Liberalism (New York: Columbia University Press, 2005) at page 463.

${ }^{2}$ Ibid at page 462 .

${ }^{3}$ Ibid.

${ }^{4}$ Ibid, at page 456.

${ }^{5}$ Ibid, at page 452.

${ }^{6}$ See John Rawls, Political Liberalism (New York: Columbia University Press, 2005) at page xxv.
} 
What the ancient world did not know was the clash between Salvationist, creedal, and expansionist religions. That is a phenomenon new to historical experience, a possibility realized by the Reformation. ${ }^{1}$

Rawls elucidates:

What is new about this clash is that it introduces into people's conceptions of their good a transcendent element not admitting of compromise. This element forces either mortal conflict moderated only by circumstance and exhaustion, or equal liberty of conscience and freedom of thought. $^{2}$

Based on Rawls aforementioned assertions it is inferable that he conceives of the problems of justice known to the modern world as essentially revolving around Salvationist, creedal, and expansionist religious doctrines that admit no compromise. Having formulated the problems of the modern world as such Rawls then describes the moral philosophy of the modern period as driven by the hope of establishing a basis of moral knowledge independent of ecclesiastical authority and available to the ordinary reasonable and conscientious person. ${ }^{3}$ On Rawls rendition of the problems of justice known to the modern world and his description of the hopes of moral philosophy we begin to get a picture of how Rawls' conceptualization of the modern world is skewed against religious comprehensive doctrines. Rawls' skewed picture of the problems of justice of the modern world is objectionable.

The difference between the problems of justice of the ancient world and that of the modern world

Firstly Rawls distinguishes the clash between Salvationist, creedal and expansionist religion as the hallmark of the difference between the problems of justice of the ancient world and the modern world. It is this significant difference on Rawls' account that justifies his theory taking to heart the absolute depth of irreconcilable latent conflict and which eventuates in the prescription to rely on 'transcendental

\footnotetext{
${ }^{1}$ Ibid.

${ }^{2}$ See John Rawls, Political Liberalism (New York: Columbia University Press, 2005) at page xxvi.

${ }^{3}$ Ibid, at page xxvi.
} 
political values. ${ }^{1}$ This difference that Rawls describes between the ancient world and the modern world is doing a lot in relation to Rawls' thesis on public reason. It suggests that the fact and nature of the type of pluralism which obtains in modern times justifies a new and different dispensation from the old order-that new and different dispensation is transcendental public reason. One may ask why it is that examining the 'problems' of justice of the ancient world and that of the modern world leads Rawls to conclude 'difference' and not 'similarity' in the very first place. In the first place it is indubitable that the ancient world and modern world share the common experience of 'problems of justice'. That idea is implicit in the very fact of Rawls' assertion that the 'problem of justice' experienced today in modern liberal democracies is not the same as that in the ancient world. Does this fact not justify the conclusion that both the ancient and the modern world have the similarity of 'problems of justice'? One would scarcely deny that modern democratic societies are far more religiously plural than societies in the ancient world. This may be attributed to various reasons including the democratic culture of free institutions, democratic values such as freedom of religion and conscience, the heightened migration of people from one country to the next, and increase in transfer of information among other things. Therefore just as modern democratic societies may be said to be different when compared to the ancient world with respect to their heightened religious pluralism, it may be said that such societies are different when compared to the ancient world with respect to the democratic culture of free institutions, the wide espousal of such democratic values as freedom of conscience and religion, heightened migration et al. Notwithstanding these undeniable differences between modern democracies and the ancient world both modern democracies and the ancient world shared the undeniable similarity of 'problems of justice' and clashes on account of these problems. Why is it that Rawls chooses to isolate and mention only one of the many differences between ancient societies and modern democracies? He not only chooses the difference in relation to the degree of religious plurality but he stresses certain features of these religions that are plural and he makes the conclusion that they characterize the 'problems of justice' which differentiate modern

\footnotetext{
${ }^{1}$ See John Rawls, Political Liberalism (New York: Columbia University Press, 2005) at page xxvi.
} 
democracies from the ancient world. People often see what they want to see and I submit that Rawls' description of the religious plurality of the modern world as reflective of a clash of Salvationist, creedal and expansionist is reflective of a presupposition in relation to religious plurality as essentially threatening in relation to democratic stability. These religions could just as aptly be described as mediatory, transformative, and promotional of ideals in relation to the public good as a counter to the narrow pursuit of self-interest. It is undeniable that many of the religions known to modern democracy have played a mediatory, reconciliatory and transformative role in human affairs at key pressure points in modern societies where democratic stability and or human rights was threatened. Take for instance the significant role the church has played in relation to the transitional justice processes that have occurred in countries like South Africa, Chile and Guatemala. ${ }^{1}$ Take for instance the role the church played in relation to the Civil Rights movement in the United States, indeed arguably the most recognizable face of that dogged struggle for human equality and human dignity was that of Martin Luther King Jr., a clergyman. Although not widely promulgated, despite the Israeli/Palestinian conflict being constantly presented as one of the stand out examples of the intractable conflicts between religions, groups of religious persons from both sides of the so called 'religious divide' have actively sought and are actively seeking to promote peaceful settlement. $^{2}$ I do not for one moment suggest that religion has always been and is always a force for the good, it is undeniable that conflict on account of religious doctrinal views have motivated resort to significant violence and bloodshed. This notwithstanding I submit that such significant violence and bloodshed or in other words such 'threats to democratic stability' are not definitive of the reality of the plurality of religions in modern plural democratic states.

The ancient world may not have known the clash between Salvationist, creedal, and expansionist religions but it undoubtedly knew of the clash between antagonistic and expansionist political systems and tribes.

\footnotetext{
${ }^{1}$ See Daniel Philpott, "Religion, Reconciliation, and Transitional Justice: The State of The Field" Social Science Research Working Papers online: 〈http://www.global.ucsb.edu/orfaleacenter/luce/luce08/documents/Philpott_SSRC-working-paper.pdf> ${ }^{2}$ See for example information on the Parents Circle-Families Forum (PC-FP) an organization formed by the parents of victims of the conflict to promote a peaceful end to the Israel/Palestine conflict. Parents Circle-Families Forum online: <http://www.theparentscircle.com/about.asp\#1>
} 
The world both ancient and modern has always known of antagonistic groups of humans expressing their disagreements via violence and bloodshed. This is fact. It may be said that seeking to argue about the different motives behind the clashes of antiquity and those of modernity does not get us anywhere. The undeniable fact is that the history and reality of humanity is in many ways one of 'problems of justice' and various 'conflicts of interest' that have eventuated in 'clashes'. One may with good reason assert that the focus ought to be on developing theories and frameworks to guide the management of such inevitable conflicts so that they do not eventuate in clashes. Since it is that with or without religious plurality humanity experiences clashes what good does it do to harp on the fact that the reality of the present age is one of religious plurality. Rawls thinks it worthwhile to his enterprise to draw a line of demarcation between the problems of justice experienced by the ancient world and the modern world. There is no reason why it may not be just as worthwhile to start by focusing on the shared fact that the "problems of justice' of both the ancient world and modern democracies have motivated clashes. By so doing the problem may contrary to Rawls' definition be framed as one concerning how clashes on account of 'problems of justice' may be managed or averted. In other words the irrefutable common denominator of these 'problems of justice' is the fact that they have resulted in clashes. One could justifiably assert that the problem of humanity throughout the ages is a problem of the will to resort to violence in the face of its problems whether religious conflict, territorial conflicts, ethnic conflicts or otherwise rather than to dialogic engagement. Therefore Rawls' particular manner of conceptualization of the problems of modern democracies in contradistinction to that of the ancient world is not a necessary conclusion but rather may be understood as reflective of a particular descriptive predilection. In light of this I submit that it is no wonder that Rawls' public reason manifests as privileging secular comprehensive doctrines as against religious comprehensive doctrines.

\section{$\underline{\text { Rawlsian public reason's disproportionate burden in relation to comprehensive religious doctrines }}$}

Religious doctrines are much more difficult to be translated into 'political values' pursuant to Rawlsian public reason's prescriptions. This is on account of the fact that quintessentially religious doctrines 
depend on transcendental principles and invocation to divinity. As Wolterstorff puts it religious reasons may be spotted from a mile away due to references to God, the Bible and other authorities that are unmistakably religious while comprehensive secular perspectives will go undetected as they do not rely on such invocations. ${ }^{1}$ Further it may be said that secular comprehensive doctrines which by and large rest on more 'worldly' interests and values are much more able to be translated into the political and thus meet the Rawlsian proviso. As a result it may be said that the Rawlsian proviso places a disproportionately heavy burden on religious comprehensive doctrines than it does in relation to secular comprehensive doctrines. Jürgen Habermas aptly and succinctly terms the disproportionate burden thus:

The translation requirement for religious reasons and the subsequent institutional precedence of secular reasons demand of the religious citizens an effort to learn and adapt that secular citizens are spared having to make. ${ }^{2}$

To the extent that the Rawlsian proviso does this it may be said to be a weapon in the arsenal of those who subscribe to the popular secularist premise that the liberal value of the 'separation of church and state' requires the state to do nothing that advances or hinders religion. ${ }^{3}$ This view of what the liberal value of 'separation of church and state' stands for is in contrast to that which considers the value as requiring that the state treat all comprehensive doctrines impartially. ${ }^{4}$ In a context where a secularist conceptualization of separation of church and state dominates and where the Rawlsian proviso stands as the gatekeeper to the public forum, it is always going to be problematic to argue in terms of sincerity of religious belief. For arguments grounded on sincerity of religious belief to be so-sincere, it requires that the proponent's true, and deep felt motivations and beliefs be articulated. Rawlsian public reason with its preoccupation with political values and political translation does not appear to have room for such. Naked

\footnotetext{
${ }^{1}$ Nicholas Wolterstorff, "The Role of Religion In Decision and Discussion of Political Issues," in Robert Audi and Nicholas Wolterstorff, Religion in the Public Square: The Place of Religious Convictions in Political Debate (Maryland: Rowman and Littlefield, 1997) at page 105.

2 Jürgen Habermas, "Religion in The Public Square", European Journal of Philosophy 14(1), at page 13.

${ }^{3}$ Nicholas Wolterstorff, "The Role of Religion In Decision and Discussion of Political Issues," in Robert Audi and Nicholas Wolterstorff, Religion in the Public Square: The Place of Religious Convictions in Political Debate (Maryland: Rowman and Littlefield, 1997) at 76.

${ }^{4}$ Ibid. Wolterstorff calls this the 'impartiality interpretation'.
} 
and sincere religious arguments in the light of the Rawlsian proviso appear as unclothed or scantily clad guests at a black tie affair-woefully unfit for the occasion and are summarily turned away at the door. On the other hand politically pitched secular arguments due to the nature of their garb are allowed entry and merge easily into the crowd at the gala of Rawlsian public reason.

Rawlsian public reason requires religious citizens to undertake “... an artificial division within their own minds without jeopardizing their existence as pious persons ". ${ }^{1}$ It fails to recognize that to many religious adherents their deep felt, religiously inspired beliefs and reasons defies being pigeonholed into such neat categories as 'private', 'religious', 'social' and 'political'. Their religion is not something other than their social and political existence. ${ }^{2}$ In other words their religion is totalizing and it is not an option to switchover their religiously rooted political convictions onto a different cognitive basis. ${ }^{3}$ The Policy position of the Presbyterian Church (USA) in relation to the role of faith in public deliberation evidences that this is the view of many religious people:

It is a limitation and denial of faith not to seek its expression in both a personal and a public manner, in such ways as will not only influence but transform the social order. Faith demands engagement in the secular order and involvement in the political realm. ${ }^{4}$

Faith indeed demands engagement in the secular order and involvement in the political realm and this has been evidenced historically as seen in how faith based advocacy played significant roles in campaigning for the abolition of the slave trade, slavery, and apartheid in South Africa to name a few instances. We see and hear of faith in action in the public sphere and demanding action in the public sphere on television, in newspaper headlines and we witness it ourselves. One then wonders why it is that Rawls conceives of the proposal to bracket religious comprehensive doctrines from public deliberation as feasible. Surely he must have known that many if not the majority of religious comprehensive doctrines take a similar position to

\footnotetext{
${ }^{1}$ Jürgen Habermas, "Religion in The Public Square", European Journal of Philosophy 14(1), at page 8.

2 Jürgen Habermas, "Religion in The Public Square", European Journal of Philosophy 14(1), at page 8.

${ }^{3}$ Ibid.

${ }^{4}$ See The Presbyterian Church (U.S.A), "God Alone is Lord of the Conscience: A Policy Statement Adopted by the $200{ }^{\text {th }}$ General Assembly" 48(1989).
} 
that expressed by the Presbyterian Church in the United States with respect to the notion that faith demands action in the political arena. The policy position quoted above declares that 'faith' demands engagement in the political arena, this signals that 'faith' demands engagement on its own terms as 'faith' not in any ersatz form or adulterated manifestation, certainly not 'masked' as secular values.

The prospective consequences for Rawlsian public reason's bracketing of religious comprehensive doctrines

Habermas provides the insight that by seeking to bracket religious reasoning from public deliberation, Rawls' thesis of public reason dismisses or ignores that:

Religious traditions have a special power to articulate moral intuitions, especially with regard to vulnerable forms of communal life. ${ }^{1}$

Therefore according to Habermas by bracketing religious arguments from the public square a polity may “...cut itself from key resources for the creation of meaning and identity". ${ }^{2}$ Habermas' observations elicit a serious question-how worthwhile can the pursuit of public reason as conceptualized by Rawls be? This is in light of the fact that its proposal to bracket religious perspectives from public deliberation may inevitably result in foreclosing the option of using a resource of great and proven utility to making public deliberation meaningful and productive in the first place. What is it about religious argumentation in public discourse that makes it desirable to bracket it from the public square notwithstanding the clear benefits to be gained from letting it in? Is it that it is such a dangerous agent that it is not worth the risk of inclusion in the public square? Is it that religion stirs up too many passions and that societal peace and stability will be impaired? I suspect that Will Kymlicka's observation regarding liberal opposition to the demands of ethnic and national minorities applies to Rawls' opposition to religious reasoning being freely permissible in relation to public deliberation about constitutional essentials and basic justice. This is evidenced by the way Rawls chooses to define the problems of justice in modern democracies as essentially that caused by the transcendent element in relation to conceptions of the good that do not

\footnotetext{
${ }^{1}$ Jürgen Habermas, "Religion in The Public Square", European Journal of Philosophy 14, at page 10.

${ }^{2}$ Ibid.
} 
admit compromise. ${ }^{1}$ According to Rawls this reality presents a choice between 'either mortal conflict or equal liberty of conscience and freedom of thought'. ${ }^{2}$

Rawls' prescription in relation to bracketing comprehensive doctrines is motivated by a practical concern for stability and solidarity in liberal states. ${ }^{3}$ Following in the vein of Kymlicka I assert that the concern that allowing religious argumentation to freely enter public deliberation may jeopardize liberal democratic stability and solidarity is overstated, unjustified and smacks of intolerance toward religious reasoning. ${ }^{4}$ The jury is still out as to whether religion has done more harm than good and though history is replete with examples of organized religion causing widespread harm it is also replete with examples of organized religion having positive consequences. One seldom hears hue and cry about the 'small' acts of kindness, selflessness and compassion influenced by religious values and promoted by religious institutions and groups. Moreover there are shining examples of religious values serving to combat oppression, human rights violations and human suffering and to inspire movements for democratic change and solidarity, and these are too many to mention. ${ }^{5}$ What makes news headlines are invariably the sensational stories of bitter sectarian violence that shock one's sensibilities. It has been a long established rule of argumentation that 'he who affirms must prove'. To single out religious arguments and viewpoints to be excised from public deliberation or to be subject to a disproportionately onerous burden of translation without more in the way of justification and evidence, seems manifestly suspect. This is especially so in light of the fact that history is replete with examples of tremendous bloodshed, wars and societal upheavals caused by nationalism, patriotism, various political and socio-economic ideologies, economic hegemony and self-interest among other secular motivations/viewpoints. ${ }^{6}$ Yet these secular

\footnotetext{
${ }^{1}$ John Rawls, Political Liberalism, at page xxvi.

${ }^{2}$ Ibid.

${ }^{3}$ See Will Kymlicka, "Multicultural Citizenship: A Liberal Theory of Minority Rights", Clarendon Press, Oxford, 1995, at page 192.

${ }^{4}$ Ibid, Kymlicka in reference to the liberal opposition to the demands of ethnic and national minorities asserts that their fears are "implausible" and evidence an "underlying ignorance or intolerance of these groups".

${ }^{5}$ A few examples are the role religious values played in galvanizing opposition against the slave trade and slavery, against the Holocaust, against Jim Crowism in the United States, against Apartheid in South Africa, and in the Solidarity movement in Poland.

${ }^{6}$ Wolterstorff, The Role of Religion in Political Issues, p. 80
} 
viewpoints have not been singled out for excision from public deliberation in fact many liberal democratic states actively seek to promote and foster an ethic of nationalism and patriotism. In fact some of these viewpoints arguably have a good claim to fall within the rubric of 'political values'. Many liberal commentators appear to be able to give due consideration to the potential for good that such ethics possess notwithstanding the potential for serious negative consequences if promoted in excess or practised awry. Indeed the rule of thumb is that anything in excess has harmful effects. It can scarcely be denied that the unmitigated pursuit of self-interest has wrought negative and disastrous consequences affecting democratic peace and stability. In recent times the economic meltdown in the United States which was felt the world over, has been attributed to greed or the unmitigated pursuit of self -interest by many commentators. ${ }^{1}$ Notwithstanding this fact rational self-interest continues to be treated as "...the organizing concept for inquiry into all social relations, whether the economy, family, or politics". ${ }^{2}$ In the same way secular ideologies/viewpoints can be recognized based on their merits notwithstanding proven instances of their deployment for harm rather than good, the same way religious viewpoints ought to be recognized as meritorious and deserving of consideration in light of their utility for good. What is good for the goose is also good for the gander. To do otherwise is to perpetuate an unjust and unfair imbalance and the perception of injustice and unfairness by the religious citizens of a polity is liable to fan the flames of resentment and discontent which are inimical to societal peace and democratic stability. Religious citizens demand a place at the table of public deliberation and they inevitably demand to be heard in a language wherein their religious values and weltanschauung is inextricably woven. Rawlsian public reason far from safeguarding stability and solidarity in liberal democratic states is likely to result in

\footnotetext{
${ }^{1}$ See for example,, Cate Reavis, "The Global Financial Crisis of 2008 - 2009: The Role of Greed, Fear and Oligarchs" (22 July 2009) online: MIT Sloan Management School of Management online <https://mitsloan.mit.edu/MSTIR/worldeconomy/Crisis-2008-2009/Documents/09-093\%20The\%20Financial\%20Crisis\%20of\%202008-2009.pdf>. Also Martin Beckford, "Archbishop of Canterbury: Greed has caused global financial crisis" The Telegraph (15 October 2008) online: The Telegraph <http://www.telegraph.co.uk/news/3204026/Archbishop-of-Canterbury-Greed-has-caused-global-financialcrisis.html>

${ }^{2}$ Jennifer Nedelsky, "Legislative Judgment and the Enlarged Mentality: Taking Religious Perspectives", in Richard Bauman \& Tsvi Kahana, eds., The Least Examined Branch: The Role of Legislatures in the Constitutional State(Cambridge University Press, 2006) 93 , at page 101.
} 
instability and dissension due to the inevitable clash between the demands of religious voices to be heard and the Rawlsian prescription to bracket them from public discourse.

A further impediment to the forward march of liberal values is the fact that the liberal voices that call for bracketing religious reasoning from the public sphere akin to Rawls are influential within the liberal tradition. These voices are so influential that to many they come to define the liberal take on religious reasoning in public discourse. As a result of the popularity of this view liberal values appear unpalatable to many prospective subscribers who wish to stay true to their religious beliefs. To many who view public reason's prescription as part and parcel of liberalism, liberal values are to be eschewed as the eraser of religious identity and a usurper hell-bent on the installation of secularist hegemony. One may respond by saying that a certain segment of a group/population will always be resistant to reform or change of any sort and therefore some religious citizens are to be expected to distrust liberal values. This notwithstanding I maintain that the fact that the inclination to bracket religious reasoning from public deliberation tends to be identified with liberalism is a 'public relations' impediment as it were and it need not be so. It is certainly inimical to liberalism's campaign to win "hearts and mind". Liberal theorists certainly have to find a better way to engage with religion and to put it more broadly-"culture". ${ }^{1}$ As I will argue in this paper, there is a better way. The prescription to bracket religious reasoning from public discourse is not a sine qua non of liberal democracy. In many ways as suggested earlier, this prescription is contrary to liberal values and there are other more eminently suitable conceptions in relation to how public deliberation may proceed in a respectful manner that conduces to the maintenance of democratic stability and the advancement of democratic values. Such a conception is the "enlarged mentality" as promoted by the scholar, Jennifer Nedelsky, which I will argue for in pages to come.

\footnotetext{
${ }^{1}$ Scholars such as Will Kymlicka in "Multicultural Citizenship: A Liberal Theory of Minority Rights", Clarendon Press, Oxford, 1995 , argue that liberal theorists ought to re-engage with "culture" particularly the demands of cultural minorities to recognition of their differentiated citizenship entitlements. According to Kymlicka the popular liberal approach is to avoid the issue or oppose the demands of minority groups due to concerns about stability and solidarity rather than from a principled position grounded in liberal values.
} 


\section{Chapter 2: A Better Way: Jennifer Nedelsky's thesis on the "Enlarged Mentality"}

\section{Part 2 (a): The Enlarged Mentality Introduced}

Professor Nedelsky's thesis on “the Enlarged Mentality” builds upon Hannah Arendt's theory of political judgment. ${ }^{1}$ She asserts that two of the most important functions of a legislature in a constitutional democracy are collective deliberation about the common good and the articulation and evolution of core constitutional values. ${ }^{2}$ She states that these legislative functions require judgment which in turn requires the exercise of the 'enlarged mentality'.3 According to her the exercise of the 'enlarged mentality' involves taking the perspective of others into account in the formation of one's judgment. She points out that this 'enlarged mentality' does not mean merely canvassing another's opinions but involves taking on the imaginative capacity to put oneself in the position of another. ${ }^{4}$ Nedelsky posits that the "enlarged mentality' requires a capacity to reflect on optimal conceptions of core values which in turn requires the ability to think in terms larger than self-interest. ${ }^{5}$

\section{Part 2(b): Accommodation Rather than Preclusion}

Nedelsky proffers that it is undemocratic to exclude any group from the range of perspectives that are considered in debating about public policy. ${ }^{6}$ She argues that the optimal exercise of the "enlarged mentality' in a democracy therefore requires taking into account the perspective of those who see policy issues in religious terms. ${ }^{7}$ She asserts that religious based argument ought to be invited into the public forum of legislative deliberation. ${ }^{8}$ Nedelsky's thesis does not favour secular worldviews over religious

\footnotetext{
${ }^{1}$ Jennifer Nedelsky, Legislative Judgment and the Enlarged Mentality: Taking Religious Perspectives" in Richard Bauman \& Tsvi Kahana, eds., The Least Examined Branch: The Role of Legislatures in the Constitutional State (Cambridge University Press, 2006) 93 at 93.

${ }^{2}$ Ibid, at page 123 .

${ }^{3}$ Ibid.

${ }^{4}$ Ibid, at page 98 .

${ }^{5} \mathrm{Ibid}$, at page 96.

${ }^{6}$ Ibid, at page 100 .

${ }^{7}$ Ibid.

${ }^{8}$ Jennifer Nedelsky, Legislative Judgment and the Enlarged Mentality: Taking Religious Perspectives" in Richard Bauman \& Tsvi Kahana, eds., The Least Examined Branch: The Role of Legislatures in the Constitutional State (Cambridge University Press, 2006) 93 at 94.
} 
worldviews or vice versa and does not confer a disproportionately onerous burden on any particular comprehensive doctrine. To that extent it may be said to be equitable in its treatment of the citizenry of a polity. It invites all comers to the seat of public deliberation on the condition that they assume a respectful posture towards the other founded on a normative framework of civility and the will to exercise the imagination and imagine themselves in the position of the other. To that extent it may be said to be facilitative of consensus building and genuine democratic dialogue. It is far more likely that a context where citizens are allowed to freely ventilate their world views in a normative framework of civility and a willingness to pursue mutual understanding will engender solidarity and genuine dialogue. Indeed the model of intercultural exchange promoted by many liberals is in keeping with the understanding that the fostering of the capacity to put oneself in the position of the other is facilitative of a genuine conversation between persons with different viewpoints/worldviews. Converse to public reason the 'enlarged mentality' proposes to recognize the citizen as she is-in her particularity inclusive of the particular way she reasons/sees the world and does not privilege any particular world view. The privileging of world views in and of itself or the perception thereof is likely to be inimical to consensus building and genuine dialogue as consensus building and genuine dialogue tend to proceed where the interlocutors perceive themselves as equals. The perception of inequality of burdens is likely to create a serious disincentive for genuine dialogic engagement-one party may likely feel that her arguments is perceived as inherently inferior while the other may consider his argument as inherently superior.

\section{Part 2(c): A Focus on Dialogic Engagement}

Nedelsky posits that a person's exercise of the enlarged mentality depends on the extent to which he or she has informed him/herself about the standpoint he or she wishes to consider. ${ }^{1}$ Thus it is clear that the 'enlarged mentality' requires that judgment be made from an informed perspective. She proffers that if one truly wants to exercise judgment from a person's religious perspective, one has to try to understand it

1 Jennifer Nedelsky, Legislative Judgment and the Enlarged Mentality: Taking Religious Perspectives" in Richard Bauman \& Tsvi Kahana, eds., The Least Examined Branch: The Role of Legislatures in the Constitutional State (Cambridge University Press, 2006) 93 at page 98. 
according to the religious terms in which it is understood. ${ }^{1}$ She therefore suggests that in many cases the translation of these religious values into secular ones would be insufficient for the exercise of judgment using the 'enlarged mentality'. ${ }^{2}$ Nedelsky states that notwithstanding its insufficiency in many cases, translation is still a useful exercise. ${ }^{3}$ She asserts that attempting translation enables both the religious speaker and listener seeking to exercise judgment to notice where the translation is difficult or inadequate. ${ }^{4}$ She further states that one cannot really take a person's perspective into account, religious or otherwise, without trying to understand how it matters to them. ${ }^{5}$ She points out that not every religious adherent will want to translate her religious core understanding of constitutional values. ${ }^{6}$ The thesis on the "enlarged mentality" has the advantage of earthiness in that it seems to cohere with real world experience in a liberal democratic polity. Some citizens attempt and will attempt translation of their religious reasoning while others will simply choose not to-the 'enlarged mentality' unobtrusively treats and lives with either reality. Rather than pushing against the tide of practice the 'enlarged mentality' proposes to utilize the imperfect attempts at translation for its didactic potential in terms of signaling where there are problems in conveying reasons. The enlarged mentality is much more likely than public reason to foster free, frank and genuine democratic dialogue in that it places no barrier on the type of reasoning that is acceptable in the public sphere while public reason does.

\footnotetext{
${ }^{1}$ ibid, at page 105.

${ }^{2}$ Jennifer Nedelsky, Legislative Judgment and the Enlarged Mentality: Taking Religious Perspectives" in Richard Bauman \& Tsvi Kahana, eds., The Least Examined Branch: The Role of Legislatures in the Constitutional State (Cambridge University Press, 2006) 93 at page 105.

${ }^{3}$ Ibid.

${ }^{4}$ Jennifer Nedelsky, Legislative Judgment and the Enlarged Mentality: Taking Religious Perspectives" in Richard Bauman \& Tsvi Kahana, eds., The Least Examined Branch: The Role of Legislatures in the Constitutional State (Cambridge University Press, 2006) 93 at p.105.

${ }^{5}$ Ibid.

${ }^{6}$ Ibid, at page 122 .
} 


\section{Part 2(d): Managing the Difficulties Associated With Religious Arguments and Reaping the Fruits}

\section{of Religious Arguments}

Nedelsky acknowledges that there are “...Deep tensions involved in engaging with religiously based argument in public forums". She submits however that the solution of keeping religious arguments “...Sequestered in the private realm, was never optimal and is no longer viable". ${ }^{2}$ She argues that the tensions can be worked through by a respectful dialogic practice that incorporates the enlarged mentality. ${ }^{3}$ She suggests that the view of religion as the antithesis of reason serves to fuel hostility and contempt towards religion. ${ }^{4}$ Nedelsky posits that in many cases religious adherents wish to contribute a sense of moral imperative and not necessarily divine command to collective deliberation. ${ }^{5}$ She acknowledges that religious adherents by and large do not hold out their foundational religious beliefs out to debate when they based their policy views on them. ${ }^{6}$ She asserts that similarly many who rely on liberal commitments base their policy views on a casual reliance on the liberal commitment to equal moral worth. ${ }^{7}$ Nedelsky's thesis does not understate the fact that there are manifest problems involved in engaging with religious reasoning but neither does it overstate it. Rather than painting an excessively dim picture of a reality where religious arguments play a role in public deliberation it prescribes how with the right kind of respectful practice founded on public spirited deliberativeness, the problems associated with religious reasoning and the existence of a plurality of perspectives may be minimized.

Nedelsky suggests that religious perspectives tend to be familiar with the notion of pursuing the public good and therefore may lend support to the public spiritedness vital to its pursuit. ${ }^{8}$ She argues that by invoking attention to the public good, religious perspectives may provide an important countervailing

\footnotetext{
${ }^{1}$ ibid, at page 123 .

${ }^{2}$ Ibid.

${ }^{3}$ Ibid.

${ }^{4}$ Ibid, p.113 in original article.

${ }^{5}$ Jennifer Nedelsky, Legislative Judgment and the Enlarged Mentality: Taking Religious Perspectives" in Richard Bauman \& Tsvi Kahana, eds., The Least Examined Branch: The Role of Legislatures in the Constitutional State (Cambridge University Press, 2006) 93 at p.115.

${ }^{6}$ Jennifer Nedelsky, Legislative Judgment and the Enlarged Mentality: Taking Religious Perspectives" in Richard Bauman \& Tsvi Kahana, eds., The Least Examined Branch: The Role of Legislatures in the Constitutional State (Cambridge University Press, 2006) 93 at p.113-114.

${ }^{7}$ ibid, at page 113 .

${ }^{8}$ Ibid, at page 100 .
} 
norm against the rational self-interest that seem to hold sway at present. ${ }^{1}$ She posits that religious discourse frequently is moral argument and that by widely engaging with such arguments, the public my may benefit in the sense of the promotion of the desirability of ethical public policy. ${ }^{2}$ She suggests that the inclusion of religious arguments enables a democratic polity to realize the democratic promise of including the perspectives of all its citizens. ${ }^{3}$ She asserts, “...Judgments are only valid for those whose perspectives one has taken into account." ${ }^{, 4}$ She argues that the status quo witnesses a situation where strident and negative religious voices have disproportionate volume and come to characterize religious argumentation. ${ }^{5}$ She posits that if the norms of public discourse were to invite religious argument from a wide variety of perspectives the distorted picture of religious argumentation may change. ${ }^{6}$ The strident and negative religious voices could come to be seen as one among many diverse examples of religious argument, and the public discourse re fundamental policy decisions could benefit from the constructive insights religious perspectives have to offer. $^{7}$ The 'enlarged mentality' approach has the distinct advantage of being welcoming of the distinct offerings of religious reasoning. As Habermas suggests, religious traditions tend to have a special power to articulate moral intuition. Therefore unlike public reason with its push to bracket religious reasoning from public discourse the enlarged mentality does not propose or require that a society cut itself off from key resources for the creation of meaning and culture. According to Nedelsky:

\footnotetext{
${ }^{1}$ bid, at page 101.

${ }^{2}$ Ibid.

${ }^{3}$ Ibid, p.100. Nedelsky says "In a democracy no group should be excluded from the range of perspectives legislators try to consider".

${ }^{4}$ Ibid, at page 100 .

${ }^{5}$ Ibid, at page 94.

${ }^{6}$ Ibid.

${ }^{7}$ Jennifer Nedelsky, "Legislative Judgment and the Enlarged Mentality: Taking Religious Perspectives" in Richard Bauman \& Tsvi Kahana, eds., The Least Examined Branch: The Role of Legislatures in the Constitutional State (Cambridge University Press, 2006) 93 at page 94.
} 
"Public debate open to religious argumentation would then dispel prejudice, open up awareness of crosscutting interests, and avoid false characterization of issues around a secular-religious dichotomy". ${ }^{1}$

It is arguable that public reason with its restraint on the use of religious reasoning and requirement that such reasoning be translated into 'proper political values' poses the risk of the political ghettoization of religious citizens in that the restriction may create a perception and reality where the deeply felt religious reasoning of citizens are not welcome in the public political square. On the other hand the "enlarged mentality" may be said to fully welcome religious citizens into the political square. In that the approach prescribed by Jennifer Nedelsky's thesis on the 'enlarged mentality' recognizes that full democratic participation is only permitted where the individual is able to make his or her contribution to public deliberation about the public good without a sense that her true and deep-felt views are viewed as unworthy or taboo.

Unlike the prescriptions of public reason, the demands the 'enlarged mentality' places on the citizen in terms of her manner of reasoning when he/she comes to the table of public deliberation is more proportionate in relation to the concern for the maintenance of democratic peace and stability. It recognizes that there will always be differences in reasoning and argumentation in the context of liberal democracy but that the answer is not to uncritically and summarily bracket any particular specie of reasoning from public deliberation. It targets the root of the problem by seeking to institute a normative framework for reasoning founded on civility, mutual respect and public spirited deliberativeness. Public reason on the other hand points out religious reasoning as 'the bad fruit liable to spoil the entire bunch' and in effect uses a machete to do the work for which only a scalpel is needed.

\footnotetext{
${ }^{1}$ Jennifer Nedelsky, "Legislative Judgment and the Enlarged Mentality: Taking Religious Perspectives" in Richard Bauman \& Tsvi Kahana, eds., The Least Examined Branch: The Role of Legislatures in the Constitutional State (Cambridge University Press, 2006) 93, at page 110.
} 


\section{Part 2(e): Democratic Pluralism Embraced Not Transcended Or Transformed}

Nedelsky's thesis on the enlarged mentality comports with the dialogic conceptualization of democracy sketched out earlier in this paper. ${ }^{1}$ Rather than seeing the disagreements and differences that inevitably subsist on account of the reality of plurality, as a reality to be transcended or avoided, Nedelsky's enlarged mentality conceives of meaningful exchange across the lines of difference. Nedelsky's enlarged mentality toes the lines of realism and idealism. It toes the lines of realism in that it recognizes that there is the ever present risk of serious conflict and instability on account of the conflicting conceptualizations of the public good. It also recognizes that from time to time we in fact witness co-operation and mutual and beneficial exchange across the lines of difference, in spite of such conflicting conceptualizations. It is idealistic in that it seeks to promote the co-operation, and mutual and beneficial exchange that sometimes results as a mainstay in democratic countries rather than the bitter conflicts and even clashes that also manifest at times. The enlarged mentality reflects the insight that the reality of difference and disagreement on account of democratic pluralism is a thing to be reckoned with rather than avoided. It recognizes that these differences cannot really be transcended as there are no 'neutral' 'political values' to be had. Inevitably the public determination concerning an issue or as I style it, 'the public verdict', reflects a decision that this or that view is more convincing than the rest. The various comprehensive doctrines or conceptualizations of morality existing in society are inevitably the fodder utilized in the processing of democratic decisions. Such decisions are inevitably informed by some moral understanding and that moral understanding is not freestanding and isolable from the moral understandings possessed by citizens in a given society. Nedelsky's enlarged mentality rather than seeking to mask this reality in a bid to ensure consensus and co-operation proffers a way to ensure that public deliberation is conceived as a dialogic engagement and therefore reflective of a respectful practice that incorporates our capacity to imagine ourselves in the position of the other. Nedelsky's enlarged mentality therefore reminds that in order to truly deliberate we must be deliberative in other words we must seek to inform ourselves fully in

\footnotetext{
${ }^{1}$ See page $49-52$ above.
} 
respect of the various perspectives that may inform our decision. Therefore we must take into consideration the perspective of others and as Nedelsky points out, we cannot really take the perspective of another into account without trying to understand how it matters to them. ${ }^{1}$ Nedelsky's enlarged mentality thus sees democratic pluralism as a continuous dialogic engagement, a phenomenon of movement and change where difference may generate a productive exchange of meaning useful for consensus building and co-operation.

Nedelsky's enlarged mentality appears to recognize that the proposal to bracket certain doctrinal perspectives in the name of neutrality or transcendence of conflict is not feasible. In other words there is no room for epistemic abstinence. A choice is inevitable therefore the proposal to bracket comprehensive moral and religious perspectives is inevitably a choice to transform public deliberation in such a way that one or the other predominates. Nedelsky clearly has the insight that the proposal to bracket such perspectives rather than conducing to stability may actually undermine stability in that certain radical voices will not be moved and as such may likely come to represent the moral/religious voice in public deliberation. In light of this insight Nedelsky suggests that since transcendence is not feasible the way to manage the risk of conflict is by a normative practice of respectful dialogic engagement where the religious and moral views of citizens are accommodated within public deliberation rather than precluded.

\section{Part 2(f): The Sites of The Enlarged Mentality And The Questions To Which It Applies.}

Nedelsky's thesis on the enlarged mentality looks primarily on the legislature of a constitutional state in its role as a locus of collective deliberation about the common good, and its role as a participant in the ongoing, dynamic, and contested definition of core constitutional values. ${ }^{2}$ She links these roles of a legislature with the ordinary practices of citizens. ${ }^{3}$ According to Nedelsky the meaning of core constitutional values such as equality and dignity require ongoing formulation both at a high level of

\footnotetext{
${ }^{1}$ Jennifer Nedelsky, "Legislative Judgment and the Enlarged Mentality: Taking Religious Perspectives" in Richard Bauman \& Tsvi Kahana, eds., The Least Examined Branch: The Role of Legislatures in the Constitutional State (Cambridge University Press, 2006) 93 at page 106.

2 Ibid, at 93.

${ }^{3}$ Ibid.
} 
abstraction and in terms of concrete application in particular cases. She asserts that the courts, the legislature and the whole political system, including the casual public discussions and deliberations of citizens play a role in this process. ${ }^{1}$ She submits that the legislatures should be in ongoing interaction with the courts and all other forums of public deliberation about the meaning of the core values. ${ }^{2}$ Nedelsky therefore seems to conceive of the deliberative processes of the legislature including its use of judgment as a model for public discourse generally.

It is inferable that unlike John Rawls' conception of public reason Nedelsky conceives of the 'enlarged mentality' as applicable to broader public deliberation about the common good rather than a narrow focus on core constitutional values. Nedelsky's conception therefore has the advantage of obviating the particular difficulty of distinguishing constitutional essentials and matters of basic justice which as I have argued before may prove problematic for the application of Rawlsian public reason.

Nedelsky conceives of the legislature as in an ongoing interaction with the courts, and with all other forums of public deliberation. To the extent that she conceives of the legislature in this way and she treats the legislature as a model for public deliberation among the citizens of a polity and in other forums of public deliberation, it is inferable that she conceives of the 'enlarged mentality' as applicable broadly with respect to public discourse. Nedelsky does not provide a definition of the public forum as she conceives it to be and she clearly states that she contemplates even casual public discussions as these play a role in relation to public deliberation about the meaning of core constitutional values. I opine that she deliberatively left the concept of the 'public forum' open in light of the fact that the reality of modern democracy is such that such concepts as 'the public forum' and the 'public sector' do not lend themselves to hard and fast circumscription. Take the example of the Catholic Church in Ontario, Canada. Ordinarily as conceived as a Christian denomination one would scarcely deny that it is a private concern but in a particular guise, the Catholic School Board of Toronto, one would scarcely deny that it is public.

\footnotetext{
${ }^{11}$ Jennifer Nedelsky, "Legislative Judgment and the Enlarged Mentality: Taking Religious Perspectives" in Richard Bauman \& Tsvi Kahana, eds., The Least Examined Branch: The Role of Legislatures in the Constitutional State (Cambridge University Press, 2006) 93 at page 95. 
Nedelsky's broad conceptualization of the 'public forum' seems flexible enough to take in cases such as these where a particular institution may manifest itself as 'public' in one sense and 'non-public' in another.

It is inferable that Nedelsky's conception of the public forum is much broader than Rawls. For one she does not conceive of a distinction between a 'public political forum and a 'non-public political culture, she speaks only of 'public discourse', 'public deliberation' and 'public discussion'. Therefore it is reasonable to infer that Nedelsky's conception of the media is broad enough to encompass the media. Nedelsky certainly conceives of an interactive engagement between the legislature and all other forums of public deliberation and it is undeniable that in modern democratic countries the media is a forum of public deliberation. I submit that Nedelsky's broad conception of the public sphere as encompassing all other forums of public deliberation including the press is evidence of her superior grasp in relation to the reality of modern democracy compared to Rawls. The significant deficiency of Rawls' conception of the public sphere evidenced by his description of the media as merely part of the non-public political culture, and the resultant incoherency of his thesis on public reason, cannot be over-emphasized. The fact that Nedelsky's thesis seems to contemplate the media as a site for the application of the enlarged mentality is a distinct advantage that her thesis possesses over that of Rawlsian public reason. Undeniably the 'enlarged mentality' must inform the processes of the media in order for it to do its work of contributing to the development of optimal contemporary norms of public discourse as Nedelsky envisages, and her conceptualization of the 'public sphere' allows for this. 


\section{Chapter 3: Canadian Constitutional Values and Their Implications for the Inclusion of Moral and Religious Arguments in Public Deliberation}

\section{Constitutional Values Defined}

The legal scholar, Owen Fiss, instructs that the values we find in a constitution such as liberty, equality and freedom of speech are ambiguous and capable of a great number of different meanings. ${ }^{1}$ This notwithstanding it is important for me to put forward a workable definition of what I mean by 'Canadian constitutional values'. The scholar, Christian Starck, provides a helpful definition of 'constitutional values', he defines it as: "The norms and cultural customs that govern our social interactions....they are also the foundations on which the basic rights rest". ${ }^{2}$ The jurist, Aharon Barak in defining the ‘constitutional values' of democratic societies, eloquently asserts:

These values reflect the constitution's democratic character, the basic values and aspirations of the legal system, and its constitutional law. They constitute it credo and the environment of every legal norm. They are the normative umbrella spread over every piece of legislation. ${ }^{3}$

In light of the insights provided by both Starck and Barak, we may conclude that constitutional values are the foundational norms and basic presuppositions that govern a particular society. Constitutional values are conventionally conceptualized as abstractions of constitutional rights and freedoms. ${ }^{4}$ Constitutional rights and freedoms on the other hand are conventionally conceptualized as more specific and circumscribed expressions of constitutional values which largely apply to the relationship between the

\footnotetext{
${ }^{1}$ Owen Fiss, "The Forms of Justice" (1979) 93 Harvard Law Review 1 at page 1.

${ }^{2}$ Christian Starck, "Human Rights and Private Law in German Constitutional Development" in Daniel Friedmann and Daphne Barak-Erez, eds., Human Rights in Private Law (Oxford: Hart, 2001) at page 103.

${ }^{3}$ Aharon Barak, Purposive Interpretation In Law (Princeton: Princeton University Press, 2005) at page 256.

${ }^{4}$ See for example Justice Rand's exposition of constitutional values and constitutional freedoms in Saumur v. Quebec, [1953] 2 S.C.R 299 at 329.
} 
individual and the state. ${ }^{1}$ Neither Rawls' thesis on public reason nor Nedelsky's thesis on the enlarged mentality envisages legal constraints on public deliberation in order to achieve the optimal norms of public deliberation they envisage. ${ }^{2}$ Therefore the prescriptions of Rawlsian public reason and Nedelsky's enlarged mentality are not likely to give rise to constitutional actions alleging breach of Charter rights and freedoms. It is indubitable however that the prescriptions of Rawlsian public reason and Nedelsky's enlarged mentality are bound to impinge on the constitutional values of the democratic polities. Indeed the operability of the two approaches in a particular democratic polity depends on whether it comports with the constitutional values of that particular polity. Therefore in light of the fact that we propose to examine the operability of the two approaches in respect of Canada, it is appropriate to do an assessment of the implications of Canadian constitutional values with respect to moral and religious argumentation in public deliberation. I do not suggest that the discussion that will follow is an exhaustive one; I will discuss some of the constitutional values that I opine are clearly impugned in terms of the prescriptive norms for public deliberation.

\section{The Canadian Charter's Preamble}

The Canadian Charter of Rights in its very first words-its preamble, unmistakably declares its moral sensitivity, it declares: "Whereas Canada is founded upon principles that recognize the supremacy of God and the rule of law... "3 The scholar, Lorne Sossin provides a very illuminating analysis of the implications of the reference to the 'supremacy of God' in the Canadian Charter of Rights. ${ }^{4}$ Sossin in his paper argues for giving meaning to this reference as “...an animating principle of constitutional interpretation, on a par with the rule of law with which it is paired". ${ }^{5}$ In line with Sossin's argument one wonders why the Canadian Supreme Court has demonstrably given meaning to the reference to the rule of

\footnotetext{
${ }^{1}$ Ibid.

'See Jonathan Chaplin, “Beyond Liberal Restraint: Defending Religiously-based Arguments in Law and Public Policy,' (2000) 33:2 U.B.C.L.Rev. (Special Issue on Law, Morality and Religion) 617, at 618. He states that few if any liberal constraints demand legal and constitutional restraints on religious argumentation.

${ }^{3}$ Preamble to the Charter of Rights and Freedoms, Part I of the Constitution Act, 1982, being Schedule B to the Canada Act 1982 (U.K.), 1982, c.11

${ }^{4}$ See Professor Lorne Sossin, "The 'Supremacy of God', Human Dignity and the Charter of Rights and Freedom” (Draft, February 2, 2003) online: University of Toronto < www.law.utoronto.ca/documents/Sossin/supremacyofgod.doc>, pages 1-15. ${ }^{5}$ Ibid, at page 2 .
} 
law as an animating principle of constitutional interpretation and yet shied away from doing the same in relation to the reference to the supremacy of God. ${ }^{1}$ The preamble invokes both the supremacy of God and the rule of law and there is no reason to accept one and reject the other. Sossin asserts that:

The supremacy of God should be seen as a twin pillar to the "rule of law" - as a moral complement to the descriptive protections and rights contained in the Charter. ${ }^{2}$

I agree with Sossin, certainly the preamble to the Charter must be hearkened to as it speaks in a narrative, deliberative and aspirational tone and appeals to both the hearts and minds of Canadian citizens. ${ }^{3}$ In line with Sossin, I submit that the reference to the supremacy of God and the rule of law in the preamble is an invocation to recognize that the descriptive protections afforded by the Charter have their fundament in moral authority in that they are reflective of our deep affirmation of the moral worth and inherent dignity of all people. ${ }^{4}$ Therefore the moral sensitivity of religious beliefs is not a feature unique to such beliefsone operative to demand sequestration from other types of argument such as 'legal', 'secular' and 'political' arguments. These other types of arguments are in many ways morally sensitive as well. Nedelsky supports this point. She suggests that just as it is that generally when people offer religiously based arguments they do not invite a debate about their underlying religious commitments, it is so when people make secular arguments about the requirements of equality for example-they do not invite a debate about the equal moral worth of human beings. ${ }^{5}$ Nedelsky states:

...The fact that people are not holding their foundational religious beliefs out for debate when they ground their policy views on them does not distinguish them from those who casually rely on

\footnotetext{
$\mathbf{1}^{\mathbf{1}}$ The Supreme Court of Canada has invoked the 'rule of law' as an animating principle of constitutional interpretation in numerous cases for example Reference re Secession of Quebec, [1998] 2 SCR 217 at paragraphs 145-151 and Re Manitoba Language Rights, [1985] 1 SCR 721 at paragraphs 67-107

${ }^{2}$ See Professor Lorne Sossin, "The 'Supremacy of God', Human Dignity and the Charter of Rights and Freedom" (Draft, February 2, 2003 online: University of Toronto <www.law.utoronto.ca/documents/Sossin/supremacyofgod.doc>, at page 3.

${ }^{3}$ See Kent Roach, "The Uses and Audiences of Preambles in Legislation", (2001) 47 McGill Law Journal 129, at page 158.

4 See Professor Lorne Sossin, "The 'supremacy of God', Human Dignity and the Charter of Rights and Freedom”(Draft, February 2, 2003, available at <www.law.utoronto.ca/documents/Sossin/supremacyofgod.doc>, at page 6.

5 Jennifer Nedelsky, "Legislative Judgment and the Enlarged Mentality: Taking Religious Perspectives", in Richard Bauman \& Tsvi Kahana, eds., The Least Examined Branch: The Role of Legislatures in the Constitutional State(Cambridge University Press, 2006) 93 , at page 113.
} 
the liberal commitment to equal moral worth. Most of what is up for debate is about what flows from a commitment to, say, equality, not the underlying commitment itself, whether secular or spiritual. $^{l}$

Charter values themselves may be said to be expressions of beliefs the premises of which are not up for debate. Canadian jurisprudence establishes that 'human dignity' is a Canadian Charter value and as Professor Sossin asserts, the concept of human dignity is inherently subjective and:

Every attempt to describe its essence or apply it as a constitutional principle embodies a claim regarding morally good and socially just relations between individuals, groups and the state. ${ }^{2}$

Professor Sossin asserts further that inevitably adopting a particular understanding of human dignity requires a leap of faith. ${ }^{3}$

The Preamble's declaration that 'Canada is founded upon principles that recognize the supremacy of God' at the most conservative interpretation bellows the fact that moral and religious values are of profound importance to the Canadian polity and ought to be reflected in public deliberation in Canada. Therefore Rawlsian public reason's prescription that moral and religious views ought to be bracketed from public deliberation in relation to constitutional essentials and matters of basic justice, clearly go against the grain of this unmistakable declaration of Canada's founding values. Nedelsky's enlarged mentality on the other hand being accommodative of moral and religious views comports with the value of moral and religious reasoning and argumentation as seemingly extolled by the Charter's Preamble.

\footnotetext{
${ }^{1}$ Ibid, page 113-114.

${ }^{2}$ See Professor Lorne Sossin, "The 'supremacy of God', Human Dignity and the Charter of Rights and Freedom"(Draft,

February 2, 2003, available at www.law.utoronto.ca/documents/Sossin/supremacyofgod.doc, at page 4.

${ }^{3}$ Ibid.
} 


\section{The Constitutional Value of Human Dignity}

The eminent jurist, Aharon Barack, asserts that human dignity is the freedom of the individual to shape his/her will, it is the freedom of choice, it regards a human being as an end, not as a means to achieve the ends of others. ${ }^{1}$ The norms that Rawlsian public reason proposes would in effect bracket religious and moral comprehensive doctrinal views from public deliberation as a result of the object of fostering consensus and democratic stability. As a result citizens would be denied the freedom to express their will in relation to the public good according to the dictates of their conscience and their deep felt aspirations. Further as we have argued in several places in this paper, the moral and religious presuppositions of the self constitute such an indelible and formative part of the self as to make it essentially an 'encumbered self' as Sandel terms it. Therefore Rawlsian public reason's preclusion of moral and religious values inferably manifests the will to derogate from the respect due to the selfhood of persons for whom their moral and religious comprehensive doctrines constitute an indelible and formative aspect of their selfhood. Rawlsian public reason in effect objectifies such selves by treating them as mere ends for the realization of the objects of consensus and democratic stability. On the other hand, it may be said that Nedelsky's enlarged mentality with its accommodativeness towards the moral and religious comprehensive doctrines of citizens, is affirmative of human dignity.

\section{The Constitutional value of Equality}

The scholars, Sharpe and Roach, assert that 'Equality' is a fundamental value in a democratic society and is one of the constitutional values of the Canadian sociopolitical order. ${ }^{2}$ Canadian courts approach the freedom of equality by essentially making three broad enquiries:

\footnotetext{
${ }_{1}^{1}$ Aharon Barack, The Judge In A Democracy (Princeton, NJ: Princeton University Press, 2006) at page 85-86.

${ }^{2}$ Robert J. Sharpe and Kent Roach, The Charter of Rights and Freedoms (Toronto: Irwin Law, 2005, at page 276-277.
} 
1. Whether the law or policy makes a formal distinction between the Claimant and others on the basis of one or more personal characteristics ${ }^{1}$;

2. Whether the Claimant is subject to differential treatment based on one or more enumerated or analogous grounds ${ }^{2}$; and

3. Whether the discriminatory treatment has the effect of perpetuating or promoting the view that the individual is less capable or worthy of recognition or value as a human being or as a member of Canadian society, equally deserving of concern, respect, and consideration? ${ }^{3}$

I take it that a similar enquiry would be apposite in evaluating whether the abstracted constitutional value of equality is impugned by particular proposals such as the normative prescriptions of Rawlsian public reason and Nedelsky's enlarged mentality. An application of the three enquiries, in order to determine whether the Rawlsian prescription to bracket religious reasons from public deliberation engages the Charter value of equality, leads to the inexorable conclusion that it does. In keeping with the first criterion, the impugned policy of bracketing religious views from public discourse unmistakably draws a distinction between religious citizens wishing to air their religious arguments in public deliberation and other citizens of secular world views, as religious citizens have a disproportionate burden in terms of meeting the Rawlsian proviso. In light of the second criterion it is evident that religious citizens are treated differentially based on religion or the analogous ground of a particular system of beliefs. In relation to the third criterion it is also evident that the benefit of participation in public discourse on the terms of their particularity is denied to them and this has the effect of promoting the view that religious citizens are less worthy of recognition as citizens. In that unlike other citizens, due to their particularity as citizens with a religious world view, they are denied the entitlement to freely contribute to public

\footnotetext{
${ }^{1}$ See Law v. Canada (Minister of Employment and Immigration), [1999] 1 S.C.R. 497, at paragraph 39.

${ }^{2}$ Ibid, the enumerated grounds are: discrimination based on race, national or ethnic origin, colour, religion, sex, age or mental or physical disability. See Canadian Charter of Rights and Freedoms, s. 15, Part I of the Constitution Act, 1982, being Schedule B to the Canada Act 1982 (U.K.), 1982, c.11.

${ }^{3}$ See Law v. Canada (Minister of Employment and Immigration), [1999] 1 S.C.R. 497, at paragraph 39.
} 
deliberation. Indeed it may be said that the public reason's prescription that religious reasons ought to be bracketed from public discourse significantly impairs the freedom of the religious citizen to shape his/her will in that he /she is denied equal opportunity to make his her/her contribution to public discourse on the basis that his/her particularity is unacceptable in the public sphere. In many ways it may be said that public reason's prescription to bracket religious views from public discourse objectifies religious citizens as a means to the end of promoting socio-political stability and solidarity on account of the view that allowing them a voice in public deliberation will be harmful to this end.

Conversely it may be said that Nedelsky's enlarged mentality does not derogate from the constitutional value of equality as it makes no distinction between religious or secular world views but seeks to accommodate various world views whether they be 'secular' or 'religious'.

Constitutional Value of Multiculturalism

Section 27 of the Canadian Charter of Rights declares that:

...it shall be interpreted in a manner consistent with the preservation and enhancement of the multicultural heritage of Canadians. ${ }^{1}$

The Multiculturalism Act of Canada which traces its lineage to the Charter value of multiculturalism states, calls upon the Canadian government to encourage the participation of all cultures "in the continuing evolution and shaping of all aspects of Canadian society... ,2

The scholar, Will Kymlicka, asserts that for meaningful individual choice to be possible, citizens of a polity need not only access to information, freedom of expression and association but they need access to a societal culture. ${ }^{3}$ He defines a societal culture as one:

\footnotetext{
1. See Canadian Charter of Rights and Freedoms, s. 15, Part I of the Constitution Act, 1982, being Schedule B to the Canada Act 1982 (U.K.), 1982, c.11

${ }^{2}$ See Canadian Multiculturalism Act, R.S.C., 1985(4th Supp.), c. 24, s. 27

${ }^{3}$ Will Kymlicka in "Multicultural Citizenship: A Liberal Theory of Minority Rights", Clarendon Press, Oxford, 1995 , at page 84.
} 
... Which provides its members with meaningful ways of life across the full range of human activities, including social, educational, religious, recreational, and economic life, encompassing both public and private spheres. ${ }^{1}$

Kymlicka suggests that the analogy between culture and religion is mistaken as it is quite possible for a state not to have an established church but that the state cannot help but give at least partial establishment to a culture when it decides which language is to be used in public schooling. ${ }^{2}$ I wish to submit however that religion and culture are analogous in that religion may plausible be brought within the definition for 'societal culture' which he provided. Further Kymlicka's reasoning in relation to religion vis a vis culture has force only where one proceeds from a narrow conceptualization of religion. If one conceives of religion as essentially a synonym for a comprehensive doctrine/world view then Kymlicka's distinction may not hold. Following from this broad conceptualization of religion, it may be argued that Canada has given at least partial establishment to a secular comprehensive doctrine/world view and therefore religious citizens are entitled to recognition of their differentiated citizenship entitlements as religious citizens. A serious commitment to multiculturalism requires a willingness to engage with religion in its manifestation as a competing word view in public deliberation about the public good and constitutional essentials. It may further be argued that religion as a competing world view is vulnerable on account of the fact that the secular orientation of the Charter (or better yet the secular orientation of conventional Charter jurisprudence) gives rise to a reality wherein secular language and values dominate public deliberation. This is buttressed by the points made by such commentators as Habermas and Nedelsky concerning the distinctive offerings of religion in terms of motivation for support of particular policies and as an aid to the articulation of moral intuitions. Rawlsian public reason's prescription to bracket religious reasoning from public discourse derogates from the recognition of multiculturalism in that it fails to acknowledge religious world views, and it deprives the society of the potential benefits of religious reasoning. Instead of signaling to the religious citizen that her particularity is treasured and

\footnotetext{
${ }^{1}$ Ibid, at page 80.

${ }^{2}$ Ibid, at page 111 .
} 
affording her the full and enlarged freedom that multiculturalism brings, public reason operates to extirpate religious reasoning from the public square and to transform it into a sphere where secular values have hegemony. On the other hand Nedelsky's enlarged mentality clearly comport with the constitutional value of multiculturalism in that it affirms the various world views of citizens and seeks to ensure that a diversity of perspectives are accommodated within public deliberation.

\section{The Constitutional value of Democracy}

In the landmark Canadian case, Reference Re Secession of Quebec, the Supreme Court of Canada made significant obiter comments in relation to the constitutional value of democracy. In that case the court declared some of the values inherent in the notion to be: “... accommodation of a wide variety of beliefs, respect for cultural and group identity, and faith in social and political institutions which enhance the participation of individuals and groups in society". ${ }^{1}$

At paragraph 68 of the judgment the Court declared:

...A functioning democracy requires a continuous process of discussion... No one has a monopoly on truth, and our system is predicated on the faith that in the marketplace of ideas, the best solutions to public problems will rise to the top. ${ }^{2}$

Based on these statements from the Supreme Court of Canada it may be said that the Canadian constitutional value of democracy does contemplate a dialogic engagement among the variety of conceptions of the good present within the Canadian polity. It is difficult to see how Rawlsian public reason's proposal to bracket comprehensive moral and religious doctrines with respect to constitutional essentials, may be reconciled with the Court's effusive rendition of the democratic value of accommodating a wide variety of beliefs and respect for group identity. The Supreme Court's elucidation of the constitutional value of democracy seems consonant with the accommodative framework propounded by Jennifer Nedelsky. Based on the court's rendition, it is inferable that the Court conceives of deliberative democracy as deliberation in relation to the varying ideas and values proffered by various

\footnotetext{
${ }^{1}$ Reference re Secession of Quebec, [1998] 2 S.C.R. 217 at paragraph 64.

${ }^{2}$ Ibid, at paragraph 68.
} 
comprehensive doctrines rather than a narrow focus on "political values". Therefore it may be concluded that Nedelsky's enlarged mentality is in keeping with the Canadian constitutional value of democracy while Rawls' enlarged mentality with its proposal to preclude rather than accommodate, derogates from it. 


\section{Chapter 4: Brief Study of the Ontario Sharia Debate in light of Rawls' Public $\underline{\text { Reason and Nedelsky's Enlarged Mentality }}$}

\section{Part 4(a): Profile of the Ontario Sharia Debate}

In 2003 a firestorm of a debate ensued in Ontario, Canada after the announcement by the recently created Islamic Institute of Civil Justice (IICJ) of plans to establish a Darul-Qada-judicial tribunal, to conduct arbitrations in Ontario according to Islamic law. ${ }^{1}$ This proposal was contexted in a reality where since 1991, arbitration decisions made according to religious laws were enforceable in Ontario courts. ${ }^{2}$ In proffering the proposal, the Islamic Institute of Civil Justice declared:

Muslim minorities living in non-Muslim countries like Canada are like wandering Bedouins for whom the Shariat applies irregardless of where or when they live. Although they are free to live according to the Divine Law to practice their faith unhindered in their homes and masjids [mosques], they have practically no say in the making of the laws of the land, and governmental institutions do not cater to their needs. ${ }^{3}$

According to the proposal, the decisions of a Muslim arbitration board would be binding on the parties and the relevant Rules of Civil Procedure would be applicable. ${ }^{4}$ The decisions would be enforceable through the government's normal enforcement agencies like any order of a Canadian court. ${ }^{5}$

There was vociferous opposition to the proposal in the Canadian media, and the debate was marked by protests in Toronto, Ontario and in other international cities. ${ }^{1}$ In some quarters, the antagonism toward the

\footnotetext{
${ }^{1}$ Trevor C.W Farrow, "Reframing The Sharia Debate", p.79, online: York University <http://osgoode.yorku.ca/osgmedia.nsf/0/D1A5E6D1FF0725408525728D006F4A07/\$FILE/ReFraming\%20the\%20Sharia\%20Arbitration\%20Debate\%20(Constitutional\%20Forum,\%202006).pdf>

${ }^{2}$ Harvey Simons, "One Law for All Ontarians”, The Star Newspaper(Tue, September 14, 2005), online: The Star <http://www.thestar.com/opinion/editorialopinion/article/860513--one-law-for-all-ontarians>

${ }^{3}$ Syed Mumtaz Ali and Rabia Mills, "Darul Qada-The beginnings of a Muslim Civil Justice System in Canada", online: <http://muslim-canada.org/DARLQADAform2andhalf.html>

${ }^{4}$ Ibid.

${ }^{5}$ Ibid.
} 
proposal was so harsh that it portrayed the proposal as presenting “...Muslim barbarians knocking on the gates of Ontario". ${ }^{2}$ A notable commentary written by a number of influential Canadian women including the celebrated writer, Margaret Attwood, characterized the debate thus:

...This is a matter of the formal separation of all religious matters from the business of the state.

This is in no way an infringement on religious freedom, which we endorse as an equally important tenet of Canadian democracy. Religion should simply remain an important part of the lives of citizens but not of public law. ${ }^{3}$

Supporters of the proposal were surprised and dismayed at the strident and in many cases caustic antagonism generated by the debate, as for more than thirteen years Jewish and Ismaili religious tribunals had been conducting analogous family law arbitrations under the existing legal framework. ${ }^{4}$ For many supporters of the proposal, the fact that opposition started to be voiced as soon as Muslims tried to establish tribunals under the existing legal framework, seemed suspect and smacked of Islamophobia. ${ }^{5}$ Among the issues engaged by the debate, such fundamental rights and interests as religious freedom, gender equality, national and cultural identity, and the role of the state in family law, figured prominently. ${ }^{6}$ The Ontario government mandated former Attorney-General, Marion Boyd, to do a study and make recommendations on the issue of family law and arbitration in Ontario, including religiousbased arbitrations. ${ }^{7}$ Boyd recommended that Ontario permit Islamic arbitrations as it did other religious arbitration. ${ }^{8}$ Among her recommendations, she recommended safeguards, that both parties to a dispute

\footnotetext{
${ }^{1}$ Trevor C.W Farrow, "Reframing The Sharia Debate", online: York University <http://osgoode.yorku.ca/osgmedia.nsf/0/D1A5E6D1FF0725408525728D006F4A07/\$FILE/Re- 
consent to arbitration and that the courts be authorized to set aside an arbitration award on the same grounds as other domestic contracts. ${ }^{1}$ Boyd asserted: "The use of arbitration may result in a ruling that is more acceptable to the individuals involved because they are more reflective of the individuals' religious and cultural values. "2

On September 11, 2005 the Ontario Government announced that it was not going to follow Boyd's recommendations. ${ }^{3}$ Ontario Premier McGuinty declared "There will be no Shariah law in Ontario. There will be no religious arbitration in Ontario. There will be one law for all Ontarians". ${ }^{4}$ He asserted that religious arbitrations "threaten our common ground," and promised that his Liberal government would introduce legislation to outlaw them in Ontario. ${ }^{5}$ In keeping with his promise, in February 2006 Ontario passed the Family Statute Law Amendment Act.

There was mixed reaction to the Premier's announcement. According to Tarek Fatah, of the Muslim Canadian Congress, "I'm just thrilled! It validates what we've been saying. It's a big victory for separation of religion and state and a huge defeat for Islamic fundamentalism". ${ }^{6}$ Riad Saloojee of The Council on American-Islamic Relations Canada (CAIR-CAN) stated:

Premier McGuinty's decision is clearly a political rather than a principled decision...He has abandoned his own process by rejecting Ms. Boyd's report and he has sent the very troubling message that public policy in Ontario will not be dictated by dispassionate and objective standards. ${ }^{\prime 7}$

\footnotetext{
${ }^{1}$ Marion Boyd, Dispute Resolution in Family Law: Protecting Choice, Promoting Inclusion, excerpted in Sharia in Ontario, Canada: Background of the debate: Government report, available at <http://www.religioustolerance.org/shariaon2.htm>

${ }^{2}$ Marion Boyd, Dispute Resolution in Family Law: Protecting Choice, Promoting Inclusion, excerpted in Sharia in Ontario, Canada: Background of the debate: Government report, available at <http://www.religioustolerance.org/shariaon2.htm>

${ }^{3}$ Trevor C.W Farrow, Reframing The Sharia Debate, p.79, available at <http://osgoode.yorku.ca/osgmedia.nsf/0/D1A5E6D1FF0725408525728D006F4A07/\$FILE/Re-

Framing\%20the\%20Sharia\%20Arbitration\%20Debate\%20(Constitutional\%20Forum,\%202006).pdf>

${ }^{4}$ Keith Leslie, McGuinty_rejects_Ontario's use of Shariah law and all religious arbitrations, Canadian Press Release, available at <http://www.nosharia.com/McGuinty\%20rejects\%20Ontario's\%20use\%20of\%20Sharia\%20Law\%20and\%20all\%20religious\%2 Oarbit>

5 ibid.

${ }^{6}$ Prithi Yelaja and Robert Benzie, "McGuinty says 'No' to Sharia Law", available at http://urbantoronto.ca/archive/index.php/t-243.html

${ }^{7}$ Abdus Sattar Ghazali, Ontario Scraps Plans for Shari ah Courts After Protests, available at http://www.ghazali.net/amp/html/ontario_scraps.html
} 
Joel Richler, Ontario region chairman of the Canadian Jewish Congress asserted, "At the very least, we would have thought the government would have consulted with us before taking away what we've had for so many years." ${ }^{1}$ The academic, Natasha Bakht, suggests that, "The irony of the date of the announcement combined with the excessive emphasis that Islam and sharia received in the religious arbitration debate in Ontario was not lost on most Muslims". ${ }^{2}$

\section{Anver Emon's Model regarding Sharia Arbitration in Ontario}

Professor Emon in his paper acknowledges the prevailing conception of Sharia as “...an inflexible and immutable code of religious rules, based on the Qur'an and traditions of the Prophet Muhammad.", According to Emon this conception is held by both non-Muslims and Muslims alike and was espoused by those involved in the debate. ${ }^{4}$ He argues that the presently prevailing conception of Islam and Sharia "...has a recent historical provenance and is the product of a particular political history." that, historically Muslim jurists converse to the presently prevailing conception of Sharia often went beyond scripture and utilized analytical discretion and reason to articulate the law. ${ }^{6}$ He states that the onset of colonialism in the Muslim World wrought significant changes in that the colonial authorities operationalized a policy of marginalization of Islamic jurisprudence. ${ }^{7}$ Emon argues that this colonial marginalizing and reductive jurisprudential approach to Islamic law resulted in the disruption of the jurisprudential approaches and the dismantlement of the legal institutions previously in play in the Muslim world. Sharia came to be perceived as fixed and rigid over time. ${ }^{8}$

\footnotetext{
${ }^{1}$ Abdus Sattar Ghazali, Ontario Scraps Plans for Shari ah Courts After Protests, available at http://www.ghazali.net/amp/html/ontario_scraps.html

2 Natasha Bakht, Were Muslim Barbarians Really Knocking On the Gates of Ontario?: The Religious

Arbitration Controversy-Another Perspective, page 1, footnote 1 .

${ }^{3}$ Anver Emon, "Islamic Law and the Canadian Mosaic: Politics, Jurisprudence and Multicultural Accommodation" (2009) 37

Can. Bar. Rev. 391, at page 395.

${ }^{4}$ ibid, p.393-394 in original article.

5 .Ibid, page 393 .

${ }^{6}$ Ibid, page 393-396.

${ }^{7}$ Ibid, p.411.

${ }^{8}$ Anver Emon, "Islamic Law and the Canadian Mosaic: Politics, Jurisprudence and Multicultural Accommodation" (2009) 37 Can. Bar. Rev. 391, at page 402.
} 
Emon's historical analysis suggests that with the dawn of independence many Muslim nations embraced Islamization campaigns and sought to assert Islamic law in its traditional form. ${ }^{1}$ However, these Islamization campaigns invariably reflected the reductive reading of Islamic law by colonial administrators. $^{2}$ Emon argues that the notion of Sharia as fixed and closed to de novo analysis is used within modern day Islam as a political strategy to support regimes and to construct national, cultural and religious identities in a post-colonial context. ${ }^{3}$ This identity is invariably conceived as in contradistinction to that of the 'Western other' and is combative of Western hegemony. ${ }^{4}$

Emon posits that the debate would have been significantly enriched by thinking of Sharia historically, methodologically, or as a rule of law system. ${ }^{5} \mathrm{He}$ submits that such an approach has potential in terms of showing how Sharia “... could be reconsidered, restructured, and made to accommodate competing Canadian legal and cultural values."

Emon proffers a model that he argues is deployable in liberal democratic states like Canada. According to this model the government would facilitate the observation of Sharia values in the area of family relations by allowing for arbitration by non-profit Muslim family service organizations that offer arbitration services for a fee. ${ }^{7}$ These arbitration services would be regulated by the government and would allow for governmental oversight via the power of judicial review by the courts. ${ }^{8}$ Emon asserts that the process of judicial review would operate as the field of dialogue where state values and religious values are balanced. ${ }^{9}$ According to Emon:

\footnotetext{
${ }^{1}$ Ibid, page 414.

${ }^{2}$ Ibid.

${ }^{3}$ Ibid, page 414-417.

${ }^{4}$ ibid, p. 417.

${ }^{5}$ Anver Emon, p.418

${ }^{6}$ Emon article, p.419.

${ }^{7}$ Emon article, p. 421-422.

${ }^{8}$ Ibid.

${ }^{9}$ Anver Emon, “Islamic Law and the Canadian Mosaic: Politics, Jurisprudence and Multicultural Accommodation” (2009) 37 Can. Bar. Rev. 391, at 422.
} 
"Ultimately Muslims who desire religiously-based family law services would have different organizations to choose from, thereby giving them a choice between competing visions of Islamic law". ${ }^{1}$

Emon addresses the concern voiced by opponents of the proposal, that Sharia arbitration would undermine the human rights of vulnerable groups such as women and children and thus would be incompatible with Canadian values. ${ }^{2}$ He asserts: "Rejecting the Arbitration model pushes oppressed women under the rug and out of public sight." ${ }^{3}$ Emon argues that his model provides an opportunity for some level of oversight via judicial review and presents an opportunity for shedding light on what is already transpiring outside the public glare in the context of the status quo of private mediation of family disputes. ${ }^{4}$ Emon argues that “...this institutional model links government and civil society in a way that balances respect for religious commitments and liberal democratic values."

It is clear that Emon does not subscribe to the view that secularization ${ }^{6}$ is desirable in a liberal democratic polity or necessary in light of constitutional values. It is inferable that Emon's model targets the kind of dialogic engagement between the government and civil society in relation to deliberation about the common good that Nedelsky promotes. Like Nedelsky, Emon suggests that religious perspectives are compatible with and may add value to deliberation about the common good in the context of democratic pluralism. Emon asserts: “...This is not a divisive model but one that legitimates a community's sense of self, it puts the state in a different position in relation to the individual which is enhancing." 7

It may be said that notwithstanding the fact that Emon argues from within the body of Islam as adherent and apologist, his arguments reflect clearly the effort to translate his message and engage other citizens who do not share his comprehensive doctrine. Indeed his arguments are not authority based but founded

\footnotetext{
1 ibid, p.424.

${ }^{2}$ Ibid, p.420.

${ }^{3}$ Anver Emon, he made this point in his response to question posed in oral lecture-October 5, 2010(Alternative Approaches, University of Toronto)

${ }^{4}$ Emon article, p.420-421.

5 ibid, p.421.

${ }^{6}$ I am using secularization as defined by the commentators Taylor and Bouchard. They define "secularization" as "the erosion of religion's influence in social mores and the conduct of individual life". See Gerard Bouchard and Charles Taylor, "Report: Building the Future, A Time for Reconciliation," Legal deposit - Bibliothèque et Archives nationales du Québec, 2008, also available at <http://www.accommodements.qc.ca/documentation/rapports/rapport-final-integral-en.pdf>, p.135

${ }^{7}$ Anver Emon's oral response to Question-"Why do you think we should the force of law to such a model?" on the occasion of his oral lecture in relation to the paper. October 5, 2010(University of Toronto).
} 
on analogizing aspects of Sharia jurisprudence and methodology with Canadian constitutional values and common law methodology. It is clear that Emon considers this manner of argumentation worthwhile for engaging with his fellow democratic citizens who do not share his comprehensive doctrine. Conscious of the prevalence of an antagonistic perspective re Sharia law, Emon articulates how it may be seen to be in keeping with Canadian constitutional values. Emon's manner of argumentation may be said to at once approach Rawl's ‘public reason' and Nedelsky's ‘enlarged mentality'. With reference to Rawlsian 'public reason', Emon's argumentation may be said to satisfy the proviso. In that it articulates his support for a proposal in keeping with his religious values by appealing to wider constitutional values, that he knows his fellow citizens would support. In relation to Nedelsky's 'enlarged mentality' Emon's manner of argumentation may be taken to reflect judgment, in that it evinces reflection on the issue from the perspective of the 'other'. This reflection on Emon's part seems evident in the way he targets his argumentation to appeal to the wider constitutional values shared by citizens in the society. Further Emon argues that Sharia is not antithetical to reason and adduces aspects of Sharia jurisprudence to this end. The fact and nature of Emon's systematic and rational argumentation evinces the benefits of opening the public forum to religious argumentation. In that it may be said to be an instantiation of Nedelsky's view that openness in the public forum may lead to a democratic polity benefiting from the constructive insights of other less heard religious voices. ${ }^{1}$ As Nedelsky suggests, this may cause a shift in the distortion caused by the predominance of loud and negative religious voices. ${ }^{2}$ Professor Emon argues that the model itself will provide similar benefits; he asserts that it "... Will allow multiple voices to express competing visions of Islamic commitments in a liberal polity.",3

I believe that Emon's model presents a democratic state like Canada with an opportunity to play a role in affirming the religious values of individuals who view their lives in terms of their comprehensive religious doctrines, while maintaining constitutional values. By so doing the state demonstrates a

\footnotetext{
${ }^{1}$ Jennifer Nedelsky, Legislative Judgment and the Enlarged Mentality: Taking Religious Perspectives, p.94.

${ }^{2}$ Ibid.

3 Anver Emon, "Islamic Law and the Canadian Mosaic: Politics, Jurisprudence and Multicultural Accommodation" (2009) 37 Can. Bar. Rev. 391, at 423.
} 
commitment to greater fulfillment of democracy's promise by displaying the will to engage in a dialogic relationship with the citizen in such a way as to recognize her particularity in terms of values and culture. I submit that such an approach reflects the recognition of the intrinsic value of human dignity which is an important Canadian constitutional value. At the heart of human dignity is the affirmation of the individual in her inherent particularity, and that the individual is an end in and of herself and not a means to achieve the end of others. Emon's model offers the democratic state the opportunity to affirm and recognize the particularity of multicultural citizens in the sense of their deeply held religious values. Further, it allows for the recognition of the fact that one can be a rational actor within the context of faith-based commitments and therefore affirms religious values while promoting constitutional values.

\section{Part 4(b): The Ontario Sharia Debate and Rawlsian Public Reason}

In applying Rawlsian public reason to the Ontario Sharia Debate it is important to determine the questions the issues raised in the Ontario Sharia debate impugned and whether the debate was one that was conducted in the public forum. As the academic Trevor Farrow points out, the debate impugned wider and far reaching public political issues such as religious freedom, gender equality, national and cultural identity, and the role of the state in family law. ${ }^{1}$ Based on this one may conclude that the debate concerned constitutional essentials and questions of basic justice and as such Rawlsian public reason is applicable to it.

As aforementioned arguments such as that proffered by Anver Emon appear to satisfy Rawls' requirement that public deliberation proceed based on invocations to political values. It is clear that much of Emon's arguments are directed at presenting the idea that Sharia may be conceived as a rule of law system and compatible with Canadian constitutional values. Emon's arguments aside, the gravamen of the Islamic Institute of Civil Justice's introductory submissions reproduced above (see page 96) was that there were significant democracy deficits experienced by the Muslim minority in Canada. Indeed the Islamic Institute of Justice sought to convey a sense of disenfranchisement in relation to the democratic decision

\footnotetext{
${ }^{1}$ Trevor C.W. Farrow, Reframing The Sharia Debate, p.79
} 
making in Ontario, and the desire to not have their religion sequestered in the private realm on account of the fact that they conceived of Sharia law being applicable irrespective of when or where they live. It may be said that this was the motive force behind the proposal. It is inferable that Rawlsian public reason is deaf and mute to such arguments. It conceives of the self as an unencumbered self distinguishable from its avowal of comprehensive moral and religious comprehensive doctrines. Further it requires that religious and moral arguments be only permitted in the public political forum if the proviso of translation into political values is met. The proposal by the Islamic Institute of Justice essentially proposed that the province of Ontario enter into a dialogic engagement with its Islamic citizens on terms of equality and respect, taking into consideration their deep-felt religious views in its own terms as "Islamic religious views" and not some ersatz manifestation. Rawlsian public reason conceives of comprehensive moral and religious doctrines as potential 'troublemakers' and 'threats' to democratic stability and would therefore not be responsive to such claims. To that extent Rawlsian public reason through its normative prescriptions would reinforce the very democratic deficits that inspired the Islamic Institute of Justice to make the proposal in the first place.

The decision reached by the McGuinty government marking the end of the Ontario Sharia debate may also be taken to be in keeping with the prescriptions of Rawlsian public reason. In that the decision reflected the will to transcend the prospect of conflict presented by the proposal to bring the religious into the light of public deliberation, on account of the interest in maintaining democratic stability. Therefore the decision reached reflected the objectionable conception that the prospect of engaging with the religious is so dangerous that avoidance/transcendence is compelled in the interest of democratic stability. The media played a significant role in how the debate was conducted and likely in relation to the actual outcome of the debate. Many newspaper articles presented the prospect of Sharia arbitration as a deathly one that would in effect bring barbarity to the shores of Canada. Rawlsian public reason does not conceive of the media as anything but a part of the non-public political culture so in light of this Rawlsian 
public reason does not appear to have any offerings in respect of the norms that ought to govern the media in relation to such issues implicating constitutional essentials.

It is not likely that the Ontario Sharia debate would have proceeded or ended differently if informed by Rawlsian public discourse. Rawls' thesis appears to comport with the general attitude of mistrust and ultimate avoidance in relation to religious values that was reflected during the debate and in the resolution reached by the McGuinty government.

\section{Part 4(c): The Ontario Sharia Debate and Nedelsky's Enlarged Mentality}

Turning to examine the Ontario Sharia debate in light of Nedelsky's thesis, it is inferable that the exercise of the 'enlarged mentality' may have allowed for unencumbered ventilation of the religious adherents deeply felt religious reasons and served to foster respectful listening on the part of all parties to the debate. This approach centered as it is on a respectful posture toward the other as a co-labourer in deliberation toward the public good, is likely to have a fostered a genuine, constructive, and deliberative dialogue in the Sharia debate. It is not naively estimated that an approach utilizing the 'enlarged mentality' would have wrought perfection in the debate, certainly strong views and offensive utterances would be expected. Nonetheless, an approach informed by the 'enlarged mentality' may have served to mitigate the level of hostility in the debate. For one, in light of the fact that the exercise of the "enlarged mentality' requires that judgment be made from an informed perspective, it is likely to have led to a situation where people actually sought out information helpful to the exercise of judgment rather than rely on mere opinion and sound bites. This openness to information and 'ascertainable evidence' may have led to serious consideration of the idea that contrary to the view that the Sharia is an inflexible code, it may be conceptualized as a rule of law system. ${ }^{1}$ Based on the propositional statement advanced by the Islamic Institute of Civil Justice it is evident that there was the lamentable perception by many Muslims that Muslim citizens have no voice in terms of public deliberation concerning the public good in $\mathrm{Canada}^{2} \mathrm{I}$

\footnotetext{
${ }^{1}$ Anver Emon, "Islamic Law and the Canadian Mosaic: Politics, Jurisprudence and Multicultural Accommodation" (2009) 37 Can. Bar. Rev. 391, at 418.

${ }^{2}$ See the excerpt from the propositional statement of the Islamic institute of Civil Justice cited on page 96 of this paper.
} 
submit that what is said about justice is applicable to democracy-'it must be manifestly and clearly be seen to be enacted'. Perception is reality. Therefore the perception of Muslims suggests the existence of democracy deficits vis a vis the participation of some Canadian citizens. As Nedelsky informs, the 'enlarged mentality' recognizes that the validity of judgment depends on taking the perspectives of all citizens into account. Thus 'the enlarged mentality' may have served to direct attention to the fact that separate and apart from the fearfulness of many citizens re the proposal, there was conspicuous need to pay serious attention to the multicultural citizenship entitlements of Muslim citizens. Accordingly a more deliberative approach to the debate may have resulted. This may have led the McGuinty government to give proper weight to the ascertainable evidence presented by the Boyd report, and a vision to depart from such evidence only if there was justification, on account of the existence of more weighty evidence. 


\section{Chapter 5: Final Act-Balancing Act}

Rawls in his theoretical exposition on public reason compares his prescriptions for precluding comprehensive moral and religious doctrines from the public sphere with the restrictive rules of evidence in criminal trials. ${ }^{1}$ The scholar, Sandel, submits that the analogy between Rawlsian public reason and restrictive rules of evidence may be suggestive of a similar balancing act in terms of a measure of cost benefit analysis. ${ }^{2}$ Sandel notes that in criminal law we arrive at rules of evidence by weighing the importance of uncovering the whole truth as against the importance of the ideals of justice that would be sacrificed if all evidence were admissible. ${ }^{3}$ He proffers that in terms of assessing Rawlsian public reason, the moral and political cost of its preclusions must be weighed against the political values they make possible. ${ }^{4}$ I propose to do a balancing exercise in light of the proportionality analysis employed in Canadian Charter jurisprudence.

In Canadian Charter jurisprudence whenever a piece of legislation is found to be in violation of a particular Charter right, Canadian courts normally proceed to inquire as to whether notwithstanding the fact that the law is in breach of the Charter, it constitutes a 'reasonable limit prescribed by law which can be demonstrably justified in a democratic society'. In the instant case there is no law to examine and the theoretical approached to public deliberation I have looked at are not understood as imposing legal constraints on the rights of citizens. I submit however, that notwithstanding this fact, the use of the balancing framework used in such cases is appropriate in light of the bid to evaluate Rawlsian public reason in light of Canadian constitutional values. For this purpose I propose to treat the Rawlsian proposal to bracket comprehensive doctrines as an analogue to a statute. Based on Rawls' rendition it may be said

\footnotetext{
${ }^{1}$ Michael J. Sandel, Liberalism and the Limits of Justice 2d ed. (Cambridge, Cambridgeshire: Cambridge University Press, 1998), at 215.

${ }^{2}$ Ibid.

${ }^{3}$ Ibid.

${ }^{4}$ Ibid.

${ }^{5}$ See Canadian Charter of Rights and Freedoms, s. 1, Part I of the Constitution Act ,1982, being Schedule B
} 
that the interest behind his proposal of the employment of public reason (our statute for the purposes of the discussion) is that of ensuring and maintaining democratic co-operation and stability. I will proceed straight to the proportionality analysis.

\section{$\underline{\text { Sufficiently important objective }}$}

Canadian constitutional jurisprudence establishes that in order to override a constitutionally protected right or freedom, the objective of a law must be of sufficient importance to warrant such an override. ${ }^{1}$ In the instant case there is no statute in question to inquire whether it has a sufficient objective but the Rawlsian proposal to bracket comprehensive moral and religious doctrines may be taken to be analogous to a law. It is undeniable that the objective envisaged by Rawls is highly important, he conceives of the reality of irreconcilable comprehensive doctrines as a serious threat to democratic co-operation and stability, so much so that he proposes to transcend the conflict. Therefore it may be concluded that the Rawlsian objective of bracketing comprehensive moral and religious perspectives as a sufficiently important objective operative to satisfy this phase of the proportionality analysis.

\section{$\underline{\text { Rational Connection between Limit and Objective }}$}

In Canadian jurisprudence this second phase of the proportionality analysis considers whether there is a rational, non-capricious connection between the legislative objective and the law that is challenged. ${ }^{2}$ Transposing this principle to the instant case implicating Rawlsian public reason, the enquiry relates to whether there is a rational, non-capricious connection between the Rawlsian objective of ensuring democratic co-operation and maintaining democratic stability and the Rawlsian proposal to preclude moral and religious comprehensive doctrines from the public political forum. I submit that the Rawlsian proposal is not rationally connected to the objective of democratic co-operation and stability. The Rawlsian proposal presupposes that by bracketing such doctrines from the public political forum it will ensure the realization of the objects, but as argued previously in this paper, it does not necessarily follow

\footnotetext{
${ }^{1}$ Robert J. Sharpe and Kent Roach, The Charter of Rights and Freedoms (Toronto: Irwin Law, 2005, at page 66.

${ }^{2}$ Ibid, at 68 .
} 
that this is so. Some choice among the competing comprehensive doctrines is inevitable as there is no value-free, freestanding conception of 'political values' to tap into in relation to the moral presuppositions that will inevitably inform public decisions. Therefore some type of comprehensive doctrines will remain in the public political forum as well as other conflicting fundamentalist voices (which from experience usually have no qualms about voicing their views) thus presenting the public political forum with the spectre of democratic instability and clashes.

\section{Minimal Impairment}

This phase of the proportionality enquiry seeks to determine whether there was some reasonable way to satisfy the objective that would not impair the right or issue or that would have less impact on the right or freedom than the law/proposal. ${ }^{1}$ In light of the subject matter at hand, Rawlsian public reason, this phase may be transposed to read: whether there is/are some reasonable way(s) to satisfy the objectives of democratic co-operation and stability without impairing the interest of citizens in freely participating in public deliberation (pursuant to the values of the constitution). I submit that Nedelsky's enlarged mentality is an eminently suitable and reasonable way for the objectives of democratic co-operation and stability without impairing the interest of citizens in freely participating in public deliberation. Nedelsky's enlarged mentality proffers a way whereby through a respectful practice of dialogic engagement rather than 'dialogic avoidance' citizens may manage the potential for conflict by ensuring that 'judgment' and the 'enlarged mentality ' informs their deliberation. In other word by focusing on common interests and by imagining oneself in the position of another, one may benefit from significant learning and insights to be had across the lines of difference.

\section{The overall balance}

This phase requires the balancing of the effectiveness of the preclusionary proposal in achieving the objective against the harms of denying the Charter values. ${ }^{2}$ It is undeniable that Canadian Charter values demand a place for moral and religious values at the roundtable of political discourse. In fact, without

\footnotetext{
${ }^{1}$ Robert J. Sharpe and Kent Roach, The Charter of Rights and Freedoms (Toronto: Irwin Law, 2005) at page 71.

${ }^{2}$ Ibid, at page 73 .
} 
public deliberation incorporating such views, it is questionable whether what would be left would qualify as 'deliberation'. The harm likely to be faced by citizens on account of having their views summarily barred from the public square is significant in that it may very well be said in such cases the citizen is effectually reduced to a spectator. Such a reality is ominous for a particular democracy as it may very be described as the very antithesis of democracy. Democracy thrives on dialogue and exchange. Without vibrant and meaningful dialogic exchange involving various comprehensive doctrines a vibrant public culture within which problematic issues are thoroughly evaluated will not result, and democratic decision making may suffer from lack of breadth and depth. This in turn may serve to instigate conflict rather than mitigate conflict.

\section{$\underline{\text { Conclusion }}$}

The epistemological prescriptions in relation to public deliberation offered by Rawlsian public reason are not in keeping with the Charter values of human dignity, equality and multiculturalism and the moral aspirations signaled by the Charter's preamble. To this extent public reason fails its own standard of compatibility with political values. Public reason targets the preservation of democratic stability and solidarity but its prescription to bracket religious views from public deliberation is misguided as it is not proportionate and there are alternatives to such a drastic step. The enlarged mentality is eminently preferable as it does not privilege one viewpoint over the other and promotes inclusivity and full democratic participation.

Public reason in many ways may be said to contradict liberal democratic principles in that by prescribing the summary excision of religious reasons from public discourse it may lead to the muzzling as it were of religious citizens and eventuate in serious democracy deficits. Further the proposal to exclude religious voices from public deliberation detracts from ideals of multiculturalism. In many ways public reason and its prescription to bracket religious voices from public discourse is disproportionate in terms of the effect it has on religious citizens and the goal of preserving democratic stability and solidarity. The 'enlarged mentality' has the manifest advantage of being equitable in its treatment of both religious and secular 
world views, it promotes a respectful practice built on a normative framework of civility and public spirited deliberativeness rather than hysteria concerning religious motivations. The Ontario Sharia debate which ensued in 2003 evidences the manifest drawbacks of allowing public deliberation to proceed based on hysteria rather than evidence. When compared with Rawlsian public reason Nedelsky's enlarged mentality is eminently preferable as a model of public deliberation in democratic polities like Canada. 


\section{BIBLIOGRAPHY}

\section{JURISPRUDENCE}

Canada

Law v. Canada (Minister of Employment and Immigration), [1999] 1 S.C.R. 497

Reference re Secession of Quebec, [1998] 2 S.C.R. 217

\section{LEGISLATION}

\section{Canada}

Broadcasting Act, S.C. 1991, c.11

Canadian Charter of Rights and Freedoms, Part I of the Constitution Act, 1982 being Schedule B to the Canada Act 1982 (U.K.), 1982, c. 11.

Canadian Multiculturalism Act, R.S.C., 1985(4th Supp.), c. 24

\section{MONOGRAPHS}

Barak, Aharon, The Judge In A Democracy (Princeton, NJ: Princeton University Press, 2006)

Barak, Aharon, Purposive Interpretation In Law (Princeton: Princeton University Press, 2005)

de Tocqueville, Alexis, Democracy in America edited by Harvey C. Mansfield and Delba Winthrop

(Chicago: University of Chicago Press, 2000)

Dworkin, Ronald, Taking Rights Seriously (London: Duckworth Press, 1977)

Galston, William A., Liberal Pluralism: The Implications of Value Pluralism for Political Theory and

Practice (Cambridge, UK: Cambridge University Press, 2002)

Greenawalt, Kent Private Consciences and Public Reasons (New York: Oxford University Press, 1995)

Hirschl, Ran, Constitutional Theocracy (Cambridge, Mass: Harvard University Press, 2010)

Kymlicka, Will, Multicultural Citizenship: A Liberal Theory of Minority Rights (Oxford: Clarendon

Press, 1995) 
Rawls, John, Political Liberalism (New York: Columbia University Press, 2005)

Sandel, Michael J., Liberalism and the Limits of Justice 2d ed. (Cambridge, Cambridgeshire: Cambridge University Press, 1998)

Sharpe, Robert J. and Roach, Kent, The Charter of Rights and Freedoms (Toronto: Irwin Law, 2005)

\section{COLLECTIONS}

Nedelsky, Jennifer, "Legislative Judgment and the Enlarged Mentality: Taking Religious Perspectives", in Richard Bauman \& Tsvi Kahana, eds., The Least Examined Branch: The Role of Legislatures in the Constitutional State (Cambridge University Press, 2006) 93

Starck, Christian, "Human Rights and Private Law in German Constitutional Development" in Daniel

Friedmann and Daphne Barak-Erez, eds., Human Rights in Private Law (Oxford: Hart, 2001)

\section{UNPUBLISHED MANUSCRIPTS/THESES}

Miller, Bradley, Appeals to Constitutional Principles in Adjudication (Chapter Five of D. Phil. Thesis, University of Oxford, 2003) [unpublished]

Mix-Ross, Derek. B, Exploring the Charter's Horizons: Universities, Free Speech, and the Role of

Constitutional Rights in Private Legal Relations (LLM Thesis, University of Toronto, 2009)

[unpublished]

Thomas, Bryan, Public Reason and Canadian Constitutional Law (LLM thesis, University of Toronto, 2008) [unpublished thesis]

\section{ARTICLES/BOOK CHAPTER}

Chaplin, Jonathan, "Beyond Liberal Restraint: Defending Religiously-based Arguments in Law and Public Policy,' (2000) 33:2 U.B.C.L.Rev. (Special Issue on Law, Morality and Religion) 617, at 618 Clifford, John, "Political Broadcasts and the Informed Electorate: A Call for Action" (1972-1973) 22

Cath. U. L. Rev. 177

Emon, Anver, "Islamic Law and the Canadian Mosaic: Politics, Jurisprudence and Multicultural Accommodation” (2009) 37 Can. Bar. Rev. 391 
Fiss, Owen, “The Forms of Justice” (1979) 93 Harvard Law Review 1

Fleming, Hazel, "Media Ownership: In the Public Interest? The Broadcasting Act 1996" (1997) 60 Mod.

L. Rev 378

Francke, Warren, “The Evolving Watchdog: The Media's Role in Government Ethics” (January, 1995)

537:1 The Annals of The American Academy of Political and Social Science 109-121, online: Sage

Journals

Greer, John G., "The Effects of Presidential Debates On The Electorate's Preferences for Candidates"

(1988) 16:4 American Politics Research 486-501, online: Sage Journals

<http://apr.sagepub.com/content/16/4/486.abstract>

Habermas, Jürgen, "Religion in the Public Square”, European Journal of Philosophy 14(1), pages 1-25

McKinney, Mitchell S., "Political Engagement Through Debates: Young Citizens' Reactions to the 2004

Presidential Debates” (May, 2007) 50:9 American Behavioral Scientist 1169-1182, online: Pine Forge

Press

Sunder, Madhavi, "Piercing the Veil”, Yale Law Journal Volume 112, April 2003

Rawls, John, “The Idea of Public Reason Revisited” (1997) 64:3 U. Chicago L. Rev p. 765

Rawls, John, “The Idea of An Overlapping Consensus” (1987) 7 Oxford J. Legal Stud. 1 at page 1.

(JSTOR)

Raz, Joseph, "Facing Diversity: The Case of Epistemic Abstinence” (1990) 19:1 Philosophy \& Public

Affairs

Roach, Kent, “The Uses and Audiences of Preambles in Legislation”, (2001) 47 McGill Law Journal 129

Sossin, Lorne, “The 'Supremacy of God', Human Dignity and the Charter of Rights and Freedom”

(Draft, February 2, 2003) online: University of Toronto

<www.law.utoronto.ca/documents/Sossin/supremacyofgod.doc>, pages 1-15

Young, Shaun P, "Political Stability and the Need for Moral Affirmation" online: (2005) 4 Minerva

Internet Journal of Philosophy 7 <http://www.ul.ie/ philos/vol4/rawls.html> 


\section{ONLINE ARTICLES}

Ali, Syed Mumtaz, and Mills, Rabia, "Darul Qada-The beginnings of a Muslim Civil Justice System in Canada”, online: <http://muslim-canada.org/DARLQADAform2andhalf.html>

Attwood, Margaret et al, “Open Letter to Ontario Premier Dalton McGuinty: Don't Ghettoize Women's Rights" Globe and Mail Newspaper (10 September 2005) A23 available at online: <http://www.butterfliesandwheels.org/2005/open-letter-dont-ghettoize-womens-rights/> Beckford, Martin “Archbishop of Canterbury: Greed Has Caused Global Financial Crisis” The Telegraph (15 October 2008) online: The Telegraph <http://www.telegraph.co.uk/news/3204026/Archbishop-ofCanterbury-Greed-has-caused-global-financial-crisis.html>

Bauder, David, “Anderson Cooper's 'Keeping Them Honest Segment Catches On” (13 June, 2011) online: Huffington Post <http://www.huffingtonpost.com/2011/06/13/anderson-coopers-keeping_n_876176.html>

Bakht, Natasha, "Were Muslim Barbarians Really Knocking On the Gates of Ontario?: The Religious Arbitration Controversy-Another Perspective”, online: Professor T. Brettel Dawson, Lawsite.ca <http://www.lawsite.ca/OLR_Barbarians-Arb_Article.pdf> Boyd, Marion, “Dispute Resolution in Family Law: Protecting Choice, Promoting Inclusion”, excerpted in Sharia in Ontario, Canada: Background of the debate: Government report, available at <http://www.religioustolerance.org/shariaon2.htm>

Fletcher, Michael A. "Sniper Kills Abortion Doctor Near Buffalo" (25 October 1998) A01, online: The Washington Post <http://www.washingtonpost.com/wpsrv/national/longterm/abortviolence/stories/sniper.htm> Ghazali, Abdus Sattar, “Ontario Scraps Plans for Shari ah Courts After Protests”, online: at <http://www.ghazali.net/amp/html/ontario_scraps.html> 
Leslie, Keith, "McGuinty rejects Ontario's use of Shariah law and All Religious Arbitrations”, Canadian Press Release, online:

<http://www.nosharia.com/McGuinty\%20rejects\%20Ontario's\%20use\%20of\%20Sharia\%20Law\%20and $\% 20$ all\%20religious\%20arbit>

The Leadership Conference on Civil and Human Rights Report, 'The State of Hate: Escalating Hate Violence Against Immigrants' part of report Confronting the New Faces of Hate: Hate Crimes in America (June, 2009) online: 〈http://www.civilrights.org/publications/hatecrimes/escalating-violence.html> Philpott, Daniel, "Religion, Reconciliation, and Transitional Justice: The State of the Field" Social Science Research Working Papers online:

<http://www.global.ucsb.edu/orfaleacenter/luce/luce08/documents/Philpott_SSRC-working-paper.pdf > Reavis, Cate “The Global Financial Crisis of 2008 - 2009: The Role of Greed, Fear and Oligarch" (22 July 2009) online: MIT Sloan Management School of Management online <https://mitsloan.mit.edu/MSTIR/world- economy/Crisis-2008-2009/Documents/09093\%20The\%20Financial\%20Crisis\%20of\%202008-2009.pdf>.

Robertson, James R. and Spano, Sebastian, The Canadian Electoral System (Ottawa: Library of Parliament, Parliamentary Information and Research Service, Law and Government Division, BP-437E, September 15, 2008) online: Library of Parliament <http://www.parl.gc.ca/Content/LOP/ResearchPublications/bp437-e.pdf> Simmons, Harvey, "One Law for All Ontarians", The Star Newspaper (published on Tue, September 14, 2005), online: The Star Newspaper, at <http://www.thestar.com/opinion/editorialopinion/article/860513-one-law-for-all-ontarians>

Yelaja, Prithi, and Benzie, Robert, "McGuinty says 'No' to Sharia Law", online: at http://urbantoronto.ca/archive/index.php/t-243.html 